\title{
The role of free fatty acids in ectopic lipid accumulation, insulin resistance and inflammation in humans.
}

Citation for published version (APA):

van Herpen, N. A. (2012). The role of free fatty acids in ectopic lipid accumulation, insulin resistance and inflammation in humans. [Doctoral Thesis, Maastricht University]. Datawyse / Universitaire Pers Maastricht. https://doi.org/10.26481/dis.20120426nh

Document status and date:

Published: 01/01/2012

DOI:

10.26481/dis.20120426nh

Document Version:

Publisher's PDF, also known as Version of record

\section{Please check the document version of this publication:}

- A submitted manuscript is the version of the article upon submission and before peer-review. There can be important differences between the submitted version and the official published version of record.

People interested in the research are advised to contact the author for the final version of the publication, or visit the DOI to the publisher's website.

- The final author version and the galley proof are versions of the publication after peer review.

- The final published version features the final layout of the paper including the volume, issue and page numbers.

Link to publication

\footnotetext{
General rights rights.

- You may freely distribute the URL identifying the publication in the public portal. please follow below link for the End User Agreement:

www.umlib.nl/taverne-license

Take down policy

If you believe that this document breaches copyright please contact us at:

repository@maastrichtuniversity.nl

providing details and we will investigate your claim.
}

Copyright and moral rights for the publications made accessible in the public portal are retained by the authors and/or other copyright owners and it is a condition of accessing publications that users recognise and abide by the legal requirements associated with these

- Users may download and print one copy of any publication from the public portal for the purpose of private study or research.

- You may not further distribute the material or use it for any profit-making activity or commercial gain

If the publication is distributed under the terms of Article $25 \mathrm{fa}$ of the Dutch Copyright Act, indicated by the "Taverne" license above, 
The role of free fatty acids in ectopic lipid accumulation, insulin resistance and inflammation in humans 


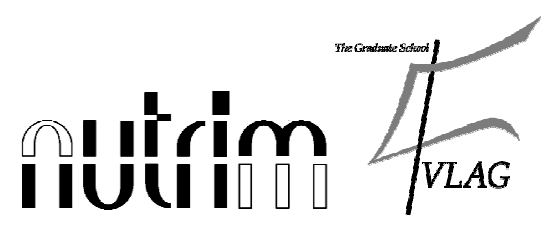

The study presented in this thesis was performed within NUTRIM, School for Nutrition, Toxocology and Metabolism, which participates in the Graduate School VLAG (Food, Technology, Agrobiotechnology, Nutrition and Health Sciences), accredited by the Royal Netherlands Academy of Arts and Sciences.

\section{DE HAAGSE HOGESCHOOL}

ACADEMIE VOOR SPORTSTUDIES

Financial support by The Hague University of Applied Sciences (Dutch: De Haagse Hogeschool) for the publication of this thesis is gratefully acknowledged.

(C) Copyright NA van Herpen, Maastricht 2012

ISBN 978-94-6159-137-1

Cover Design: Thomas van Sante

Afbeelding op cover: Mestreechter Geis - Mari Andriessen (1897-1979), 1962

Lay-out: Noud van Herpen

Printed by: Datawyse, Universitaire Pers Maastricht 


\title{
The role of free fatty acids in ectopic lipid accumulation, insulin resistance and inflammation in humans
}

\author{
PROEFSCHRIFT \\ ter verkrijging van de graad van doctor \\ aan de Universiteit Maastricht \\ op gezag van de Rector Magnificus Prof. mr. G.P.M.F. Mols, \\ volgens het besluit van het College van Decanen, \\ in het openbaar te verdedigen \\ op donderdag 26 april 2012 om 12.00 uur \\ door
}

Noud Antonius van Herpen

geboren te Boxtel op 26 april 1984

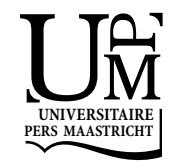




\section{Promotores}

Prof. dr. P. Schrauwen

Prof. dr. ir. R.P. Mensink

\section{Beoordelingscommissie}

Prof. dr. E.E. Blaak (voorzitter)

Prof. dr. M van Baak

Dr. G.H. Koek

Prof. dr. M.R. Müller (Wageningen University \& Research centre)

Dr. J. Plat 


\section{Contents}

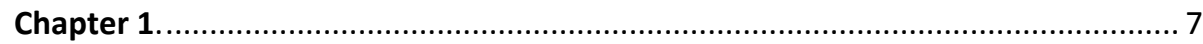

General Introduction

Chapter 2.

Lipid accumulation in non-adipose tissue and lipotoxicity

\section{Chapter 3}

Prolonged fasting identifies skeletal muscle mitochondrial dysfunction as consequence rather than cause of human insulin resistance

\section{Chapter 4}

Prolonged fasting and the effects on biomarkers of inflammation and several adipokines including chemerin in healthy subjects

\section{Chapter 5}

A high-fat diet increases intrahepatic lipid accumulation in healthy overweight men without affecting tissue specific or whole-body insulin sensitivity

\section{Chapter 6.}

A high-fat diet impairs metabolic flexibility and reduces genes involved in fatty acid oxidation without affecting insulin sensitivity and mitochondrial content in healthy overweight men

Chapter 7.

General discussion

Summary

Samenvatting

Dankwoord

Curriculum Vitae.

Scientific Output. 


\section{Part 1. - General introduction}

Chapter 1.

Introduction

Chapter 2.

Lipid accumulation in non-adipose tissue and lipotoxicity 
Chapter 1.

\section{Introduction}

N.A. van Herpen 


\subsection{Obesity, ectopic lipid accumulation and type II diabetes}

When the term 'obesity' is used in a search engine like Google, one will get $87,900,000$ hits (accessed on December 2, 2011). If a search engine for scientific papers is used you will get more than 154000 papers related to obesity, of which more than 96000 have been published during the last decade (accessed on December 2,2011$)$. These numbers indicate that obesity is a problem in which millions of people and / or researchers are interested worldwide and is receiving more and more attention every day. This is probably because obesity is related to some of the most common diseases, such as cardiovascular diseases (CVD), type II diabetes (T2DM), liver diseases, such as non-alcoholic fatty liver disease and cancer (1-3). Lipid accumulation in non-adipose tissue has been suggested to be a link between obesity and T2DM and CVD. These diseases have a major impact on people's health and are therefore staggering public health costs. Lipid accumulation in non-adipose tissue is also known as ectopic lipid accumulation. The involvement between obesity, ectopic lipid accumulation and the metabolic consequences is depicted in figure 1 in chapter 2.

\subsection{The measurement of lipid accumulation in non-adipose tissue}

Lipid accumulation in non-adipose tissue is of major importance to understand the relation between obesity and type II diabetes. Research on ectopic fat accumulation took a major leap forward when it became possible to study lipid content in nonadipose tissue with Magnetic Resonance Spectroscopy $\left({ }^{1} \mathrm{H}-\mathrm{MRS}\right)$. First, determination of lipid content in muscle became possible with a standard clinical whole body scanner $(4 ; 5)$. The advantage was that, besides being non-invasive, a larger area could be studied, typically a few $\mathrm{cm}^{3}$, and that it became possible to study the same muscle area repeatedly. At a later stage, it also became possible to measure lipid accumulation in other tissues than the muscle. Nowadays it is for example possible to measure lipid content in pancreas, liver and heart. In this thesis we investigated lipid content using MRS in the liver according to the method of Szczepaniak et al (6).

A more traditional method of quantifying lipid accumulation is by assessing the amount of lipids in a biopsy. Taking a biopsy from a, most often quadriceps, muscle is widely used in research and the needle biopsy technique became well-known already in 1967 (7). After the biopsy is taken, the lipid content is quantified either biochemically or by electron- or light microscopy in combination with dedicated staining. The technique used in this thesis is known as the Oil red 0 staining (8), which makes it possible to determine lipid accumulation muscle fiber type specific. The latter allows to investigate if lipid accumulation is more pronounced in fibers 
identified as slow, oxidative (type 1) fibers or in fast, less oxidative and more glycolytic (type 2) fibers.

\subsection{Models to study lipid-induced insulin resistance}

Obesity is the effect of a long-term misbalance between energy intake and energy expenditure. Becoming obese, however, does not directly imply that insulin resistance is developed during the same time span. This makes it hard to study the development of insulin resistance in the general population, furthermore we need models in which we can study the development of insulin resistance. Therefore, we used two different types of interventions in this thesis to study insulin sensitivity.

A general accepted way to affect insulin sensitivity is by using a lipid infusion, which is well known to increase plasma free fatty acids (FFA) concentrations and to induce insulin resistance (9). A disadvantage of the model of lipid infusion is that the levels of FFA need to be raised to super physiological levels to influence insulin sensitivity within the still acceptable time frame of several hours. Therefore we used a model in which FFA and intramuscular fat levels are elevated in a physiological way, but still decreases insulin sensitivity. Prolonged fasting is such a model $(10 ; 11)$. Interestingly, the model of prolonged fasting does not lead to hyperinsulinemia or hyperglycemia, which makes it possible to study the effects of physiologically increased FFA concentrations apart from those of increased insulin and glucose concentrations.

Another model for the development of insulin resistance may be high-fat feeding. The high availability of fast food nowadays seems to be one of the important factors related to the obesity epidemic. High-fat diets therefore have been suggested to lead to insulin resistance (12), via the accumulation of fat in non-adipose tissues such as skeletal muscle and liver (13). The evidence in humans is however rather limited and furthermore, high-fat diets were not given in energy balance in all studies. Therefore, it cannot be concluded if an effect on insulin sensitivity was due to excess energy intake or to higher fat content of the diet. Therefore our second model is an isocaloric high-fat vs. low-fat dietary intervention. We choose to do this in subjects at risk for developing the metabolic syndrome as previous work has been done in young lean subjects on the one hand or in obese women who already have hepatic steatosis on the other hand.

\subsection{Fat accumulation, mitochondrial function and insulin resistance}

There is still much debate about the cause of this lipid accumulation, besides a mismatch between supply and expenditure. As already mentioned, we have used 
two different dietary approaches to manipulate lipid accumulation in both muscle and liver to get more insight in the causes and consequences of this lipid accumulation.

It has been suggested that a decreased capacity to oxidize fat is a cause of lipid accumulation in non-adipose tissue. A decreased metabolic flexibility is a perturbation in which the body is less capable to switch between substrate sources. Furthermore it has been shown that a high-fat diet causes a decreased metabolic flexibility (14). How humans adapt their fat oxidative capacity to prolonged high-fat feeding is relatively unknown.

Another reason why people might have decreased capacity to oxidize fat is a decreased mitochondrial function. Mitochondrial dysfunction or loss of oxidative capacity has been related to aging, type 2 diabetes and cardiovascular diseases since many years (15-20). In agreement, the existence of mitochondrial abnormalities in type 2 diabetes mellitus has extensively been reported during the last decade (21-25), but there is no evidence that a reduced mitochondrial function is a primary factor in the pathophysiology of this disease. In fact, alternative theories state that the impaired mitochondrial capacity is secondary to the insulin resistant- or diabetic state.

\subsection{Inflammation}

Inflammation has been linked to insulin resistance for some years now, as reviewed by Shoelson et al (26). This review clearly describes the link between FFA, insulin resistance, hyperinsulinemia and hyperglycemia, which can be summarized as follows: obesity, which is associated with an increase in FFA, is related to increased activaties of IKK- $\beta$ / NF-KB and JNK pathways in adipocytes, hepatocytes, and associated macrophages. Stimuli that have been shown to activate these pathways during metabolic dysregulation include ligands for TNF- $\alpha$, IL-1, and advanced glycation end products (AGE) receptors. Obesity-induced IKK- $\beta$ activation leads to NF-KB translocation and the increased expression of numerous markers and potential mediators of inflammation that can cause insulin resistance. Obesity-induced JNK activation promotes the phosphorylation of IRS-1 at serine sites that negatively regulate signaling through the insulin receptor/IRS-1 axis, and therefore can cause insulin resistance. The individual contributions to inflammation of FFA, insulin resistance, hyperinsulinemia and hyperglycemia are unknown. Therefore the model of prolonged fasting is very interesting as this does not lead to hyperinsulinemia or hyperglycemia, which makes it possible to study the effects of physiologically increased FFA concentrations and insulin resistance on inflammation markers apart from those of increased insulin and glucose concentrations. 


\subsection{Outline thesis}

Chapter $\mathbf{2}$ is a review of the literature from the past decade on the effects of lipid accumulation in non-adipose tissue. In this review we describe how to measure ectopic lipid accumulation. This review further summarizes studies on lipid accumulation in muscle, liver, heart and pancreas.

In chapter $\mathbf{3}$ we have examined whether prolonged fasting leads to lipid accumulation in muscle, results in insulin resistance, and whether this is accompanied by mitochondrial dysfunction as measured with an oxygraph. If this would be the case then skeletal muscle mitochondrial dysfunction could be seen as consequence rather than a cause of human insulin resistance.

Diabetes has been linked more and more with inflammation. In chapter 4 we have studied inflammation with the model of prolonged fasting. This is very interesting because prolonged fasting does not lead to hyperinsulinemia or hyperglycemia, which makes it possible to disentangle the effects of physiologically increased FFA concentrations and insulin resistance from those of increased insulin and glucose concentrations.

In chapter $\mathbf{5}$ we used a different model to study lipid accumulation in muscle and liver. We used a randomized control trial in which twenty subjects started with a three-week low-fat diet (15 En\% protein, 65 En\% carbohydrates and $20 \mathrm{En \%}$ fat), after which half of the subjects switched to a three-week isocaloric high-fat diet (15 En\% protein, $30 \mathrm{En} \%$ carbohydrates and $55 \mathrm{En \%}$ fat). We investigated lipid accumulation and insulin sensitivity of both liver and muscle. Furthermore we also examined metabolic flexibility.

In chapter 6 we further investigated the effects of a high-fat diet on skeletal muscle gene expression to examine if high-fat feeding would lead to reductions in oxidative genes and reduced mitochondrial content as has been suggested previously. We used skeletal muscle biopsies (vastus lateralis) to determine mRNA expression for genes involved in lipid and glucose metabolism, mitochondrial content and function.

Finally chapter 7 summarizes the findings of the different studies described in this thesis. The main results and conclusions from the previous chapters are discussed and put into a broader perspective and future directions for research within this field are addressed. 


\section{References}

1. McGarry JD: Banting lecture 2001: dysregulation of fatty acid metabolism in the etiology of type 2 diabetes. Diabetes 51:7-18, 2002

2. Wilson PW, D'Agostino RB, Sullivan L, Parise H, Kannel WB: Overweight and obesity as determinants of cardiovascular risk: the Framingham experience. Arch Intern Med 162:1867-1872, 2002

3. Craigie AM, Caswell S, Paterson C, Treweek S, Belch JJ, Daly F, Rodger J, Thompson J, Kirk A, Ludbrook A, Stead M, Wardle J, Steele RJ, Anderson AS: Study protocol for BeWEL: The impact of a BodyWEight and physicaL activity intervention on adults at risk of developing colorectal adenomas. BMC Public Health 11:184, 2011

4. Schick F, Eismann B, Jung WI, Bongers H, Bunse M, Lutz O: Comparison of localized proton NMR signals of skeletal muscle and fat tissue in vivo: two lipid compartments in muscle tissue. Magn Reson Med 29:158-167, 1993

5. Boesch C, Slotboom J, Hoppeler H, Kreis R: In vivo determination of intra-myocellular lipids in human muscle by means of localized 1H-MR-spectroscopy. Magn Reson Med 37:484-493, 1997

6. Szczepaniak LS, Nurenberg P, Leonard D, Browning JD, Reingold JS, Grundy S, Hobbs HH, Dobbins $\mathrm{RL}$ : Magnetic resonance spectroscopy to measure hepatic triglyceride content: prevalence of hepatic steatosis in the general population. Am J Physiol Endocrinol Metab 288:E462-468, 2005

7. Bergstrom J, Hermansen L, Hultman E, Saltin B: Diet, muscle glycogen and physical performance. Acta Physiol Scand 71:140-150, 1967

8. Koopman R, Schaart G, Hesselink MK: Optimisation of oil red O staining permits combination with immunofluorescence and automated quantification of lipids. Histochem Cell Biol 116:63-68, 2001

9. Itani SI, Ruderman NB, Schmieder F, Boden G: Lipid-induced insulin resistance in human muscle is associated with changes in diacylglycerol, protein kinase C, and IkappaB-alpha. Diabetes 51:20052011, 2002

10. Johnson NA, Stannard SR, Mehalski K, Trenell MI, Sachinwalla T, Thompson CH, Thompson MW: Intramyocellular triacylglycerol in prolonged cycling with high- and low-carbohydrate availability. J Appl Physiol 94:1365-1372, 2003

11. Stannard SR, Thompson MW, Fairbairn K, Huard B, Sachinwalla T, Thompson CH: Fasting for $72 \mathrm{~h}$ increases intramyocellular lipid content in nondiabetic, physically fit men. Am J Physiol Endocrinol Metab 283:E1185-1191, 2002

12. Riccardi G, Giacco R, Rivellese AA: Dietary fat, insulin sensitivity and the metabolic syndrome. Clin Nutr 23:447-456, 2004

13. Shulman GI: Cellular mechanisms of insulin resistance. J Clin Invest 106:171-176, 2000

14. Bisschop PH, de Metz J, Ackermans MT, Endert E, Pijl H, Kuipers F, Meijer AJ, Sauerwein HP, Romijn JA: Dietary fat content alters insulin-mediated glucose metabolism in healthy men. Am J Clin Nutr 73:554-559, 2001

15. Pearl R: The rate of living. New York, Knopf, 1928

16. Harman D: Aging: a theory based on free radical and radiation chemistry. J Gerontol 11:298-300, 1956

17. Miquel J, Economos AC, Fleming J, Johnson JE, Jr.: Mitochondrial role in cell aging. Exp Gerontol 15:575-591, 1980

18. Beckman KB, Ames BN: The free radical theory of aging matures. Physiol Rev 78:547-581, 1998

19. Cardellach F, Galofre J, Cusso R, Urbano-Marquez A: Decline in skeletal muscle mitochondrial respiration chain function with ageing. Lancet 2:44-45, 1989

20. Goodell S, Cortopassi G: Analysis of oxygen consumption and mitochondrial permeability with age in mice. Mech Ageing Dev 101:245-256, 1998

21. Petersen KF, Befroy D, Dufour S, Dziura J, Ariyan C, Rothman DL, DiPietro L, Cline GW, Shulman GI: Mitochondrial dysfunction in the elderly: possible role in insulin resistance. Science 300:11401142,2003 
22. Petersen KF, Dufour S, Befroy D, Garcia R, Shulman GI: Impaired mitochondrial activity in the insulin-resistant offspring of patients with type 2 diabetes. N Engl J Med 350:664-671, 2004

23. Kelley DE, He J, Menshikova EV, Ritov VB: Dysfunction of mitochondria in human skeletal muscle in type 2 diabetes. Diabetes 51:2944-2950, 2002

24. Phielix E, Schrauwen-Hinderling VB, Mensink M, Lenaers E, Meex R, Hoeks J, Kooi ME, MoonenKornips E, Sels JP, Hesselink MK, Schrauwen P: Lower intrinsic ADP-stimulated mitochondrial respiration underlies in vivo mitochondrial dysfunction in muscle of male type 2 diabetic patients. Diabetes 57:2943-2949, 2008

25. Mogensen M, Sahlin K, Fernstrom M, Glintborg D, Vind BF, Beck-Nielsen H, Hojlund K: Mitochondrial respiration is decreased in skeletal muscle of patients with type 2 diabetes. Diabetes 56:15921599, 2007

26. Shoelson SE, Lee J, Goldfine AB: Inflammation and insulin resistance. J Clin Invest 116:1793-1801, 2006 



\section{Chapter 2. \\ Lipid accumulation in non-adipose tissue and lipotoxicity}

N.A. van Herpen

and V.B. Schrauwen-Hinderling

Physiology \& Behaviour. 2008; 94: 231-241. 


\section{Abstract}

Obesity is a well-known risk factor for the development of type 2 diabetes mellitus and cardiovascular disease. Importantly, obesity is not only associated with lipid accumulation in adipose tissue, but also in non-adipose tissues. The latter is also known as ectopic lipid accumulation and may be a possible link between obesity and its comorbidities such as insulin resistance, type 2 diabetes mellitus and cardiovascular disease.

In skeletal muscle and liver, lipid accumulation has been associated with the development of insulin resistance, an early hallmark of developing type 2 diabetes mellitus. More specifically, accumulation of intermediates of lipid metabolism, such as diacylglycerol (DAG) and Acyl-CoA have been shown to interfere with insulin signaling in these tissues. Initially, muscular and hepatic insulin resistance can be overcome by an increased insulin production by the pancreas, resulting in hyperinsulinemia. However, during the progression towards overt type 2 diabetes, pancreatic failure occurs resulting in reduced insulin production. Interestingly, also in the pancreas lipid accumulation has been shown to precede dysfunction.

Finally, accumulation of fat in the heart has been associated with cardiac dysfunction and heart failure, which may be an explanation for diabetic cardiomyopathy.

Taken together, we conclude that evidence for deleterious effects of lipid accumulation in non-adipose tissue (lipotoxicity) is strong. However, while ample human data is available for skeletal muscle, future research should focus on lipid accumulation in the human liver, the pancreas and the heart. 


\section{Introduction}

Obesity is due to a chronic positive energy balance, which increases the amount of triglycerides (TG) in adipose tissue. However, the TG can also be stored in nonadipose tissue, such as muscle, liver, pancreas and heart. Indeed, obesity has been shown to lead to excessive deposition of TG in these organs, which is termed ectopic fat deposition or steatosis. Lipid droplets accumulate in the cytoplasm of the cells and an excessive accumulation of these lipids may lead to cell dysfunction or cell death, a phenomenon known as lipotoxicity [1, 2]. As obese individuals are at much greater risk to develop type 2 diabetes mellitus and cardiovascular disease (CVD), it has been suggested that ectopic fat is a link between obesity and these diseases $[3,4]$.

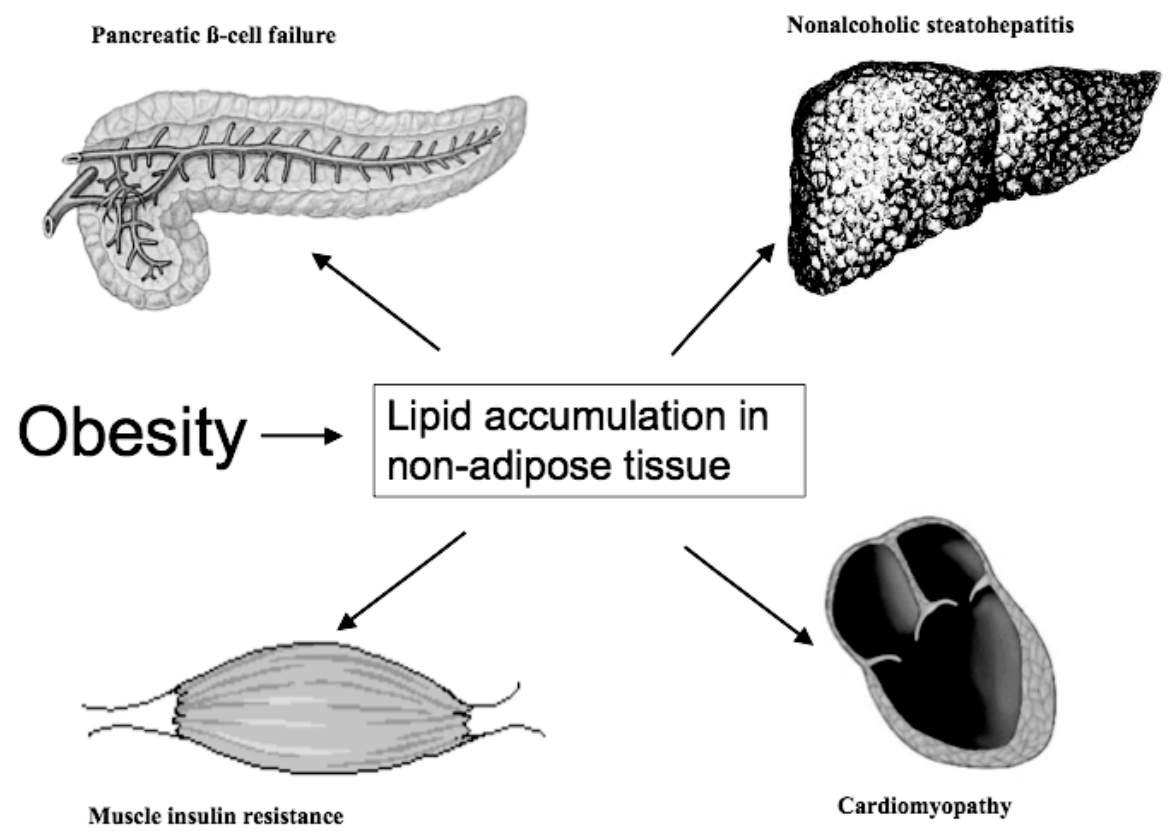

Figure 1. Effects of obesity on lipid accumulation in non-adipose tissue

Indeed, human and animal data have shown that ectopic lipid accumulation is associated with insulin resistance in muscle and liver, and with functional losses in the pancreas and the heart in animal models. The combination of insulin resistance of skeletal muscle and liver on the one hand, and pancreatic insufficiency on the other hand, are well known factors that lead to the development of type 2 diabetes mellitus. As stated above, obesity is also an important risk factor for CVD and also here may ectopic fat deposition play a role. Indeed, data from animal models suggest a 
causal relationship between cardiac lipid accumulation and dilated cardiomyopathy and ultimately heart failure [5-9].

Lipid accumulation in ectopic sites can occur either by increased uptake of fatty acids (FAs), increased synthesis within the tissue involved, or reduced FA oxidation/disposal [10]. However, the relative contribution of these factors to ectopic lipid accumulation varies in different physiological states and in different tissues. The purpose of this article is to review the evidence for lipotoxic mechanisms accompanying lipid storage in skeletal muscle, liver, pancreas and myocardium. (See also Fig. 1)

\section{Skeletal muscle}

Lipid droplets in healthy skeletal muscle (also known as intramyocellular lipids (IMCL)) can be visualized, either by light microscopy using oil-red-O staining (See also Fig. 2a) or by electron microscopy. The IMCL content can also be quantified by biochemical lipid analysis of biopsy specimens or in vivo by proton magnetic resonance spectroscopy ( ${ }^{1} \mathrm{H}-\mathrm{MRS}$ ) (See also Fig.2b). The localization of the lipid droplets close to the mitochondria suggests that lipids inside the muscle are used as fuel for muscular activity. Based on the earlier studies that have used biochemical quantification of muscular lipids there was some controversy if IMCL is decreased during exercise. Studies using electron microscopy and the more recent studies, using $\mathrm{H}$ MRS to quantify IMCL, agree however on a decrease of lipids inside the muscle after exercise [11-14]. The controversy in the earlier studies could have been due to the large variation of biochemical lipid analysis [15]. In line with a role of IMCL as substrate during physical activity, IMCL content is also increased after endurance training and in particular the (oxidative) type I fibers, which rely more on fat oxidation. Considering these findings, the physiological role of IMCL as substrate source during exercise seems well established and the increase of IMCL with training is a healthy physiological response. However, it has been reported that IMCL is also increased in subjects at risk for type 2 diabetes mellitus and strongly correlates with insulin resistance in sedentary subjects $[16,17]$. From these results, it has been suggested that IMCL content may impair insulin sensitivity. This seems paradoxical in the light of the high IMCL content in trained subjects $[18,19]$, as it is well known that endurance trained subjects are very insulin sensitive [20-22].

Interestingly, while endurance training increases IMCL due to an increased demand of intramyocellular substrate, also a high availability of FA can result in a high IMCL content. Two days to 5 weeks of a high-fat diet increases IMCL stores and this accumulation of intramuscular fat may simply be due to a positive fat balance when changing to a high-fat diet [23-27]. 
Figure 2. Methods of lipid quantification

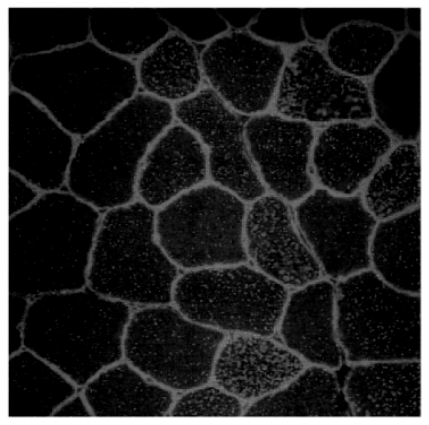

Figure 2a: Quantification of IMCL by histochemistry. The figure shows a stained section of rat tibialis anterior muscle. The grey dots originates from Oil Red $\mathrm{O}$, showing IMCL; the light grey signal originates from a laminin staining, showing the cell membranes

Lean healthy subject

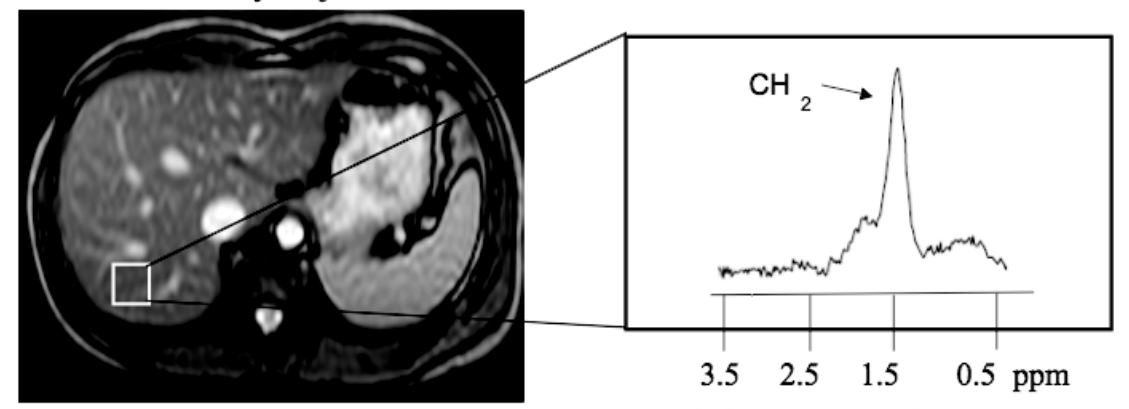

Relative resonance frequency

Figure 2b: Quantification of IHL by MRS. The figure shows an MR image from a human liver and a ${ }^{1} \mathrm{H}-$ MRS spectrum. In the MR image the volume is shown, from which the spectrum is acquired.

Physically inactive humans consuming a high-energy, high-fat diet, may have a chronically positive energy and fat balance, resulting in fat accumulation in adipose tissue and probably also in skeletal muscle. Indeed, obesity is correlated with increased IMCL $[28,29]$. In accordance with the above suggestion, other conditions with high FA availability also increases IMCL content. For example, the elevation of plasma free fatty acids (FFA) by infusions and 72 hours of fasting increased IMCL [30-32]. Also, submaximal exercise, which is well known to elevate plasma FFA, results in increased IMCL content in non-active muscle [33]. Therefore, the increase of IMCL with training is a physiological adaptation which is demand-driven and paired with an increased fat oxidative capacity. Under the other conditions, fat in muscle is simply stored, because the FA availability and oxidation are not in balance. These two situations can have different consequences concerning insulin resistance and strong evidence is accumulating that this is due to differential accumulation of 
lipid intermediates $[10,34]$. When fat oxidative capacity is high, concentrations of lipid intermediates such as diacylglycerol (DAG), ceramides, acyl-CoA will stay low, while situations with a high fat availability but low fat oxidative capacity leads to increased concentrations of these intermediates [29]. In relation to insulin sensitivity, the capacity to use IMCL may be more important than IMCL levels per se. Indeed, it has been reported that correlations between acyl-CoA and insulin resistance are stronger than those between IMCL and insulin resistance [29].

For DAG it has been shown in humans that the insulin resistance observed in human muscle when plasma FFA levels were elevated during euglycemichyperinsulinemic clamping was associated with increases in DAG [35]. In vitro was found that this metabolite can activate PKC, thereby triggering a serine/threonine kinase cascade, leading to phosphorylation of serine/threonine sites on insulin receptor substrates (IRS-1 and IRS-2). This reduces the ability of the insulin receptor substrates to activate phosphatidylinositol 3 - kinase, which ultimately results in a reduced GLUT 4 translocation to the cell membrane. In this way, increased DAG concentrations may decrease insulin-stimulated muscle glucose uptake [36-40].

\section{Liver}

The liver plays a major role in a number of vital functions. Next to playing an important role in glycogen storage, plasma protein synthesis, and drug detoxification, it is a central organ for lipid metabolism. The liver synthesizes cholesterol and TG, and produces and takes up lipoproteins. Considering this role in the trafficking of lipids, it is not surprising that hepatocytes are capable of storing lipids in the form of small droplets of TG. However, usually the hepatic lipid content is low (below $5 \%$ of fat by wet weight) and when the liver lipid stores exceed this value, this is known as a fatty liver or liver steatosis. A well-known cause for a fatty liver is alcohol abuse, but a fatty liver is also found in overweight and obese subjects. As the prevalence of obesity is reaching pandemic proportions, a significant part of the population will be affected by liver steatosis. Figures from the US and Japan show that nowadays already up to one third of the general population may have a fatty liver [41, 42].

Fat accumulation in the liver is generally associated with the cluster of metabolic abnormalities related to the metabolic syndrome [43]. It has been suggested that non-alcoholic fatty liver disease (NAFLD), in its whole spectrum ranging from pure fatty liver to non-alcoholic steatohepatitis (NASH) and cryptogenic cirrhosis, which in the end may lead to hepatocellular carcinoma, is simply the hepatic manifestation of the metabolic syndrome [44]. Therefore, it is not surprising that a fatty liver is associated with an increased risk of all-cause death [45].

The mechanisms underlying the development of NAFLD are not completely understood but it has been shown that FA in the liver come from several different sources: dietary fat, FA released from adipose tissue, and from de novo hepatic 
lipogenesis. An imbalance of any of the pathways involved in FA and TG delivery, synthesis, export or oxidation could contribute to lipid accumulation in the liver.

Regarding dietary fat, many studies in mice [46] and rats $[47,48]$ have documented that a high-fat diet rapidly induces hepatic steatosis. Also in humans, it was shown that 2 weeks of high fat diet (56\% of energy as fat) increased lipid accumulation in the liver, while an isocaloric low fat diet (16\% of total energy as fat) decreased liver fat content [49].

Interestingly, animal data suggest that saturated FA lead to more fat accumulation compared with unsaturated FA [50]. Especially, n-3 FA from fish oil appeared to be protective. As these n-3 FA are known to stimulate peroxisome proliferatorsactivated receptor- $\gamma$ (PPAR- $\gamma$ ), this effect may be due to an increased FA oxidation. However, these animal studies did often use very high doses of n-3 FA and it is questionable to what extend these results can be extrapolated to the human situation [51-53].

In NAFLD patients, the postprandial suppression of adipose tissue lipolysis is blunted, leading to elevated plasma FA levels, thereby providing the liver with ample substrate for re-esterification of TG [54]. Therefore, adipose tissue can contribute considerably to the development of liver steatosis by releasing FA. Additionally, adipokines released from this tissue may play an important role. For example, adiponectin (which is released from adipose tissue in quantities inversely related to adipose tissue mass) may have a protective effect, as plasma levels of adiponectin were significantly lower in subjects with NAFLD compared to body mass index (BMI) matched controls [55]. Adiponectin levels have also been found to correlate negatively with hepatic fat $[55,56]$. Further support for an important role of adiponectin comes from a mouse model, in which steatohepatitis was induced by a high fat/alcohol diet. Adiponectin administration alleviated hepatic steatosis, and significantly attenuated hepatic inflammation and elevated levels of transaminases by increasing FA oxidation in the liver and decreasing the activities of enzymes involved in FA synthesis [57].

Next to dietary FA and FA released from adipose tissue, the liver is also capable of de novo lipogenesis. Although the de novo lipogenesis is probably not very important in healthy lean subjects [54], it has been shown in patients with NAFLD that de novo lipogenesis can attribute up to $24 \%$ of TG in he liver. This de novo lipogenesis was twice as high as the $10 \%$ reported previously in obese, hyperinsulinemic subjects [58] and is $4-5$ times higher than the $5 \%$ observed in healthy populations [59, 60]. In addition low fat/high carbohydrate diets have been shown to increase de novo lipogenesis in healthy subjects with body weights between 80 and $120 \%$ of their ideal body weight [61]. Therefore, not only a high fat content, i.e. the above mentioned $56 \%$ of energy as fat [49], but also a high carbohydrate intake may be a concern. 
It is not completely known how liver steatosis leads to insulin resistance. However, it is very likely that similarly as in skeletal muscle, not the TG per se, but lipid intermediates are important. In vitro studies have indeed shown that increases in intracellular DAG activate PKC, which binds to and inactivates the insulin receptor kinase resulting in reduced insulin-stimulated IRS-1 and IRS-2 tyrosine phosphorylation. This in turn results in reduced insulin activation of PI 3-kinase and AKT2. Reduced AKT2 activation results in lower glycogen synthase kinase-3 phosphorylation and lower forkhead box protein O (FOXO) phosphorylation. This in turn results in lower insulin-stimulated liver glycogen synthesis and decreased suppression of hepatic gluconeogenesis, which results in an increase in GLUT2 translocation and an increase in glucose released, respectively [39]. This decreased hepatic glucose storage and higher endogenous glucose production are clearly major factors in developing impaired glucose tolerance and diabetes.

Hepatic insulin resistance is also associated with increased insulin plasma concentrations, which in turn stimulates de novo lipogenesis and therefore enhances liver steatosis further. Animal studies have clearly shown that insulin activates the membrane-bound transcription factor sterol receptor binding protein 1-c (SREBP1c), which transcriptionally activates most genes required for lipogenesis. In mice, even in the insulin resistant state, insulin stimulates hepatic SREBP-1c transcription and increases lipogenesis [62]. In addition over-expression of SREBP-1c in transgenic mice leads to increased lipogenesis and the development of hepatic steatosis [63]. On the other hand, inactivation of the SREBP-1c gene in livers of ob/ob mice, a genetic model of leptin deficiency that develops obesity and hepatic steatosis, reduced the hepatic TG content by approximately 50\% [64]. These data indicate that liver steatosis results in a vicious cycle by causing insulin resistance, which again favors hepatic lipid accumulation.

Several interventional studies have demonstrated that normalization of liver fat content also normalizes insulin resistance and disturbed glucose metabolism. In this respect, the effect of weight loss was investigated in two independent studies. The first study [65] showed that in subjects with type 2 diabetes mellitus $8 \%$ weight reduction after consuming a moderately hypocaloric very-low-fat diet resulted within 7 weeks in $80 \%$ reduction of intrahepatic lipids (IHL), which was associated with improvement in hepatic insulin resistance. In the other study [66] moderate weight loss resulted in reduction of $\mathrm{IHL}$, which was associated with an increase in splanchic glucose uptake. Together, these data demonstrate that reduction of liver fat by moderate weight loss, can improve glucose metabolism in the liver. Furthermore, after treatment with pioglitazone for 16 weeks, the hepatic fat content in subjects with type 2 diabetes mellitus was decreased from $19.6 \%$ to $10.4 \%$, while the splanchic glucose uptake increased from $33.0 \%$ to $46.2 \%$. [67].

Besides hepatic insulin resistance, the inflammatory character associated with the development from liver steatosis to NASH is a concern. Although the patho- 
genesis of NASH has not yet been fully elucidated, it has been suggested that, next to the accumulation of FA in the liver, cytochrome P4502E1 (CYP2E1) has an important role. CYP2E1 plays a key role in the pathogenesis of alcoholic liver injury, including alcoholic steatohepatitis, because of the oxidative stress it generates [68, 69]. Indeed, CYP2E1 concentrations increase not only in experimental animals which mimic human obesity [70], but also in morbid obese men with NAFLD or patients with NASH [71, 72]. CYP2E1 concentrations are invariably elevated in the liver of patients with NASH [72] because FA and ketones, which are increased in diabetes, are also substrates for CYP2E1 [69]. An excess of these substrates upregulates CYP2E1. The resulting oxidative stress and liver injury are exacerbated by a diet low in carbohydrates and rich in fat, including unsaturated lipids, which promote CYP2E1 induction [73, 74].

Oxidative stress causes also various types of functional and structural damage and commonly increases tumour necrosis factor (TNF)- $\alpha$ production in patients with NASH [75], in addition to the already increased release of TNF- $\alpha$ by adipose tissue. Adipose tissue produces and releases a variety of cytokines (interleukin-1, TNF- $\alpha$ ), that appear to mediate the inflammatory response that accompanies obesity [76]. In addition, it is noteworthy that the expression of TNF- $\alpha$ is increased in adipose tissue of obese individuals and this expression correlates with BMI, percentage of body fat and hyperinsulinemia $[77,78]$.

Besides the release of TNF- $\alpha$ from adipose tissue and the activation via oxidative stress, obese patients with NASH also have enhanced expression of TNF- $\alpha$ mRNA in hepatic tissue, whereas obese patients without NASH have not [79]. This proinflammatory cytokine probably contributes to the inflammation and the steatosis as shown in alcoholic steatohepatitis [80]. Due to the inflammation that is associated with NASH, it is a risk factor for progressive liver disease and finally hepatocellular carcinoma.

\section{Heart}

There is increasing evidence for ectopic fat accumulation inside the heart to play a role in cardiomyopathy, and eventually heart failure, which may presently be an underestimated risk factor. Similarly as in skeletal muscle and liver, metabolic dysregulation in lipid-overloaded hearts may induce insulin resistance. Sharma et al. suggested that because failing hearts already exhibit impaired FA oxidation [81], a superimposed myocardial insulin resistance may impair glucose oxidation resulting in "energy starvation" of the heart, causing heart failure [8]. Furthermore, it has been suggested that lipid metabolites may be toxic to cardiomyocytes by inducing apoptosis $[9,82]$. Due to the limited accessibility of cardiac tissue, this cardiolipotoxic mechanisms have so far mainly been studied in rodents rather than in humans. 
In one human study, the lipid content in hearts after heart failure was investigated. A significantly increased intramyocardial lipid deposition was found in patients with heart failure and diabetes and/or obesity. This lipid accumulation was associated with a gene expression profile similar to that in animal models of cardiac steatosis and heart failure [8]. In the Zucker diabetic fatty (ZDF) rat, a model of obesity secondary to genetic unresponsiveness to leptin, TG accumulated rapidly in the heart, as they do in other nonadipose tissues, when the animals became increasingly obese. This lipid accumulation was associated with a progressive increase in ceramide content and iNOS expression. By 14 weeks of age, DNA laddering was increased markedly, evidence of severe cardiac apoptosis [9]. These changes were accompanied by functional losses, as ZDF rats also developed eccentric left ventricular remodeling, increased left ventricular pressure and septal wall thickening $[5,9]$.

The extreme obesity in the ZDF rat model made it difficult to determine whether the cardiac maladaptations are related to excessive myocardial lipid accumulation or to increased expression of conventional risk factors for CVD. To address this limitation, various lean genetic mouse models of cardiac-restricted steatosis have recently been developed [5-7, 82-87]. These animals displayed increased myocardial lipid content in the absence of obesity or any other traditional cardiovascular risk factors. FA accumulation in these animals can be caused by either decreased FA oxidation or increased FA uptake.

Transgenic mice with decreased cardiac FA oxidation were generated to produce cardiomyocyte-restricted deletion of PPAR- $\delta$. This down regulated constitutive expression of key FA oxidation genes and decreased basal myocardial FA oxidation. These mice had severe lipid accumulation in the heart and consequently, cardiac dysfunction, cardiac hypertrophy and congestive heart failure with reduced survival [6].

To test whether a mismatch between myocardial FA uptake and utilization may lead to the accumulation of cardiotoxic lipid species, a transgenic mouse line that overexpresses long-chain acyl-CoA synthesis in the heart (MHC-ACS) was generated. This protein plays an important role in FA transport across the membrane. The mice showed severe cardiac steatosis, systolic dysfunction and hypertrophy. The results of this study further demonstrated that a FA uptake/utilization mismatch lead to accumulation of lipid species which are toxic to cardiac myocytes [82]. Indications of the causal relationship between cardiac steatosis and cardiac dysfunction came from results showing that reversing steatosis also restores cardiac function. The same MHC-ACS mice were made hyperleptinemic by treatment with a recombinant adenovirus containing the leptin cDNA. The heart of the hyperleptinemic MHC-ACStransgenic mice had normalised TG contents and exhibited normal echocardiograms [7].

Another study of the reversibility of cardiac lipid storage was performed in mice treated with streptozocin, a toxin inducing diabetes by affecting pancreatic $\beta$-cells. 
Treatment with streptozocin leaded to cardiac lipid accumulation. Interestingly, over-expression of apolipoprotein $B(\mathrm{apoB})$, which increases the ability of cells to secrete TG-rich lipoproteins, reversed cardiac lipid accumulation in streptozocin treated animals. Mice, treated with streptozocin, overexpressing human apoB in the heart showed a decrease of $48 \%$ in TG content after 12 weeks with echocardiographic indexes of heart function being normal or only marginally affected, in comparison with the wild-type mice treated with streptozocin. These findings suggest that TG accumulation in the heart is important for the development of diabetic cardiomyopathy in mice, and that apoB formation by cardiomyocytes plays an integrated role in cardiac lipid metabolism [86]. Similarly, other treatments that ameliorated cardiac lipid accumulation, by downregulation or knocking out of PPAR- $\alpha$ also rescued the heart from dilated cardiomyopathy [84, 85].

Taken together, there is strong evidence for lipotoxic mechanisms in rodent showing that lipid accumulation in the heart leads to heart failure. As mentioned earlier human cardiac tissue is not readily available and the study of cardiac lipid accumulation largely relies on non-invasive methods. $1 \mathrm{H}-\mathrm{MRS}$ has been developed for quantifying lipid content in skeletal muscle and liver [14, 88, 89]. Recently $1 \mathrm{H}$ MRS has been successfully adapted to also quantify lipid content in cardiac muscle of human subjects [90]. The employment of this technique showed that TG was detectable in the myocardium of healthy human subjects even in those who are very lean. In overweight subjects myocardial TG content was elevated and is accompanied by increased left ventricular mass and a subtle reduction of septal wall thickening, which represent a mild systolic dysfunction [90]. While it has been shown that the consumption of a single high-fat meal did not influence cardiac lipid content, despite of a 2-fold increase in serum TG, 48h of fasting increased cardiac TG accumulation significantly [91]. In addition, myocardial fat was found to be higher in obese than in lean subjects and myocardial fat correlated with FFA levels, epicardial fat, and waist-to-hip ratio. Epicardial fat was positively associated with peripheral vascular resistance and negatively with the cardiac index. Together, these human data may indicate that the cardiac accumulation of TG is related to FFA exposure, generalized ectopic fat excess, and peripheral vascular resistance and that these changes precede left ventrikel overload and hypertrophy [92]. Clearly, further human studies are needed to investigate this further.

\section{Pancreas}

As obesity develops, insulin secretion increases parallel to insulin resistance in order to maintain normal glucose homeostasis. Patients predisposed to diabetes, however, fail to compensate adequately for the greater insulin requirements [93]. It has now also been suggested that the eventual impairment of insulin secretion in subjects with type 2 diabetes mellitus is related to ectopic fat accumulation inside the 
pancreas and high levels of FFA, which are both hallmarks of obesity [94, 95]. Indeed, this relationship between obesity and lipid accumulation inside the pancreas, in addition to lipid accumulation inside the muscle and liver, was found in vivo in healthy Mexican-American girls, 14-17 years old and with a BMI ranging from 17.7 $\mathrm{kg} / \mathrm{m} 2$ to $46 \mathrm{~kg} / \mathrm{m} 2$ [96]. Support for the notion that chronic exposure of the $\beta$-cell to elevated FFA levels can be damaging to its function come mainly from studies with isolated islets exposed to high concentrations of FFA for periods of 24-48 $\mathrm{h}$ $[97,98]$. Evidence for islet lipotoxicity in vivo comes from studies with the ZDF rat, which, as noted earlier, shares many of the features of obesity-related type 2 diabetes mellitus in humans. In a study [95] was shown that when ZDF rats ( $f a / f a)$ were fed standard chow diet the male ZDF rat developed marked hyperglycemia after 9 weeks of age. This does not hold true in the fatty females or in lean littermates $(\mathrm{fa} /+$ or $+/+$ ) of the male animals. The obese ZDF females rarely exhibit hyperglycemia $[99,100]$, although they have levels of obesity and insulin resistance comparable to males. In line with this, the male ZDF rat displayed a marked elevation of plasma FFA levels from 5 weeks of age onward in comparison to the female ZDF rat. Interestingly, just before the appearance of diabetes, an abrupt and massive increase in islet TG content appeared that coincided with severe disruption of islet morphology and $\beta$-cell function. Furthermore, energy restriction of these animals from 6 weeks of age greatly reduced their islet fat accumulation and under these circumstances, islet function was largely restored and hyperglycemia did not develop. Taken together, this implicates that fat accumulation in the islet is an important contributor to $\beta$-cell failure in the ZDF rat, and probably in other rodent models of type 2 diabetes mellitus. Whether this is also true in humans is not yet clear, in part because of the scarcity of suitable pancreas specimens for histochemical analysis from individuals with increasing degrees of $\beta$-cell malfunction [101].

To show the direct relationship between fat accumulation in the pancreas and insulin secretion the reversibility of pancreatic dysfunction with normalization of TG content inside the pancreas was demonstrated in animal models. In PPAR- $\gamma$ deficient $(P P A R-\gamma+/-)$ mice on a high-fat diet, insulin secretion was impaired and this was associated with increased islet TG content. Pioglitazone, a PPAR- $\gamma$ agonist, decreased islet TG content and simultaneously restored the impaired insulin secretion in these animals [102].

Different mechanisms by which long-term exposure to FFA can lead to $\beta$-cell dysfunction have been proposed. FFA may have direct effects on insulin biosynthesis, preproinsulin gene expression and the expression of uncoupling proteins (UCP).

Firstly, FFA are shown to decrease insulin biosynthesis in isolated rat islets [103]. This study also indicated that at least some FFAs exert detrimental effects on pancreatic $\beta$-cell function by impairing preproinsulin gene expression. Therefore, long-term exposure to elevated FFA levels may be a factor in the development of Type 2 diabetes mellitus due to their effects on preproinsulin gene expression. 
In addition long-term exposure to FFA can also modify UCP expression and thereby changing glucose-stimulated insulin secretion by uncoupling the mitochondria and decreasing ATP production. A glucose-induced change in ATP/ADP ratio plays a crucial role in the coupling of glucose metabolism to insulin secretion and any factor uncoupling ATP formation from substrate oxidation will decrease glucose-stimulated insulin secretion. It has been shown that the pancreatic $\beta$-cells express the uncoupling protein UCP2 and FAs increase its expression and partly uncouple the $\beta$-cells [104].

Furthermore, long chain acyl-CoA (LC-CoA) may mediate the effects of FFAs. This because FFA that cannot be oxidized may form LC-CoA and their effect on $\beta$-cell dysfunction are twofold. First, LC-CoA may activate the KATP channel and hyperpolarize the $\beta$-cell, rendering its depolarization by glucose more difficult and decrease glucose-stimulated insulin secretion in this way [105]. Second, a constitute reservoir of LC-CoA may downregulate specific PKC isoforms and suppress their incretin action on insulin secretion [106]. Incretin action means that with matched glucose concentrations the insulin secretion is greater following ingestion of glucose than it is following infusion of glucose.

In addition to the general hazardous effects of high concentrations of FFA on $\beta$ cell function, the saturated palmitic acid seems to be specifically toxic. Among all the FAs studied in vitro on human and rodents pancreatic islets, palmitic acid rapidly induced $\beta$-cell apoptosis and reduced their proliferative capacity $[107,108]$. Increased levels of palmitic acid correlated with de novo synthesis of ceramides, known to activate the apoptotic pathway in several cell types, including the $\beta$-cells. The unsaturated oleic acid prevented apoptosis induced by palmitate, probably by mediating upregulation of the antiapoptotic protein bcl-2 [108].

In summary, fat accumulation in the pancreatic islets leads to a decreased insulin secretion and might explain why insulin resistant people cannot meet the higher demands of insulin and ultimately develop type 2 diabetes mellitus [103-108]. However, in obese nondiabetic subjects a greater proportion of pancreatic fat was associated with increased, not decreased, insulin levels. This may indicate that the deleterious effect of pancreatic fat accumulation might require a long time before manifesting in impaired $\beta$-cell function. Indeed, it has been estimated that pancreatic $\beta$-cell damage is present for more than a decade before diabetes is diagnosed [109].

\section{Conclusion}

The Health Survey for England showed that in 2-10 year old children, $16 \%$ of boys and $12 \%$ of girls were obese (BMI >=95th centile), and that in 11-15 year olds a staggering $24 \%$ of boys and $26 \%$ of girls were obese in 2004 [110]. Unfortunately, 
the alarming consequences of overweight and obesity are likely to increase as well as this new generation of overweight children with a longer duration of excess body weight, than any of their overweight predecessors, reaches adulthood.

It is well known that overweight and obesity are strong risk factors for cardiovasular disease and type 2 diabetes mellitus, which put a heavy load on the health care systems. As reviewed here, ectopic lipid accumulation may be a link between an increased body fat mass and these diseases. To summarize, there is strong evidence from human studies that hepatic and intramuscular lipid accumulation can cause insulin resistance in these tissues. Rodent data further suggest that pancreatic insufficiency may also occur due to excessive exposure to lipids. The combination of insulin resistance of skeletal muscle and liver on the one hand, and pancreatic insufficiency on the other hand, are the factors well known to lead to the development of type 2 diabetes mellitus. As stated above, obesity is also an important risk factor for CVD and also here, ectopic fat deposition may play an important role. Indeed, data from animal models suggest a causal relationship between cardiac lipid accumulation and dilated cardiomyopathy and ultimately heart failure.

Taken together, we conclude that evidence for a hazardous role of lipid accumulation in non-adipose tissue (lipotoxicity) is strong. However, while quite a lot of human data is available from skeletal muscle, future research should focus on lipid accumulation in the human liver, the pancreas and the heart. Newly available noninvasive methods, i.e. $1 \mathrm{H}-\mathrm{MRS}$, make it possible to conduct interventions to investigate the causes, the time-course and the consequences of lipid accumulation in these tissues and to investigate the effectiveness of possible treatments. 


\section{References}

1. Unger RH, Orci L. Diseases of liporegulation: new perspective on obesity and related disorders. Faseb J 2001;15:312-21.

2. $\quad$ Schaffer JE. Lipotoxicity: when tissues overeat. Curr Opin Lipidol 2003;14:281-7.

3. Roger VL, Weston SA, Redfield MM, Hellermann-Homan JP, Killian J, Yawn BP, et al. Trends in heart failure incidence and survival in a community-based population. Jama 2004;292:344-50.

4. Wilson PW, D'Agostino RB, Sullivan L, Parise H, Kannel WB. Overweight and obesity as determinants of cardiovascular risk: the Framingham experience. Arch Intern Med 2002;162:1867-72.

5. Bjorkegren J, Veniant M, Kim SK, Withycombe SK, Wood PA, Hellerstein MK, et al. Lipoprotein secretion and triglyceride stores in the heart. J Biol Chem 2001;276:38511-7.

6. Cheng L, Ding G, Qin Q, Huang $\mathrm{Y}$, Lewis $\mathrm{W}, \mathrm{He} \mathrm{N}$, et al. Cardiomyocyte-restricted peroxisome proliferator-activated receptor-delta deletion perturbs myocardial fatty acid oxidation and leads to cardiomyopathy. Nat Med 2004;10:1245-50.

7. Lee Y, Naseem RH, Duplomb L, Park BH, Garry DJ, Richardson JA, et al. Hyperleptinemia prevents lipotoxic cardiomyopathy in acyl CoA synthase transgenic mice. Proc Natl Acad Sci U S A 2004;101:13624-9.

8. Sharma S, Adrogue JV, Golfman L, Uray I, Lemm J, Youker K, et al. Intramyocardial lipid accumulation in the failing human heart resembles the lipotoxic rat heart. Faseb J 2004;18:1692-700.

9. Zhou YT, Grayburn P, Karim A, Shimabukuro M, Higa M, Baetens D, et al. Lipotoxic heart disease in obese rats: implications for human obesity. Proc Natl Acad Sci U S A 2000;97:1784-9.

10. Shulman GI. Cellular mechanisms of insulin resistance. J Clin Invest 2000;106:171-6.

11. Schrauwen-Hinderling VB, Schrauwen P, Hesselink MK, van Engelshoven JM, Nicolay K, Saris WH, et al. The increase in intramyocellular lipid content is a very early response to training. J Clin Endocrinol Metab 2003;88:1610-6.

12. Rico-Sanz J, Moosavi M, Thomas EL, McCarthy J, Coutts GA, Saeed N, et al. In vivo evaluation of the effects of continuous exercise on skeletal muscle triglycerides in trained humans. Lipids 2000;35:1313-8.

13. Krssak M, Petersen KF, Bergeron R, Price T, Laurent D, Rothman DL, et al. Intramuscular glycogen and intramyocellular lipid utilization during prolonged exercise and recovery in man: a $13 \mathrm{C}$ and $1 \mathrm{H}$ nuclear magnetic resonance spectroscopy study. J Clin Endocrinol Metab 2000;85:748-54.

14. Boesch C, Slotboom J, Hoppeler H, Kreis R. In vivo determination of intra-myocellular lipids in human muscle by means of localized 1H-MR-spectroscopy. Magn Reson Med 1997;37:484-93.

15. Wendling PS, Peters SJ, Heigenhauser GJ, Spriet LL. Variability of triacylglycerol content in human skeletal muscle biopsy samples. J Appl Physiol 1996;81:1150-5.

16. Jacob S, Machann J, Rett K, Brechtel K, Volk A, Renn W, et al. Association of increased intramyocellular lipid content with insulin resistance in lean nondiabetic offspring of type 2 diabetic subjects. Diabetes 1999;48:1113-9.

17. Krssak M, Falk Petersen K, Dresner A, DiPietro L, Vogel SM, Rothman DL, et al. Intramyocellular lipid concentrations are correlated with insulin sensitivity in humans: a $1 \mathrm{H}$ NMR spectroscopy study. Diabetologia 1999;42:113-6.

18. Goodpaster BH, He J, Watkins S, Kelley DE. Skeletal muscle lipid content and insulin resistance: evidence for a paradox in endurance-trained athletes. J Clin Endocrinol Metab 2001;86:5755-61.

19. Thamer C, Machann J, Bachmann O, Haap M, Dahl D, Wietek B, et al. Intramyocellular lipids: anthropometric determinants and relationships with maximal aerobic capacity and insulin sensitivity. J Clin Endocrinol Metab 2003;88:1785-91.

20. Horton ES. Exercise and physical training: effects on insulin sensitivity and glucose metaboism. Diabetes Metab Rev 1986;2:1-17.

21. Mikines KJ, Sonne B, Farrell PA, Tronier B, Galbo H. Effect of physical exercise on sensitivity and responsiveness to insulin in humans. Am J Physiol 1988;254:E248-59. 
22. Rosenthal M, Haskell WL, Solomon R, Widstrom A, Reaven GM. Demonstration of a relationship between level of physical training and insulin-stimulated glucose utilization in normal humans. Diabetes 1983;32:408-11.

23. Hill JO, Peters JC, Reed GW, Schlundt DG, Sharp T, Greene HL. Nutrient balance in humans: effects of diet composition. Am J Clin Nutr 1991;54:10-7.

24. Vogt M, Puntschart A, Howald H, Mueller B, Mannhart C, Gfeller-Tuescher L, et al. Effects of dietary fat on muscle substrates, metabolism, and performance in athletes. Med Sci Sports Exerc 2003;35:952-60.

25. Helge JW, Watt PW, Richter EA, Rennie MJ, Kiens B. Fat utilization during exercise: adaptation to a fat-rich diet increases utilization of plasma fatty acids and very low density lipoproteintriacylglycerol in humans. J Physiol 2001;537:1009-20.

26. Johnson NA, Stannard SR, Mehalski K, Trenell MI, Sachinwalla T, Thompson CH, et al. Intramyocellular triacylglycerol in prolonged cycling with high- and low-carbohydrate availability. J Appl Physiol 2003;94:1365-72.

27. Zderic TW, Davidson CJ, Schenk S, Byerley LO, Coyle EF. High-fat diet elevates resting intramuscular triglyceride concentration and whole body lipolysis during exercise. Am J Physiol Endocrinol Metab 2004;286:E217-25.

28. Forouhi NG, Jenkinson G, Thomas EL, Mullick S, Mierisova S, Bhonsle U, et al. Relation of triglyceride stores in skeletal muscle cells to central obesity and insulin sensitivity in European and South Asian men. Diabetologia 1999;42:932-5.

29. Hulver MW, Berggren JR, Cortright RN, Dudek RW, Thompson RP, Pories WJ, et al. Skeletal muscle lipid metabolism with obesity. Am J Physiol Endocrinol Metab 2003;284:E741-747.

30. Bachmann OP, Dahl DB, Brechtel K, Machann J, Haap M, Maier T, et al. Effects of intravenous and dietary lipid challenge on intramyocellular lipid content and the relation with insulin sensitivity in humans. Diabetes 2001;50:2579-84.

31. Boden G, Lebed B, Schatz M, Homko C, Lemieux S. Effects of acute changes of plasma free fatty acids on intramyocellular fat content and insulin resistance in healthy subjects. Diabetes 2001;50:1612-7.

32. Stannard SR, Thompson MW, Fairbairn K, Huard B, Sachinwalla T, Thompson CH. Fasting for $72 \mathrm{~h}$ increases intramyocellular lipid content in nondiabetic, physically fit men. Am J Physiol Endocrinol Metab 2002;283:E1185-91.

33. Schrauwen-Hinderling VB, van Loon L, Koopman R, Nicolay K, Saris WH, Kooi ME. Intramyocellular lipid content is increased after exercise in nonexercising human skeletal muscle. J Appl Physiol 2003;95:2328-32.

34. Kelley DE, Mandarino LJ. Fuel selection in human skeletal muscle in insulin resistance: a reexamination. Diabetes 2000;49:677-83.

35. Itani SI, Ruderman NB, Schmieder F, Boden G. Lipid-induced insulin resistance in human muscle is associated with changes in diacylglycerol, protein kinase C, and IkappaB-alpha. Diabetes 2002;51:2005-11.

36. Dresner A, Laurent D, Marcucci M, Griffin ME, Dufour S, Cline GW, et al. Effects of free fatty acids on glucose transport and IRS-1-associated phosphatidylinositol 3-kinase activity. J Clin Invest 1999;103:253-9.

37. Griffin ME, Marcucci MJ, Cline GW, Bell K, Barucci N, Lee D, et al. Free fatty acid-induced insulin resistance is associated with activation of protein kinase $C$ theta and alterations in the insulin signaling cascade. Diabetes 1999;48:1270-4.

38. Morino K, Petersen KF, Dufour S, Befroy D, Frattini J, Shatzkes N, et al. Reduced mitochondrial density and increased IRS-1 serine phosphorylation in muscle of insulin-resistant offspring of type 2 diabetic parents. J Clin Invest 2005;115:3587-93.

39. Savage DB, Petersen KF, Shulman GI. Disordered lipid metabolism and the pathogenesis of insulin resistance. Physiol Rev 2007;87:507-520. 
40. Yu C, Chen Y, Cline GW, Zhang D, Zong H, Wang Y, et al. Mechanism by which fatty acids inhibit insulin activation of insulin receptor substrate-1 (IRS-1)-associated phosphatidylinositol 3-kinase activity in muscle. J Biol Chem 2002;277:50230-6.

41. Browning JD, Szczepaniak LS, Dobbins R, Nuremberg P, Horton JD, Cohen JC, et al. Prevalence of hepatic steatosis in an urban population in the United States: impact of ethnicity. Hepatology 2004;40:1387-95.

42. Jimba S, Nakagami T, Takahashi M, Wakamatsu T, Hirota Y, Iwamoto Y, et al. Prevalence of nonalcoholic fatty liver disease and its association with impaired glucose metabolism in Japanese adults. Diabet Med 2005;22:1141-5.

43. Unger RH. Lipotoxic diseases. Annu Rev Med 2002;53:319-36.

44. Marchesini G, Bugianesi E, Forlani G, Cerrelli F, Lenzi M, Manini R, et al. Nonalcoholic fatty liver, steatohepatitis, and the metabolic syndrome. Hepatology 2003;37:917-23.

45. Adams LA, Angulo P. Recent concepts in non-alcoholic fatty liver disease. Diabet Med 2005;22:1129-33.

46. McCuskey RS, Ito Y, Robertson GR, McCuskey MK, Perry M, Farrell GC. Hepatic microvascular dysfunction during evolution of dietary steatohepatitis in mice. Hepatology 2004;40:386-93.

47. Lieber CS, Leo MA, Mak KM, Xu Y, Cao Q, Ren C, et al. Model of nonalcoholic steatohepatitis. Am J Clin Nutr 2004;79:502-9.

48. Samuel VT, Liu ZX, Qu X, Elder BD, Bilz S, Befroy D, et al. Mechanism of hepatic insulin resistance in non-alcoholic fatty liver disease. J Biol Chem 2004;279:32345-53.

49. Westerbacka J, Lammi K, Hakkinen AM, Rissanen A, Salminen I, Aro A, et al. Dietary fat content modifies liver fat in overweight nondiabetic subjects. J Clin Endocrinol Metab 2005;90:2804-9.

50. Videla LA, Rodrigo R, Araya J, Poniachik J. Oxidative stress and depletion of hepatic long-chain polyunsaturated fatty acids may contribute to nonalcoholic fatty liver disease. Free Radic Biol Med 2004;37:1499-507.

51. Capanni M, Calella F, Biagini MR, Genise S, Raimondi L, Bedogni G, et al. Prolonged n-3 polyunsaturated fatty acid supplementation ameliorates hepatic steatosis in patients with non-alcoholic fatty liver disease: a pilot study. Aliment Pharmacol Ther 2006;23:1143-51.

52. Delarue J, LeFoll C, Corporeau C, Lucas D. N-3 long chain polyunsaturated fatty acids: a nutritional tool to prevent insulin resistance associated to type 2 diabetes and obesity? Reprod Nutr Dev 2004;44:289-99.

53. Demirel G, Wachira AM, Sinclair LA, Wilkinson RG, Wood JD, Enser M. Effects of dietary n-3 polyunsaturated fatty acids, breed and dietary vitamin $\mathrm{E}$ on the fatty acids of lamb muscle, liver and adipose tissue. Br J Nutr 2004;91:551-65.

54. Donnelly KL, Smith Cl, Schwarzenberg SJ, Jessurun J, Boldt MD, Parks EJ. Sources of fatty acids stored in liver and secreted via lipoproteins in patients with nonalcoholic fatty liver disease. J Clin Invest 2005;115:1343-51.

55. Hui JM, Hodge A, Farrell GC, Kench JG, Kriketos A, George J. Beyond insulin resistance in NASH: TNF-alpha or adiponectin? Hepatology 2004;40:46-54.

56. Bugianesi E, Pagotto U, Manini R, Vanni E, Gastaldelli A, de lasio R, et al. Plasma adiponectin in nonalcoholic fatty liver is related to hepatic insulin resistance and hepatic fat content, not to liver disease severity. J Clin Endocrinol Metab 2005;90:3498-504.

57. Xu A, Wang Y, Keshaw H, Xu LY, Lam KS, Cooper GJ. The fat-derived hormone adiponectin alleviates alcoholic and nonalcoholic fatty liver diseases in mice. J Clin Invest 2003;112:91-100.

58. Schwarz JM, Linfoot P, Dare D, Aghajanian K. Hepatic de novo lipogenesis in normoinsulinemic and hyperinsulinemic subjects consuming high-fat, low-carbohydrate and low-fat, high-carbohydrate isoenergetic diets. Am J Clin Nutr 2003;77:43-50.

59. Hudgins LC, Hellerstein MK, Seidman CE, Neese RA, Tremaroli JD, Hirsch J. Relationship between carbohydrate-induced hypertriglyceridemia and fatty acid synthesis in lean and obese subjects. J Lipid Res 2000;41:595-604. 
60. Parks EJ. Dietary carbohydrate's effects on lipogenesis and the relationship of lipogenesis to blood insulin and glucose concentrations. Br J Nutr 2002;87 Suppl 2:S247-53.

61. Hudgins LC, Hellerstein M, Seidman C, Neese R, Diakun J, Hirsch J. Human fatty acid synthesis is stimulated by a eucaloric low fat, high carbohydrate diet. J Clin Invest 1996;97:2081-91.

62. Shimomura I, Bashmakov Y, Horton JD. Increased levels of nuclear SREBP-1c associated with fatty livers in two mouse models of diabetes mellitus. J Biol Chem 1999;274:30028-32.

63. Shimano H, Horton JD, Shimomura I, Hammer RE, Brown MS, Goldstein JL. Isoform 1c of sterol regulatory element binding protein is less active than isoform $1 \mathrm{a}$ in livers of transgenic mice and in cultured cells. J Clin Invest 1997;99:846-54.

64. Yahagi N, Shimano H, Hasty AH, Matsuzaka T, Ide T, Yoshikawa T, et al. Absence of sterol regulatory element-binding protein-1 (SREBP-1) ameliorates fatty livers but not obesity or insulin resistance in Lep(ob)/Lep(ob) mice. J Biol Chem 2002;277:19353-7.

65. Petersen KF, Dufour S, Befroy D, Lehrke M, Hendler RE, Shulman GI. Reversal of nonalcoholic hepatic steatosis, hepatic insulin resistance, and hyperglycemia by moderate weight reduction in patients with type 2 diabetes. Diabetes 2005;54:603-8.

66. Sato F, Tamura Y, Watada H, Kumashiro N, Igarashi Y, Uchino H, et al. Effects of Diet-induced Moderate Weight Reduction on Intrahepatic and Intramyocellular Triglycerides and Glucose Metabolism in Obese Subjects. J Clin Endocrinol Metab 2007.

67. Bajaj M, Suraamornkul S, Pratipanawatr T, Hardies L, Pratipanawatr W, Glass L, et al. Pioglitazone reduces hepatic fat content and augments splanchnic glucose uptake in patients with type 2 diabetes. Diabetes 2003;52:1364-70.

68. Lieber CS. Medical and Nutritional Complications of Alcoholism: Mechanisms and Management. New York: Plenum Press 1992.

69. Lieber CS. Cytochrome P-4502E1: its physiological and pathological role. Physiol Rev 1997;77:51744.

70. Raucy JL, Lasker JM, Kraner JC, Salazar DE, Lieber CS, Corcoran GB. Induction of cytochrome P450IIE1 in the obese overfed rat. Mol Pharmacol 1991;39:275-80.

71. Emery MG, Fisher JM, Chien JY, Kharasch ED, Dellinger EP, Kowdley KV, et al. CYP2E1 activity before and after weight loss in morbidly obese subjects with nonalcoholic fatty liver disease. Hepatology 2003;38:428-35.

72. Weltman MD, Farrell GC, Hall P, Ingelman-Sundberg M, Liddle C. Hepatic cytochrome P450 $2 E 1$ is increased in patients with nonalcoholic steatohepatitis. Hepatology 1998;27:128-33.

73. Teschke R, Moreno F, Petrides AS. Hepatic microsomal ethanol oxidizing system (MEOS): respective roles of ethanol and carbohydrates for the enhanced activity after chronic alcohol consumption. Biochem Pharmacol 1981;30:1745-51.

74. Yoo JS, Ning SM, Pantuck CB, Pantuck EJ, Yang CS. Regulation of hepatic microsomal cytochrome P450IIE1 level by dietary lipids and carbohydrates in rats. J Nutr 1991;121:959-65.

75. Pessayre D, Mansouri A, Fromenty B. Nonalcoholic steatosis and steatohepatitis. V. Mitochondrial dysfunction in steatohepatitis. Am J Physiol Gastrointest Liver Physiol 2002;282:G193-9.

76. Aggarwal BB, Natarajan K. Tumor necrosis factors: developments during the last decade. Eur Cytokine Netw 1996;7:93-124.

77. Hotamisligil GS, Arner P, Caro JF, Atkinson RL, Spiegelman BM. Increased adipose tissue expression of tumor necrosis factor-alpha in human obesity and insulin resistance. J Clin Invest 1995;95:240915.

78. Ronti T, Lupattelli G, Mannarino E. The endocrine function of adipose tissue: an update. Clin Endocrinol (Oxf) 2006;64:355-65.

79. Crespo J, Cayon A, Fernandez-Gil P, Hernandez-Guerra M, Mayorga M, Dominguez-Diez A, et al. Gene expression of tumor necrosis factor alpha and TNF-receptors, p55 and p75, in nonalcoholic steatohepatitis patients. Hepatology 2001;34:1158-63.

80. Yin M, Wheeler MD, Kono H, Bradford BU, Gallucci RM, Luster MI, et al. Essential role of tumor necrosis factor alpha in alcohol-induced liver injury in mice. Gastroenterology 1999;117:942-52. 
81. Sack MN, Rader TA, Park S, Bastin J, McCune SA, Kelly DP. Fatty acid oxidation enzyme gene expression is downregulated in the failing heart. Circulation 1996;94:2837-42.

82. Chiu HC, Kovacs A, Ford DA, Hsu FF, Garcia R, Herrero P, et al. A novel mouse model of lipotoxic cardiomyopathy. J Clin Invest 2001;107:813-22.

83. Chiu HC, Kovacs A, Blanton RM, Han X, Courtois M, Weinheimer CJ, et al. Transgenic expression of fatty acid transport protein 1 in the heart causes lipotoxic cardiomyopathy. Circ Res 2005;96:22533.

84. Dewald O, Sharma S, Adrogue J, Salazar R, Duerr GD, Crapo JD, et al. Downregulation of peroxisome proliferator-activated receptor-alpha gene expression in a mouse model of ischemic cardiomyopathy is dependent on reactive oxygen species and prevents lipotoxicity. Circulation 2005;112:407-15.

85. Finck BN, Han X, Courtois M, Aimond F, Nerbonne JM, Kovacs A, et al. A critical role for PPARalphamediated lipotoxicity in the pathogenesis of diabetic cardiomyopathy: modulation by dietary fat content. Proc Natl Acad Sci U S A 2003;100:1226-31.

86. Nielsen LB, Bartels ED, Bollano E. Overexpression of apolipoprotein B in the heart impedes cardiac triglyceride accumulation and development of cardiac dysfunction in diabetic mice. J Biol Chem 2002;277:27014-20.

87. Yagyu H, Chen G, Yokoyama M, Hirata K, Augustus A, Kako Y, et al. Lipoprotein lipase (LpL) on the surface of cardiomyocytes increases lipid uptake and produces a cardiomyopathy. J Clin Invest 2003;111:419-26.

88. Schick F, Eismann B, Jung WI, Bongers H, Bunse M, Lutz O. Comparison of localized proton NMR signals of skeletal muscle and fat tissue in vivo: two lipid compartments in muscle tissue. Magn Reson Med 1993;29:158-67.

89. Thomsen C, Becker U, Winkler K, Christoffersen P, Jensen M, Henriksen O. Quantification of liver fat using magnetic resonance spectroscopy. Magn Reson Imaging 1994;12:487-95.

90. Szczepaniak LS, Dobbins RL, Metzger GJ, Sartoni-D’Ambrosia G, Arbique D, Vongpatanasin W, et al. Myocardial triglycerides and systolic function in humans: in vivo evaluation by localized proton spectroscopy and cardiac imaging. Magn Reson Med 2003;49:417-23.

91. Reingold JS, McGavock JM, Kaka S, Tillery T, Victor RG, Szczepaniak LS. Determination of triglyceride in the human myocardium by magnetic resonance spectroscopy: reproducibility and sensitivity of the method. Am J Physiol Endocrinol Metab 2005;289:E935-9.

92. Kankaanpaa M, Lehto HR, Parkka JP, Komu M, Viljanen A, Ferrannini E, et al. Myocardial triglyceride content and epicardial fat mass in human obesity: relationship to left ventricular function and serum free fatty acid levels. J Clin Endocrinol Metab 2006;91:4689-95.

93. Poitout V. Beta-cell lipotoxicity: burning fat into heat? Endocrinology 2004;145:3563-5.

94. Carpentier A, Mittelman SD, Bergman RN, Giacca A, Lewis GF. Prolonged elevation of plasma free fatty acids impairs pancreatic beta-cell function in obese nondiabetic humans but not in individuals with type 2 diabetes. Diabetes 2000;49:399-408.

95. Lee $\mathrm{Y}$, Hirose $\mathrm{H}$, Ohneda $\mathrm{M}$, Johnson JH, McGarry JD, Unger RH. Beta-cell lipotoxicity in the pathogenesis of non-insulin-dependent diabetes mellitus of obese rats: impairment in adipocyte-betacell relationships. Proc Natl Acad Sci U S A 1994;91:10878-82.

96. Kovanlikaya A, Mittelman SD, Ward A, Geffner ME, Dorey F, Gilsanz V. Obesity and fat quantification in lean tissues using three-point Dixon MR imaging. Pediatr Radiol 2005;35:601-7.

97. Bollheimer LC, Skelly RH, Chester MW, McGarry JD, Rhodes CJ. Chronic exposure to free fatty acid reduces pancreatic beta cell insulin content by increasing basal insulin secretion that is not compensated for by a corresponding increase in proinsulin biosynthesis translation. J Clin Invest 1998;101:1094-101.

98. Zhou YP, Grill V. Long term exposure to fatty acids and ketones inhibits B-cell functions in human pancreatic islets of Langerhans. J Clin Endocrinol Metab 1995;80:1584-90.

99. Clark JB, Palmer CJ, Shaw WN. The diabetic Zucker fatty rat. Proc Soc Exp Biol Med 1983;173:6875. 
100. Peterson RG, Shaw WN, Neel MA, Little LA, Eichberg J. Zucker diabetic fatty rat as a model for noninsulin-dependent diabetes mellitus. ILAR news 1990;32:16-19.

101. McGarry JD. Banting lecture 2001: dysregulation of fatty acid metabolism in the etiology of type 2 diabetes. Diabetes 2002;51:7-18.

102. Matsui J, Terauchi Y, Kubota N, Takamoto I, Eto K, Yamashita T, et al. Pioglitazone reduces islet triglyceride content and restores impaired glucose-stimulated insulin secretion in heterozygous peroxisome proliferator-activated receptor-gamma-deficient mice on a high-fat diet. Diabetes 2004;53:2844-54.

103. Ritz-Laser B, Meda P, Constant I, Klages N, Charollais A, Morales A, et al. Glucose-induced preproinsulin gene expression is inhibited by the free fatty acid palmitate. Endocrinology 1999;140:400514.

104. Lameloise N, Muzzin P, Prentki M, Assimacopoulos-Jeannet F. Uncoupling protein 2: a possible link between fatty acid excess and impaired glucose-induced insulin secretion? Diabetes 2001;50:8039.

105. Branstrom R, Leibiger IB, Leibiger B, Corkey BE, Berggren PO, Larsson O. Long chain coenzyme A esters activate the pore-forming subunit (Kir6. 2) of the ATP-regulated potassium channel. J Biol Chem 1998;273:31395-400.

106. Liang Y, Buettger C, Berner DK, Matschinsky FM. Chronic effect of fatty acids on insulin release is not through the alteration of glucose metabolism in a pancreatic beta-cell line (beta HC9). Diabetologia 1997;40:1018-27.

107. El-Assaad W, Buteau J, Peyot ML, Nolan C, Roduit R, Hardy S, et al. Saturated fatty acids synergize with elevated glucose to cause pancreatic beta-cell death. Endocrinology 2003;144:4154-63.

108. Maedler K, Oberholzer J, Bucher P, Spinas GA, Donath MY. Monounsaturated fatty acids prevent the deleterious effects of palmitate and high glucose on human pancreatic beta-cell turnover and function. Diabetes 2003;52:726-33.

109. Oakes ND, Bell KS, Furler SM, Camilleri S, Saha AK, Ruderman NB, et al. Diet-induced muscle insulin resistance in rats is ameliorated by acute dietary lipid withdrawal or a single bout of exercise: parallel relationship between insulin stimulation of glucose uptake and suppression of long-chain fatty acyl-CoA. Diabetes 1997;46:2022-8.

110. Updating of trend tables to include childhood obesity data. 2004, Health Survey for England www.ic.nhs.uk/pubs/hsechildobesityupdate. 


\section{Part 2. - Prolonged fasting}

\section{Chapter 3.}

Prolonged fasting identifies skeletal muscle mitochondrial dysfunction as consequence rather than cause of human insulin resistance

\section{Chapter 4.}

Prolonged fasting and the effects on biomarkers of inflammation and several adipokines including chemerin in healthy subjects 



\section{Chapter 3. Prolonged fasting identifies skeletal muscle mitochondrial dysfunction as consequence rather than cause of human insulin resistance}

N.A. van Herpen, J. Hoeks,

M. Mensink, E. Moonen-Kornips,

D.van Beurden, M.K.C. Hesselink and P. Schrauwen

Diabetes. 2010; 59: 2117-2125. 


\section{Abstract}

\section{Objective}

Type 2 diabetes and insulin resistance have been associated with mitochondrial dysfunction, but it is debated whether this is a primary factor in the pathogenesis of the disease.

To test the concept that mitochondrial dysfunction is secondary to the development of insulin resistance we employed the unique model of prolonged fasting in humans. Prolonged fasting is a physiological condition in which muscular insulin resistance develops in the presence of increased free fatty acid (FFA) levels, increased fat oxidation and low glucose and insulin levels.

It is therefore anticipated that skeletal muscle mitochondrial function is maintained to accommodate the increased fat oxidation unless factors secondary to insulin resistance exert negative effects on mitochondrial function.

\section{Research Design and Methods}

Twelve healthy males fasted for $60 \mathrm{~h}$ or received a control diet, while in a respiration chamber. Afterwards, insulin-sensitivity was assessed using a hyperinsulinemiceuglycemic clamp and mitochondrial function was quantified ex vivo in permeabilized muscle fibers using high-resolution respirometry.

\section{Results}

Indeed, FFA levels were increased $~ 9$-fold after sixty hours of fasting in healthy male subjects leading to elevated intramuscular lipid levels and a decreased muscular insulin sensitivity. Despite an increase in whole-body fat oxidation, we observed an overall reduction in both coupled state 3 respiration and maximally uncoupled respiration in permeabilized skeletal muscle fibers, which could not be explained by changes in mitochondrial density.

\section{Conclusions}

These findings confirm that the insulin resistant state has secondary negative effects on mitochondrial function. Given the low insulin- and glucose levels after prolonged fasting, hyperglycemia and insulin action per se can be excluded as underlying mechanisms, pointing towards elevated plasma FFA and/or intramuscular fat accumulation as possible causes for the observed reduction in mitochondrial capacity. 


\section{Introduction}

Although the existence of mitochondrial abnormalities in type 2 diabetes mellitus is extensively reported during the last decade (1-5), there is no evidence that a reduced mitochondrial function is a primary factor in the pathophysiology of this disease. In fact, alternative theories state that the impaired mitochondrial capacity is secondary to the insulin resistant- or diabetic state. In this context, it has been shown that insulin can stimulate mitochondrial biogenesis and increases ATP synthesis in skeletal muscle $(6 ; 7)$. A reduced insulin action in skeletal muscle as observed in type 2 diabetic patients could thereby contribute to the origin of mitochondrial dysfunction. Additionally, the increased exposure of skeletal muscle mitochondria to elevated levels of free fatty acids (FFA), seen in insulin resistance and type 2 diabetes, has been suggested to interfere with proper mitochondrial function. Thus, Szendroedi et al. (8) showed that plasma FFA levels negatively correlated with mitochondrial function measured by magnetic resonance spectroscopy. Furthermore, we have shown that the acute elevation of plasma FFA by lipid infusion, was accompanied by downregulation of the transcriptional coactivator peroxisome proliferator-activated receptor gamma coactivator-1 $\alpha$ (PGC1 $\alpha)$ and other genes involved in mitochondrial metabolism (9). Moreover, it was shown in a comparable study that short-term elevation of lipid availability reduces insulin-stimulated increase in ATP synthase flux in skeletal muscle (10), although this may mainly reflect an effect of muscular insulin resistance on ATP flux. Prolonged fasting ( $>48$ hours) in humans is accompanied by a reduction in insulin sensitivity, elevated plasma FFA levels, elevated intramuscular fat levels, but also an increase in whole-body fat oxidative capacity $(11 ; 12)$. Furthermore, prolonged fastinginduced insulin resistance is not accompanied by hyperglycemia and/or hyperinsulinemia, factors that have been suggested to cause mitochondrial dysfunction in diabetes $(7 ; 13)$. In fact, prolonged fasting is a physiological condition in which insulin resistance develops to spare glucose for utilization by the brain, and increased FFA levels are accompanied by increased fat oxidation. It could therefore be anticipated that despite the development of insulin resistance, mitochondrial function is maintained to accommodate increased fat oxidation during prolonged fasting. Alternatively, if (lipid-induced) insulin resistance or factors associated with the insulin resistant state indeed cause mitochondrial dysfunction, we anticipate a reduction in mitochondrial function upon prolonged fasting. Therefore, we here aim to test the concept that mitochondrial dysfunction originates secondary to the development of insulin resistance by employing the physiological model of prolonged fasting-induced insulin resistance. 


\section{Methods}

\section{Subjects}

Twelve healthy lean male volunteers, lacking a family history of diabetes mellitus or any other endocrine disorder, participated in this study (table 1). None of the subjects engaged in sports activities for more than $2 \mathrm{~h}$ per week. Body composition (14) and maximal aerobic capacity (15) was measured as described previously. The study protocol was reviewed and approved by the Medical Ethical Committee of Maastricht University Medical Center+ and all subjects gave their written informed consent before participating in the study.

Table 1 Subjects Characteristics

\begin{tabular}{ll}
\hline Parameter & Mean \pm SEM \\
\hline Age $(\mathrm{y})$ & $23.6 \pm 1.0$ \\
Body weight $(\mathrm{kg})$ & $78.5 \pm 2.5$ \\
Fat free mass $(\mathrm{kg})$ & $65.9 \pm 1.8$ \\
Height $(\mathrm{m})$ & $1.86 \pm 0.02$ \\
Body mass index $(\mathrm{kg} / \mathrm{m} 2)$ & $22.6 \pm 0.5$ \\
Maximal aerobic capacity $(\mathrm{ml} \mathrm{O2} / \mathrm{kgFFM} / \mathrm{min})$ & $57.5 \pm 1.5$ \\
\hline
\end{tabular}

Values are mean \pm SEM

\section{Experimental design}

Subjects participated in two experimental trials: a $60 \mathrm{~h}$ fast and a $60 \mathrm{~h}$ normal fed condition, in a randomized crossover design with a 2-week wash-out period. In the fast condition, subjects were fasted for $60 \mathrm{~h}$ (calorie-free drinks only) while in the second condition subjects were fed in energy balance (50-35-15\% of energy as carbohydrates, fat and protein, respectively). Before the start of each experimental period a standardized evening meal was provided. Subject stayed in a respiration chamber during the entire $60 \mathrm{~h}$ to ensure compliance to the dietary regime and to allow the measurement of $24 \mathrm{~h}$ substrate oxidation and energy expenditure (16). In the respiration chamber subjects followed an activity protocol as previously described (17). During the intervention blood samples were taken after 12, 36 and 60 hours - after an overnight fast in case of the control condition.

\section{Hyperinsulinemic-euglycemic clamp}

After leaving the respiration chamber on the morning of the third day, a muscle biopsy was taken (18) and a hyperinsulinemiceuglycemic clamp procedure (4) was performed. Insulin-stimulated plasma glucose rate of disappearance (Rd), endogenous glucose production (EGP) and non-oxidative glucose disposal (mainly reflecting glycogen synthesis) were calculated as in (4). Substrate oxidation in the basal and 
the insulinstimulated state was measured using indirect calorimetry (Omnical, Maastricht, The Netherlands) and calculated according to Frayn (19).

\section{Muscle Biopsy}

After taking the muscle biopsy, a portion of the muscle tissue was directly frozen in melting isopentane and stored at $-80^{\circ} \mathrm{C}$ until assayed. Another portion ( $30 \mathrm{mg}$ ) was immediately placed in ice-cold preservation medium (4).

\section{Blood analyses}

Plasma nonesterified fatty acids (Wako Nefa C test kit; Wako Chemicals, Neuss, Germany) and glucose (hexokinase method; LaRoche, Basel, Switzerland) were measured with enzymatic assays automated on a Cobas Fara/Mira. Insulin concentration was determined using a radioimmunoassay (Linco Reseach, St. Charles, MO).

\section{Intramuscular triacylglycerols}

Fresh cryosections $(5 \mu \mathrm{m})$ were stained for intramuscular triacylglycerols (IMTG) by Oil Red $O$ staining combined with fibertyping and immunolabelling of the basal membrane marker laminin to allow quantification of IMTG, as described previously $(20 ; 21)$.

\section{Mitochondrial DNA copy number and citrate synthase activity}

Mitochondrial DNA (mtDNA) copy number, the ratio of NADH dehydrogenase subunit 1 (ND1) to lipoprotein lipase (LPL) (mtDNA/nuclear DNA) was determined as described previously (4). Citrate synthase (CS) activity was measured spectrophotometrically as described previously (22).

\section{High resolution respirometry}

Permeabilized skeletal muscle fibers were immediately prepared from the muscle tissue collected in the preservation medium, as described elsewhere $(4 ; 23)$. Subsequently, the permeabilized muscle fibers ( $2.5 \mathrm{mg}$ wet weight) were analyzed for mitochondrial function using an oxygraph (OROBOROS ${ }^{\circledR}$ Instruments, Innsbruck, Austria), in essence according to (4). To prevent oxygen limitation, the respiration chambers were hyper-oxygenated up to $\sim 500 \mu \mathrm{mol} / \mathrm{L}$ O2. Subsequently, 2 different multi-substrate/inhibition protocols were used in which substrates and inhibitors were added consecutively in saturating concentrations. State 2 respiration was measured after the addition of malate $(4 \mathrm{mM})$ plus octanoylcarnitine $(50 \mu \mathrm{M})$ or malate $(4 \mathrm{mM})$ plus glutamate $(10 \mathrm{mM})$. Subsequently, an excess of $2 \mathrm{mM}$ of ADP 
was added to determine coupled (state 3 ) respiration. Coupled respiration was then maximized with convergent electron input through complex I and complex II, by adding saturating concentrations of succinate $(10 \mathrm{mM})$. Finally, the chemical uncoupler carbonylcyanide-4- (trifluoromethoxy)-phenylhydrazone (FCCP) was titrated or oligomycin $(2 \mu \mathrm{g} / \mathrm{ml})$ was added to evaluate the maximal capacity of the electron transport chain and the respiration not coupled to ATP synthesis (state 40 respiration), respectively. The integrity of the outer mitochondrial membrane was assessed by the addition of cytochrome $C(10 \mu \mathrm{mol} / \mathrm{L})$ upon maximal coupled respiration. All measurements were performed in duplicate.

\section{Western Blotting}

OXPHOS protein levels and mitochondrial uncoupling protein 3 (UCP3) content were measured in whole muscle by western blotting as described previously (24). UCP3 was expressed as a ratio over the sum of OXPHOS complexes, to correct for differences in mitochondrial density.

\section{Statistics}

Data are reported as means \pm SEM. Statistical analyses were performed using the statistical computer program SPSS 16.0 for Mac OS X. Statistical comparisons between the two conditions (fed vs. fast) were performed using the paired Student's $t$ test. Plasma FFA, glucose and insulin over time were compared by two-way repeated measures ANOVA for investigation of treatment and time (treatment*time) interactions. When the interaction was significant we performed post-hoc testing to determine the exact location of the difference. Differences were considered statistically significant when $p<0.05$.

\section{Results}

\section{Plasma parameters}

A significant treatment*time interaction $(p<0.001)$ was observed for all plasma parameters (figure 1). At the start of the intervention ( $t=12$, after an overnight fast) plasma FFA levels (fig. 1A) were similar between both conditions ( $221 \pm 18$ vs. $215 \pm$ $27 \mu \mathrm{M}$ respectively, $\mathrm{p}=0.82$ ). Upon 60 hours of fasting, plasma FFA increased dramatically, up to $1981 \pm 95 \mu \mathrm{M}$ vs. $387 \pm 37$ in the fed condition $(\mathrm{p}<0.001)$. Plasma glucose values (fig. 1B) were similar at baseline averaging $5.05 \pm 0.09$ and $4.98 \pm$ $0.06 \mathrm{mM}$ in the fed- and the fasted state, respectively $(\mathrm{p}=0.28)$, and remained unchanged throughout the fed condition. During fasting however, plasma glucose levels gradually decreased down to $3.72 \pm 0.13 \mathrm{mM}$ at $\mathrm{t}=60$ hours $(\mathrm{p}<0.001)$. Base- 
line plasma insulin levels (fig. 1C) were similar in both conditions (12.9 \pm 0.9 vs. 11.9 $\pm 1.2 \mu \mathrm{U} / \mathrm{ml}$ in fed vs. fasted, respectively, $\mathrm{p}=0.25$ ) and did not change in the fed condition. In the fasted condition however, plasma insulin levels were markedly reduced to $7.1 \pm 0.6 \mu \mathrm{U} / \mathrm{ml}$ at $\mathrm{t}=36(\mathrm{p}<0.001)$ and were maintained at this lower level $(7.0 \mu \mathrm{U} / \mathrm{ml} \pm 0.74)$ at $\mathrm{t}=60(\mathrm{p}<0.001)$.
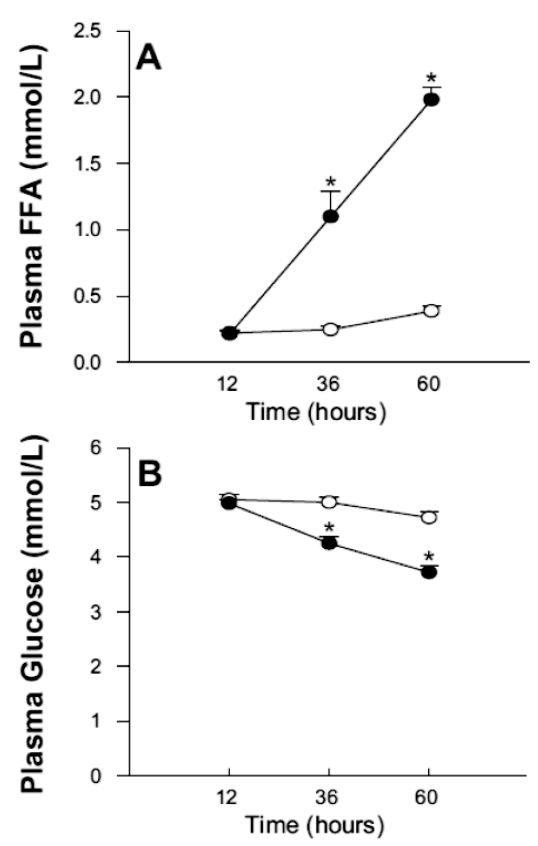

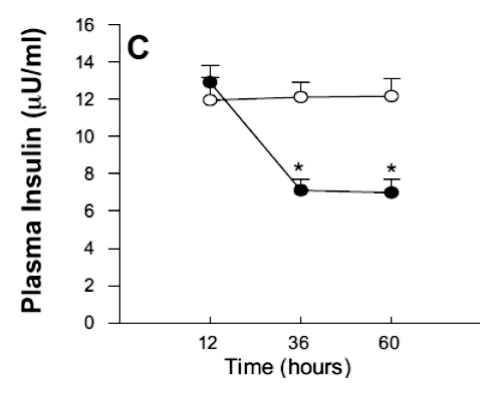

Figure 1. Blood parameters

Plasma non-esterifed fatty acids (A) plasma glucose (B) and plasma insulin (C) levels after 12, 36 and 60 hours of fasting. Open circles / bars represent the fed control group, closed circles / bars represent the fasted group. Values are mean \pm SEM. ${ }^{*} p<0.05$.

\section{Indirect Calorimetry.}

Twenty-four hour energy expenditure during the last $24 \mathrm{~h}$ of the 60 -hour intervention was slightly but significantly reduced upon prolonged fasting (10.88 \pm 0.33 vs. $10.30 \pm 0.30 \mathrm{MJ} /$ day, in fed vs. fasted, respectively, $p=0.02$ ). The difference was mainly due to a reduction in diet-induced thermogenesis, and not due to a decrease in resting metabolic rate (data not shown). Additionally, whole-body $24 \mathrm{~h}$ fat oxidation was increased upon prolonged fasting as evidenced by a significant reduction in 24h-RER ( $0.91 \pm 0.009$. vs. $0.77 \pm 0.003$ in fed vs. fasted, respectively, $p<0.001)$.

\section{Insulin sensitivity}

All subjects displayed a decrease in glucose infusion rate upon 60 hours of fasting (figure 2A). We also calculated the insulin sensitivity index (SI), an index that takes into account the variation in insulin and glucose levels during the clamp (25). Insulin 
sensitivity index was reduced by $\sim 45 \%$ upon 60 hours of fasting, as compared to the fed condition (fig. $2 \mathrm{~B}, \mathrm{p}<0.001$ ). The reduction in whole body insulin sensitivity was mainly accounted for by a reduction in insulin-stimulated glucose disposal (delta Rd, $\mathrm{p}<0.001$, table 2). The reduced insulin-stimulated glucose disposal after fasting, mainly reflecting muscle glucose uptake, was due to both a reduced insulin stimulation of glucose oxidation and a reduced non-oxidative glucose disposal (table 2). However, insulin-stimulated glucose oxidation seemed to be more severely suppressed by $60 \mathrm{~h}$ fasting (table 2 ). Also baseline endogenous glucose production was reduced after 60 hours of fasting. However, insulin-induced suppression of endogenous glucose production, reflecting hepatic insulin sensitivity, was only marginally affected by fasting and was almost complete in both conditions (table 2).

Figure 2. Insulin sensitivity
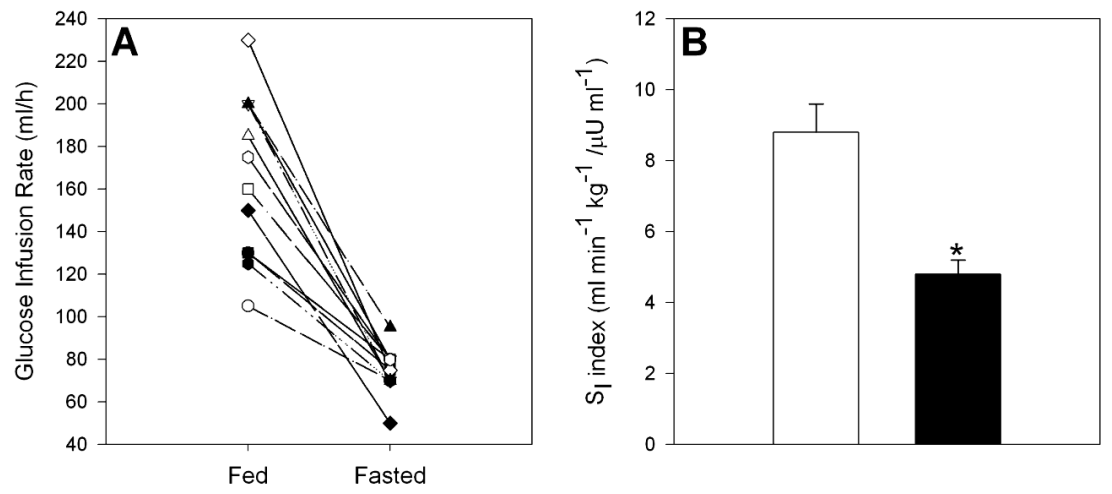

Assessment of insulin sensitivity by hyperinsulinemic-euglycemic clamping after 60 hours of fasting. Panel A represents the individual data for the glucose infusion rate. Panel B displays the group results of the SIindex, i.e. the glucose infusion rate corrected for body weight and plasma glucose and -insulin levels during the clamp procedure. The white bar represents the fed control group while the black bar depicts the fasted group. Values are mean \pm SEM. ${ }^{*} p<0.05$. 
Figure 3. Indirect calorimetry
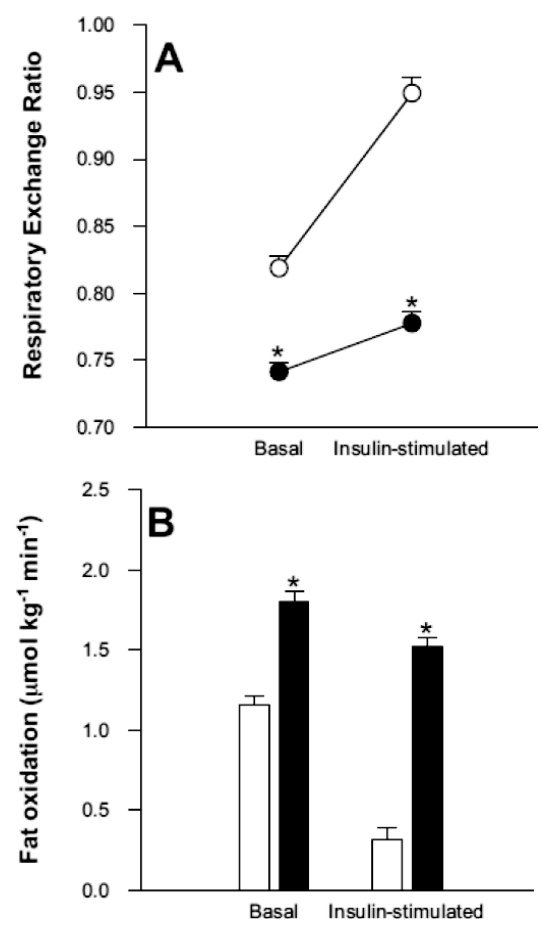

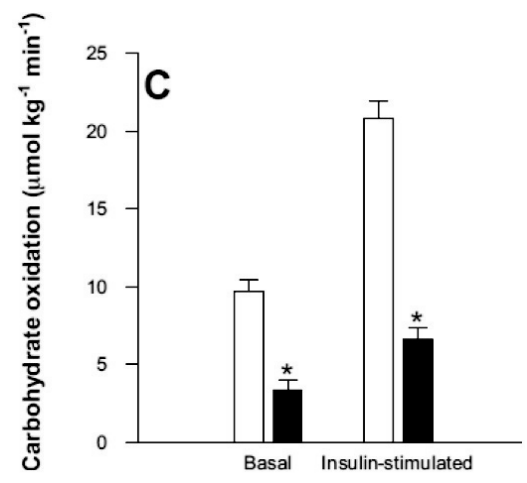

Indirect calorimetry results after 60 hours of fasting in the basal state and upon the hyperinsulinemic-euglycemic clamp. Panel A shows that metabolic flexibility, defined as the change in respiratory exchange ratio upon insulin stimulation, is blunted upon prolonged fasting. Panel B and $C$ display whole body lipid- and carbohydrate oxidation, respectively. White bars represent the fed condition, black bars represent the fasted condition. Values are mean \pm SEM. ${ }^{*} p<$ 0.05 .

\section{Metabolic flexibility}

Metabolic flexibility was blunted in the fasted condition when compared with the fed condition (fig. $3 \mathrm{~A}, \mathrm{p}<0.001$ ). Basal whole-body fat oxidation was increased by 1.5 -fold upon prolonged fasting (fig. $3 B, p<0.001$ ). During the glucose clamp, fat oxidation significantly decreased in both conditions ( $\left.p \_0.001\right)$ but the suppression was significantly less in the fasted condition (fig. 3B, $p<0.001$ ). Basal carbohydrate oxidation after fasting was only $\sim 35 \%$ of the value obtained in the fed situation $(p<0.001)$ but increased in both conditions during the glucose clamp (fig. 3C). However, this insulin-induced change in carbohydrate oxidation was blunted upon fasting $(p<0.001)$. 
Table 2 Substrate kinetics

\begin{tabular}{|c|c|c|}
\hline & Fed & Fasted \\
\hline \multicolumn{3}{|c|}{ Rd Glucose $(\mu \mathrm{mol} / \mathrm{kg} / \mathrm{min})$} \\
\hline Basal & $11.3 \pm 0.6$ & $7.6 \pm 0.4^{*}$ \\
\hline Clamp & $38.0 \pm 2.8$ & $18.8 \pm 0.9 *$ \\
\hline Delta & $26.7 \pm 2.6$ & $11.2 \pm 1.0^{*}$ \\
\hline \multicolumn{3}{|c|}{$\mathrm{EGP}(\mu \mathrm{mol} / \mathrm{kg} / \mathrm{min})$} \\
\hline Basal & $10.7 \pm 0.6$ & $6.8 \pm 0.3^{*}$ \\
\hline Clamp & $-1.0 \pm 0.4$ & $0.7 \pm 0.4^{*}$ \\
\hline Delta absolute & $-11.7 \pm 0.6$ & $-6.07 \pm 0.5^{*}$ \\
\hline Delta \% & $111.6 \pm 5.9$ & $90.0 \pm 6.7^{*}$ \\
\hline \multicolumn{3}{|c|}{$\mathrm{CHO}$ oxidation $(\mu \mathrm{mol} / \mathrm{kg} / \mathrm{min})$} \\
\hline Basal & $9.7 \pm 0.8$ & $3.4 \pm 0.6^{*}$ \\
\hline Clamp & $20.8 \pm 1.1$ & $6.6 \pm 0.8^{*}$ \\
\hline Delta & $11.1 \pm 0.9$ & $3.4 \pm 0.7^{*}$ \\
\hline \multicolumn{3}{|c|}{$\operatorname{NOGD}(\mu \mathrm{mol} / \mathrm{kg} / \mathrm{min})$} \\
\hline Basal & $1.6 \pm 0.5$ & $4.2 \pm 0.8^{*}$ \\
\hline Clamp & $17.2 \pm 2.2$ & $12.6 \pm 0.8^{*}$ \\
\hline Delta & $15.6 \pm 2.4$ & $8.2 \pm 1.1^{*}$ \\
\hline \multicolumn{3}{|c|}{ Lipid oxidation ( $\mu \mathrm{mol} / \mathrm{kg} / \mathrm{min})$} \\
\hline Basal & $1.2 \pm 0.0$ & $1.8 \pm 0.2^{*}$ \\
\hline Clamp & $0.3 \pm 0.1$ & $1.52 \pm 0.1^{*}$ \\
\hline Delta & $-0.8 \pm 0.1$ & $-0.31 \pm 0.1^{*}$ \\
\hline
\end{tabular}

Values are mean \pm SEM. $* p<0.05$.

$\mathrm{EGP}=$ Endogenous glucose production, $\mathrm{CHO}=$ Carbohydrate, $\mathrm{NOGD}=$ Non-oxidative glucose disposal.

\section{Intramuscular triacylglycerols}

The mean IMTG area fraction (fig. 4), was 2.7-fold higher after 60 hours of fasting in comparison with the fed condition $(p=0.001)$. The increase in lipid accumulation was more pronounced ( 3.5 fold, $p<0.001$ ) in fibers identified as slow, oxidative (type 1) fibers. Within type 2 muscle fibers IMTG levels increased by $\sim 2$-fold after 60 hours of fasting $(p=0.015)$. 
Figure 4. Lipid accumulation in the muscle

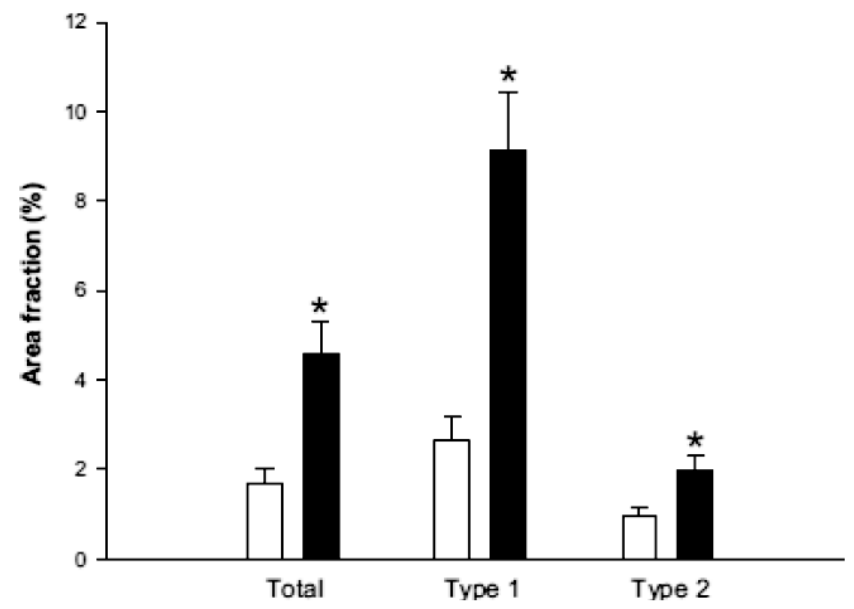

Intramuscular triacylglycerols measured by Oil Red O staining combined with an immunofluorescence staining against slow myosin heavy chain (sMHC), to determine fibertyping. White bars represent the fed condition, black bars represent the fasted condition. Values are mean \pm SEM. * $p<$ 0.05 .

\section{Mitochondrial Function}

Mitochondrial DNA copy number was similar in both the fed and the fasting condition (fig 5A, $p=0.96$ ). Also OXPHOS protein levels (Complex I: $21.2 \pm 6.4$ vs. $17.7 \pm 5.7$ $\mathrm{AU}, \mathrm{p}=0.50$; Complex II: $48.7 \pm 14.6$ vs. $48.3 \pm 16.2 \mathrm{AU}, \mathrm{p}=0.97$; Complex III: $11.6 \pm$ 1.5 vs. $11.9 \pm 1.1 \mathrm{AU}, p=0.88$; Complex IV: $92.8 \pm 7.0$ vs. $93.7 \pm 9.1 \mathrm{AU}, p=0.85$; Complex V: $4.4 \pm 0.7$ vs. $4.8 \pm 0.9, p=0.66)$ and CS activity (76.2 \pm 7.3 vs. $70.2 \pm 6.6$ $\mu \mathrm{mol} / \mathrm{min} / \mathrm{g}$ protein, $\mathrm{p}=0.41$ ) were similar in the fed vs. the fasted state, respectively, confirming an equal mitochondrial mass in both conditions. Nonetheless, we adjusted the oxygen fluxes for individual differences in mtDNA copy number. However, similar results were obtained without this correction (see supplemental figure 1 in the online appendix available at http://diabetes.diabetesjournals.org).

State 2 respiration, i.e. respiration in the presence of substrate alone, was not different between conditions on any of the substrate combinations studied (fig. 5B). However, ADP-stimulated (state 3 ) respiration on a lipid substrate (malate + octanoyl-carnitine, $\mathrm{MO}$ ) was significantly reduced upon fasting, as compared to the fed situation ( $p=0.03$, fig. $5 C$ ). Similarly, state 3 upon the complex I substrates malate + glutamate (MG) was $\sim 22 \%$ lower after fasting, although this did not reach statistical significance ( $p=0.12$, fig. $5 D)$. 
Figure 5. Evaluation of mitochondrial function
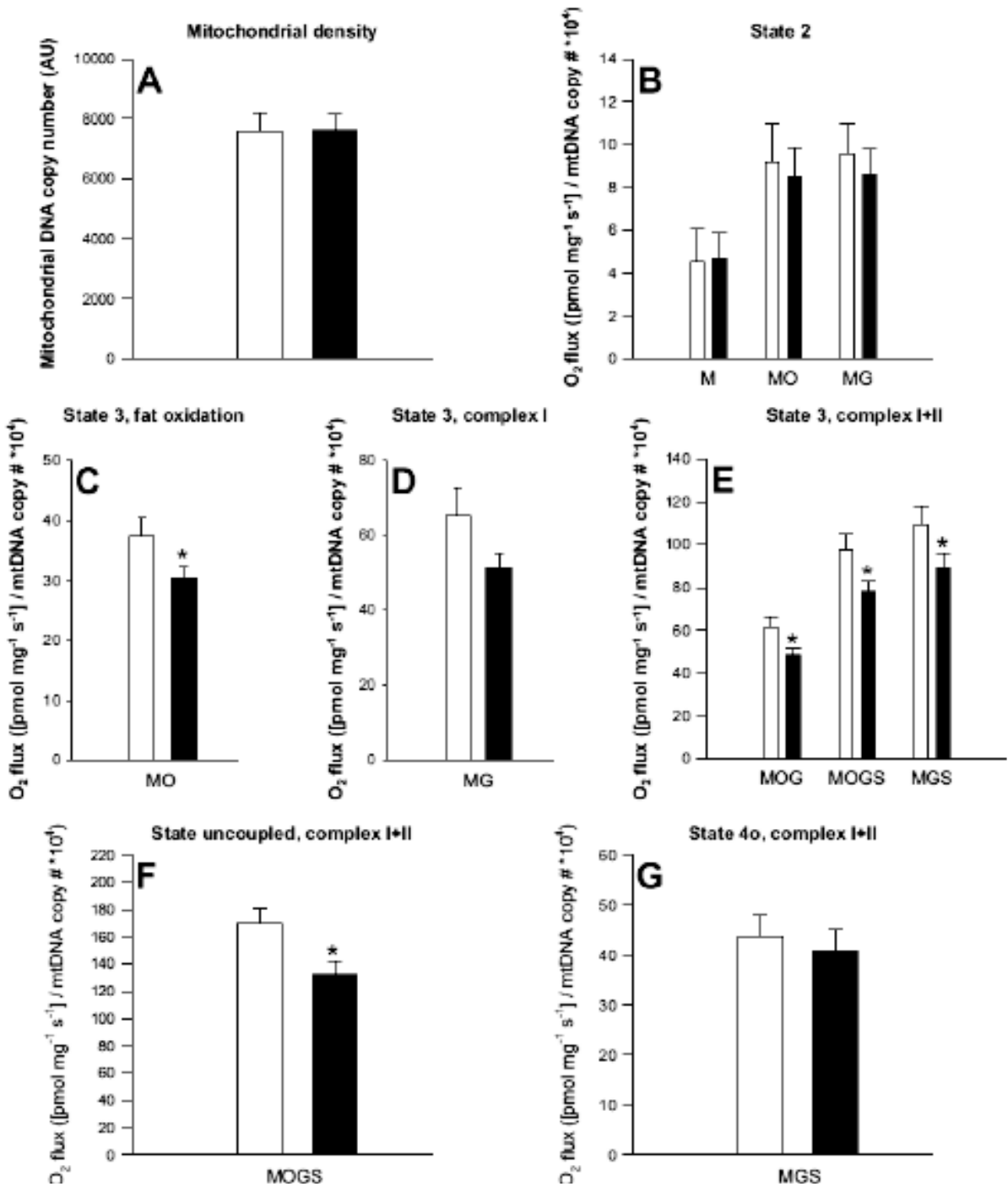

Evaluation of mitochondrial function. A) Mitochondrial density; B) Mitochondrial respiration upon substrates only (state 2); C) ADP-stimulated respiration (state 3) upon a lipid substrate; D) State 3 respiration fuelled by Complex I linked substrates; E) State 3 respiration upon parallel electron input into Complex I and II; F) Maximally uncoupled respiration upon FCCP; G) Mitochondrial respiration uncoupled from ATP synthesis (state 4o). White bars represent the fed condition, black bars represent the fasted condition. Values are mean $\pm \mathrm{SEM}, \mathrm{n}=10 .{ }^{*} \mathrm{p}<0.05$. $\mathrm{M}=$ malate, $\mathrm{O}=$ octanoyl-carnitine, $\mathrm{G}=$ glutamate, $\mathrm{S}=$ succinate.

Additionally, respiration upon parallel electron input to both complex I and II was reduced by $\sim 20 \%$ upon prolonged fasting. Thus, state 3 respiration upon malate + octanoyl-carnitine + glutamate (MOG) was significantly lower in the fasted state as 
compared to the fed condition ( $p=0.01$, fig. $5 E$ ). Similar differences were observed for state 3 respiration upon malate + octanoylcarnitine + glutamate + succinate (MOGS, $p=0.02$, fig. 5E) and malate + glutamate + succinate (MGS, $p=0.04$, fig. 5E). Maximally FCCP-induced uncoupled respiration, reflecting the maximal capacity of the electron transport chain, was also reduced by $23 \%$ after 60 hours of fasting $(p=0.008$, fig. $5 F)$. Finally, state 40 respiration (reflecting mitochondrial proton leak) was similar between the fed and fasted state ( $p=0.48$, fig. $5 G$ ). The average increase in oxygen consumption upon cytochrome $C$ was less than $10 \%$ (underscoring the viability of the muscle fibers) and was similar in both conditions ( $p=0.54)$.

\section{UCP3}

Mitochondrial uncoupling protein 3 (UCP3) did not change upon 60 hours of fasting in humans and averaged $2.21 \pm 0.38$ vs. $2.20 \pm 0.41 \mathrm{AU}$ in the fed vs. fasted condition $(p=0.96)$.

\section{Discussion}

In the present study we evaluated the effect of prolonged fasting on skeletal muscle mitochondrial functional capacity in humans in order to examine whether the mitochondrial dysfunction that is frequently reported in insulin resistance and type 2 diabetes mellitus can be a consequence of lipid-induced insulin resistance, rather than a cause. In contrast to the hyperglycaemia and hyperinsulinaemia accompanying 'energy excess'-induced insulin resistance (lipid infusion, high-fat diets), prolonged fastinginduced insulin resistance is associated with hypoglycaemia and hypoinsulinemia. Moreover, prolonged fasting-induced lipid accumulation and insulin resistance areconsidered to be a functional physiological response. Thus, reduced insulin sensitivity saves carbohydrates for the central nervous system, being obligate for glucose and not requiring insulin for its uptake, while increased lipid availability at the same time can serve as a direct available energy source for the muscle and is paralleled by an enhanced fat oxidative capacity (12).

Therefore we anticipated that skeletal muscle mitochondrial function would not be impaired in this model, unless mitochondrial function is impaired by factors that are secondary to the lipid-induced insulin resistant state. Intriguingly, we found that only 60 hours of fasting in humans was accompanied by an overall reduction in skeletal muscle mitochondrial capacity, which was not explained by changes in mitochondrial density.

We assessed mitochondrial functional capacity in detail (fig. 5) by using a wide variety of substrates and substrate combinations, in order to determine the maxi- 
mum ADP-stimulated respiration (state 3 ) fuelled by a lipid substrate, by complex I substrates and upon parallel electron input into complex I (NADH) and II (FADH2).

Interestingly, state 3 respiration was reduced by $\sim 20 \%$ upon all substrates, which reduces the possibility that the decline is due to substrate-specific alterations such as substrate uptake into the mitochondria. Therefore, both a reduction in the activity of the electron transport chain and the oxidative phosphorylation system could underlie the reduced state 3 respiration. Using the chemical uncoupler FCCP, control over respiration by the oxidative phosphorylation system is bypassed; thus FCCP-induced respiration reflects the maximal capacity of the electron transport chain. Irrespective of the intervention, FCCP was able to enhance mitochondrial respiration considerably over state 3 values, indicating that the electron transport chain is not rate-limiting in state 3 . However, FCCP-induced respiration in itself was reduced by $\sim 23 \%$ upon prolonged fasting (fig. $5 \mathrm{~F}$ ), indicating that a combined reduction of both the capacity of the electron transport chain and oxidative phosphorylation underlies the reduced mitochondrial oxidative capacity upon fasting.

The reduced mitochondrial capacity was not accounted for by a reduction in mitochondrial density. Thus mtDNA copy number, CS activity and OXPHOS protein levels remained unaffected by fasting. Although this does not exclude the possibility that prolonged exposure to high FFA and/or insulin resistance may lead to a reduced mitochondrial function as observed in type 2 diabetes mellitus via reduced mitochondrial biogenesis (e.g. via PGC-1 $\alpha$ ), this finding indicates that fasting interferes with intrinsic mitochondrial capacity in skeletal muscle. Interestingly, a similar reduction in intrinsic mitochondrial capacity, without differences in mitochondrial content, was recently reported by us in type 2 diabetic patients and first-degree relatives when compared to BMI- and age-matched obese control subjects (4). Thus, the reduction in mitochondrial function upon fasting mimics the situation as observed in the diabetic state, and suggests that similar (secondary) effects are involved in causing mitochondrial dysfunction. However, it should be noted that fasting is not a direct model for type 2 diabetes. Furthermore, although the available data in literature underpin the notion that fasting-induced lipid accumulation is responsible for the reduced insulin sensitivity upon fasting, we cannot exclude the possibility that the reduced mitochondrial function upon prolonged fasting triggers the insulin resistance observed.

Resistance of skeletal muscle to insulin action per se has been suggested to explain the reduction in mitochondrial functional capacity observed in diabetes. Thus, in healthy individuals it was shown that a $7 \mathrm{~h}$ insulin infusion increased mitochondrial protein synthesis, cytochrome $C$ oxidase (COX) and citrate synthase (CS) enzyme activities and ATP production (26). Moreover, it has been reported that exposing human primary muscle cells to insulin up-regulates the expression of PGC-1 $\alpha$ (27). Therefore, the reduction in insulin action in type 2 diabetes mellitus may underlie the observed mitochondrial defects. 
In agreement with this hypothesis, it was demonstrated that at low doses of insulin (reflecting post-absorptive levels) the skeletal mitochondrial ATP synthesis rate was not different between diabetic patients and controls, indicating that there is no intrinsic muscle mitochondrial defect in type 2 diabetic patients (7). On the other hand, high (postprandial) levels of insulin increased the mitochondrial ATP production rate in nondiabetic subjects, whereas this increase was absent in type 2 diabetic patients (7). Furthermore, the lack of response in the diabetic patients was accompanied by a reduced expression of PGC-1 $\alpha$, CS and COX.

Besides a reduced insulin action, the hyperglycemia associated with insulin resistance and type 2 diabetes has also been suggested to exert harmful effects on mitochondrial functional capacity via induction of oxidative stress. Indeed, hyperglycemia was shown to increase mitochondrial ROS production in endothelial cells (28) as well as in other cell types (29). In addition, it was reported that severe hyperglycemia inhibited respiration in human skeletal muscle, which was restored upon insulin treatment (13). It should be noted that the insulin resistant state after prolonged fasting was accompanied by hypoinsulinemia and hypoglycemia. Mitochondrial function was thus assessed after exposure to low insulin and glucose concentrations. It is therefore unlikely that the reduced mitochondrial functional capacity observed here is caused by hyperinsulinemia and/or hyperglycemia associated with a reduced insulin action. However, it remains possible that chronic hyperinsulinemia and/or hyperglycemia may negatively affect mitochondrial function in type 2 diabetes mellitus patients.

An alternative candidate to explain the observed reduction in mitochondrial capacity upon fasting is the prolonged exposure to elevated plasma FFA levels. This is underscored by previous findings in isolated mouse- and human skeletal muscle mitochondria showing a dose-dependent inhibition of ATP synthesis upon incubation with high but physiological levels of FFA metabolites (30). Furthermore, it was shown in mice that prolonged consumption of a highfat diet for the duration of 16 weeks reduced mitochondrial function (31). Also in human in vivo studies, negative associations between high fatty acid availability and markers for mitochondrial function have been reported. Thus, PGC-1_ expression (9) and the insulin-stimulated increase in skeletal muscle ATP synthesis (10) were reduced upon lipid infusion.

Furthermore, it was recently shown that mitochondrial membrane potential was impaired upon short-term lipid infusion in healthy individuals, although several other markers of mitochondrial function remained unaffected (32). Despite the reported negative associations between mitochondrial function and (plasma) FFA, there are also several lines of evidence suggesting the opposite. Thus, raising plasma FFA by high-fat feeding combined with daily heparin injections for 4 weeks in rats increased skeletal muscle mitochondrial biogenesis and mitochondrial enzymes involved in fat oxidation, the citric acid cycle and the respiratory chain (33). 
Furthermore, we previously showed that high-fat feeding in rats for 8 weeks resulted in a 2-fold increase of PGC-1 $\alpha$ protein levels (34). Despite the obvious species differences between these studies, it remains unclear what the explanation is for the discrepancy in these results. Adding to the complexity is the fact that several approaches (high-fat feeding, lipid infusion combined with a hyperinsulinemiceuglycemic clamp) to elevate plasma FFA levels are accompanied by hyperinsulinemia and/or hyperglycemia and insulin resistance, all factors that have also been suggested to interfere with mitochondrial capacity $(26 ; 29)$.

Finally, differences in absolute levels of plasma FFA achieved in the different studies may contribute to (part of) the variation. Within the context of mitochondrial lipotoxicity, we and others have previously postulated that mitochondrial uncoupling protein 3 (UCP3) may be involved in protecting mitochondria against (lipidinduced) oxidative damage (for review, see (35)). Therefore, we determined protein levels of UCP3 and found that UCP3 content was similar between the fed and the fasted condition. This is a surprising finding since fasting has been quite convincingly shown to increase UCP3 protein levels in animal studies $(36 ; 37)$. Moreover, UCP3 mRNA levels were also elevated after $15 \mathrm{~h}$ ( $~ 5$-fold) and $40 \mathrm{~h}$ ( 10 -fold) of fasting in humans (38). It should be noted, however, that this is the first study to evaluate UCP3 protein content upon prolonged fasting in humans. The impressive increase in plasma FFA upon prolonged fasting is in line with previous findings in humans (12; $39)$, although the absolute values achieved in this study ( $2000 \mu \mathrm{M})$ are high. Also the 2 2.7-fold increase in IMTG levels after 60 hours of fasting is slightly higher in comparison with previous reports $(12 ; 39)$. The high plasma FFA and IMTG levels might be caused by complete compliance to the fasting regimen in the present study since, in contrast to other studies, the subjects stayed in a respiration chamber throughout the whole period. The reduction in insulin-stimulated glucose uptake observed in the present study confirms previous observations showing that prolonged fasting reduced glucose $\mathrm{Rd}$, which was accounted for by a reduction in both insulinstimulated glucose oxidation and nonoxidative glucose disposal (40). In line with previous reports (40), we also detected a decreased metabolic flexibility (i.e. the ability to switch from predominantly fat oxidation to glucose oxidation upon insulin stimulation) upon prolonged fasting (fig. 3). However, not all studies show this effect (41). As anticipated, whole-body fat oxidation increased significantly upon prolonged fasting. Therefore, the decrease in mitochondrial capacity in skeletal muscle is counterintuitive, especially since this decrease was substrateindependent and also apparent upon a lipid substrate.

These results indicate that the reduced mitochondrial capacity is secondary to the fatty acid surplus associated with the insulin resistant state. It is important to note however, that the reduction in muscle mitochondrial capacity does not (yet) affect the capability of the body to enhance fat oxidation. This is an important finding since it has generally been assumed that a reduction in musclemitochondrial 
function will result in reductions in whole-body fat oxidative capacity $(3-5 ; 42 ; 43)$. Here, we show that this extrapolation may not be justified, although we can not exclude that the fasting-induced reduced mitochondrial function in muscle may decrease muscle-specific fat oxidationcompensated by increased fat oxidation in other organs, or may have an impact on the capacity to switch from carbohydrate to fat oxidation (metabolic flexibility).

In conclusion, 60 hours of fasting in humans lowered insulin-stimulated glucose uptake down to $\sim 50 \%$ along with drastically elevated plasma FFA and IMTG levels. This was accompanied by an overall reduction in intrinsic mitochondrial functional capacity in skeletal muscle, despite a pronounced increase in whole-body fat oxidation. Since prolonged fasting is a physiological condition in which increased fat oxidation becomes very important, a reduced mitochondrial function seems unbeneficial from a physiological point of view. Our findings suggest that the elevated plasma FFA and/or intramuscular lipid levels associated with the insulin resistant state are responsible for the secondary negative effects on mitochondrial function. 


\section{References}

1. Petersen KF, Befroy D, Dufour S, Dziura J, Ariyan C, Rothman DL, DiPietro L, Cline GW, Shulman GI: Mitochondrial dysfunction in the elderly: possible role in insulin resistance. Science 300:11401142, 2003

2. Petersen KF, Dufour S, Befroy D, Garcia R, Shulman GI: Impaired mitochondrial activity in the insulin-resistant offspring of patients with type 2 diabetes. N Engl J Med 350:664- 671, 2004

3. Kelley DE, He J, Menshikova EV, Ritov VB: Dysfunction of mitochondria in human skeletal muscle in type 2 diabetes. Diabetes 51:2944-2950, 2002

4. Phielix E, Schrauwen-Hinderling VB, Mensink M, Lenaers E, Meex R, Hoeks J, Kooi ME, MoonenKornips E, Sels JP, Hesselink MK, Schrauwen P: Lower intrinsic ADP-stimulated mitochondrial respiration underlies in vivo mitochondrial dysfunction in muscle of male type 2 diabetic patients. Diabetes 57:2943-2949, 2008

5. Mogensen M, Sahlin K, Fernstrom M, Glintborg D, Vind BF, Beck-Nielsen H, Hojlund K: Mitochondrial respiration is decreased in skeletal muscle of patients with type 2 diabetes. Diabetes 56:15921599, 2007

6. Pagel-Langenickel I, Bao J, Joseph JJ, Schwartz DR, Mantell BS, Xu X, Raghavachari N, Sack MN: PGC1alpha integrates insulin signaling, mitochondrial regulation, and bioenergetic function in skeletal muscle. J Biol Chem 283:22464-22472, 2008

7. Asmann YW, Stump CS, Short KR, Coenen-Schimke JM, Guo Z, Bigelow ML, Nair KS: Skeletal muscle mitochondrial functions, mitochondrial DNA copy numbers, and gene transcript profiles in type 2 diabetic and nondiabetic subjects at equal levels of low or high insulin and euglycemia. Diabetes 55:3309-3319, 2006

8. Szendroedi J, Schmid Al, Chmelik M, Toth C, Brehm A, Krssak M, Nowotny P, Wolzt M, Waldhausl W, Roden M: Muscle mitochondrial ATP synthesis and glucose transport/phosphorylation in type 2 diabetes. PLoS Med 4:e154, 2007

9. Hoeks J, Hesselink MK, Russell AP, Mensink M, Saris WH, Mensink RP, Schrauwen P: Peroxisome proliferator-activated receptor-gamma coactivator-1 and insulin resistance: acute effect of fatty acids. Diabetologia 49:2419-2426, 2006

10. Brehm A, Krssak M, Schmid Al, Nowotny P, Waldhausl W, Roden M: Increased lipid availability impairs insulin-stimulated ATP synthesis in human skeletal muscle. Diabetes 55:136-140, 2006

11. Johnson NA, Stannard SR, Mehalski K, Trenell MI, Sachinwalla T, Thompson CH, Thompson MW: Intramyocellular triacylglycerol in prolonged cycling with high- and lowcarbohydrate availability. $J$ Appl Physiol 94:1365-1372, 2003

12. Stannard SR, Thompson MW, Fairbairn K, Huard B, Sachinwalla T, Thompson CH: Fasting for $72 \mathrm{~h}$ increases intramyocellular lipid content in nondiabetic, physically fit men. Am J Physiol Endocrinol Metab 283:E1185-1191, 2002

13. Rabol R, Hojberg PM, Almdal T, Boushel R, Haugaard SB, Madsbad S, Dela F: Effect of hyperglycemia on mitochondrial respiration in type 2 diabetes. J Clin Endocrinol Metab 94:1372-1378, 2009

14. Hoeks J, van Baak MA, Hesselink MK, Hul GB, Vidal H, Saris WH, Schrauwen P: Effect of beta1- and beta2-adrenergic stimulation on energy expenditure, substrate oxidation, and UCP3 expression in humans. Am J Physiol Endocrinol Metab 285:E775-782, 2003

15. Kuipers H, Verstappen FT, Keizer HA, Geurten P, van Kranenburg G: Variability of aerobic performance in the laboratory and its physiologic correlates. Int J Sports Med 6:197-201, 1985

16. Schoffelen PF, Westerterp KR, Saris WH, Ten Hoor F: A dual-respiration chamber system with automated calibration. J Appl Physiol 83:2064-2072, 1997

17. Schrauwen $P$, van Marken Lichtenbelt WD, Saris WH, Westerterp KR: Changes in fat oxidation in response to a high-fat diet. Am J Clin Nutr 66:276-282, 1997

18. Bergstrom J, Hermansen L, Hultman E, Saltin B: Diet, muscle glycogen and physical performance. Acta Physiol Scand 71:140-150, 1967 
19. Frayn KN: Calculation of substrate oxidation rates in vivo from gaseous exchange. J Appl Physiol 55:628-634, 1983

20. Roorda BD, Hesselink MK, Schaart G, Moonen-Kornips E, Martinez-Martinez P, Losen M, De Baets $\mathrm{MH}$, Mensink RP, Schrauwen P: DGAT1 overexpression in muscle by in vivo DNA electroporation increases intramyocellular lipid content. J Lipid Res 46:230-236, 2005

21. Koopman R, Schaart G, Hesselink MK: Optimisation of oil red O staining permits combination with immunofluorescence and automated quantification of lipids. Histochem Cell Biol 116:63-68, 2001

22. Shepherd D, PB G: Citrate synthase from rat liver. In Methods in enzymology, vol XIII New York, Academic Press, 1969, p. 11-16

23. Boushel R, Gnaiger E, Schjerling P, Skovbro M, Kraunsoe R, Dela F: Patients with type 2 diabetes have normal mitochondrial function in skeletal muscle. Diabetologia 50:790-796, 2007

24. Schrauwen P, Mensink M, Schaart G, Moonen-Kornips E, Sels JP, Blaak EE, Russell AP, Hesselink MK: Reduced skeletal muscle uncoupling protein-3 content in prediabetic subjects and type 2 diabetic patients: restoration by rosiglitazone treatment. J Clin Endocrinol Metab 91:1520-1525, 2006

25. Bergman RN, Finegood DT, Ader M: Assessment of insulin sensitivity in vivo. Endocr Rev 6:45-86, 1985

26. Stump CS, Short KR, Bigelow ML, Schimke JM, Nair KS: Effect of insulin on human skeletal muscle mitochondrial ATP production, protein synthesis, and mRNA transcripts. Proc Natl Acad Sci U S A 100:7996-8001, 2003

27. Al-Khalili L, Forsgren M, Kannisto K, Zierath JR, Lonnqvist F, Krook A: Enhanced insulin-stimulated glycogen synthesis in response to insulin, metformin or rosiglitazone is associated with increased RNA expression of GLUT4 and peroxisomal proliferator activator receptor gamma co-activator 1. Diabetologia 48:1173-1179, 2005

28. Brownlee M: The pathobiology of diabetic complications: a unifying mechanism. Diabetes 54:16151625, 2005

29. Yu T, Robotham JL, Yoon Y: Increased production of reactive oxygen species in hyperglycemic conditions requires dynamic change of mitochondrial morphology. Proc Natl Acad Sci U S A 103:2653-2658, 2006

30. Abdul-Ghani MA, Muller FL, Liu Y, Chavez AO, Balas B, Zuo P, Chang Z, Tripathy D, Jani R, MolinaCarrion M, Monroy A, Folli F, Van Remmen H, DeFronzo RA: Deleterious action of FA metabolites on ATP synthesis: possible link between lipotoxicity, mitochondrial dysfunction, and insulin resistance. Am J Physiol Endocrinol Metab 295:E678-685, 2008

31. Bonnard C, Durand A, Peyrol S, Chanseaume E, Chauvin MA, Morio B, Vidal H, Rieusset J: Mitochondrial dysfunction results from oxidative stress in the skeletal muscle of diet induced insulinresistant mice. J Clin Invest 118:789-800, 2008

32. Chavez AO, Kamath S, Jani R, Sharma LK, Monroy A, Abdul-Ghani MA, Centonze VE, Sathyanarayana P, Coletta DK, Jenkinson CP, Bai Y, Folli F, Defronzo RA, Tripathy D: Effect of Short-Term Free Fatty Acids Elevation on Mitochondrial Function in Skeletal Muscle of Healthy Individuals. J Clin Endocrinol Metab, 2009

33. Garcia-Roves P, Huss JM, Han DH, Hancock CR, Iglesias-Gutierrez E, Chen M, Holloszy JO: Raising plasma fatty acid concentration induces increased biogenesis of mitochondria in skeletal muscle. Proc Natl Acad Sci U S A 104:10709-10713, 2007

34. Hoeks J, Briede JJ, de Vogel J, Schaart G, Nabben M, Moonen-Kornips E, Hesselink MK, Schrauwen $P$ : Mitochondrial function, content and ROS production in rat skeletal muscle: effect of high-fat feeding. FEBS Lett 582:510-516, 2008

35. Schrauwen P, Hoeks J, Hesselink MK: Putative function and physiological relevance of the mitochondrial uncoupling protein-3: involvement in fatty acid metabolism? Prog Lipid Res 45:17-41, 2006

36. Moreno M, Lombardi A, De Lange P, Silvestri E, Ragni M, Lanni A, Goglia F: Fasting, lipid metabolism, and triiodothyronine in rat gastrocnemius muscle: interrelated roles of uncoupling protein 3, mitochondrial thioesterase, and coenzyme Q. Faseb J 17:1112-1114, 2003 
37. Cadenas S, Buckingham JA, Samec S, Seydoux J, Din N, Dulloo AG, Brand MD: UCP2 and UCP3 rise in starved rat skeletal muscle but mitochondrial proton conductance is unchanged. FEBS Lett 462:257-260, 1999

38. Tunstall RJ, Mehan KA, Hargreaves M, Spriet LL, Cameron-Smith D: Fasting activates the gene expression of UCP3 independent of genes necessary for lipid transport and oxidation in skeletal muscle. Biochem Biophys Res Commun 294:301-308, 2002

39. Johnson NA, Stannard SR, Rowlands DS, Chapman PG, Thompson CH, O'Connor H, Sachinwalla T, Thompson MW: Effect of short-term starvation versus high-fat diet on intramyocellular triglyceride accumulation and insulin resistance in physically fit men. Exp Physiol 91:693-703, 2006

40. Bergman BC, Cornier MA, Horton TJ, Bessesen DH: Effects of fasting on insulin action and glucose kinetics in lean and obese men and women. Am J Physiol Endocrinol Metab 293:E1103-1111, 2007

41. Soeters MR, Sauerwein HP, Dubbelhuis PF, Groener JE, Ackermans MT, Fliers E, Aerts JM, Serlie MJ: Muscle adaptation to short-term fasting in healthy lean humans. J Clin Endocrinol Metab 93:29002903, 2008

42. Ortenblad N, Mogensen M, Petersen I, Hojlund K, Levin K, Sahlin K, Beck-Nielsen H, Gaster M: Reduced insulin-mediated citrate synthase activity in cultured skeletal muscle cells from patients with type 2 diabetes: evidence for an intrinsic oxidative enzyme defect. Biochim Biophys Acta 1741:206-214, 2005

43. Ritov VB, Menshikova EV, He J, Ferrell RE, Goodpaster BH, Kelley DE: Deficiency of subsarcolemmal mitochondria in obesity and type 2 diabetes. Diabetes 54:8-14, 2005 
Chapter 4.

Prolonged fasting and the effects on biomarkers of inflammation and several adipokines including chemerin in healthy subjects

N.A. van Herpen

H. Sell, J. Eckel

P. Schrauwen

and R.P. Mensink

(Submitted), 2011. 


\begin{abstract}
Introduction

Obesity and insulin resistance are associated with metabolic complications such as low-grade systemic inflammation. Elevated plasma FFA, glucose and insulin levels have all been suggested to underlie this systemic inflammation. Prolonged fasting induces insulin resistance due to elevated plasma FFA, but is not accompanied by hyperinsulinemia or hyperglycemia, allowing to study the effects of physiologically increased FFA concentrations apart from those of increased insulin and glucose concentrations on inflammatory markers.
\end{abstract}

\title{
Methods
}

A randomized crossover design with a 2-week wash-out period was used. Subjects were fasted or fed in energy balance for 60 hours. Subject stayed in a respiration chamber during the entire $60 \mathrm{~h}$ periods to ensure compliance. Blood samples were taken after 12, 36 and 60 hours, and afterwards a hyperinsulinemic-euglycemic clamp was performed.

\section{Results}

Fasting decreased insulin sensitivity by $45 \%$. FFA were increased 5 -fold when compared to the fed period. Fasting-induced increases in FFA concentrations did not relate to changes in the concentrations of the inflammatory cytokines TNF- $\alpha$, IL-1b, IL- 6 and IL- 8 , or of hs-CRP. At $t=60$ hours, VEGF concentrations were significantly increased during the fasted period $(P<0.05)$. At the same time point, chemerin $(P<0.01)$ and leptin $(P<0.01)$ were significantly decreased after fasting. For leptin this decrease was also significant after 36 hours $(P<0.01)$. Adiponectin levels remained unchanged.

\section{Conclusion}

Our study with healthy male subjects indicates that fasting-induced increases in FFA leading to insulin resistance do not lead to changes in the concentrations of the inflammatory cytokines. VEGF concentrations increased and those of chemerin decreased. These results suggest that hyperglycemia and/or hyperinsulinemia may be more important than elevated FFA levels or insulin sensitivity per se in obesityassociated chronic inflammation. 


\section{Introduction}

Obese subjects have increased concentrations of free fatty acids (FFA), which may relate to the frequently observed associations between increased body fat content and insulin resistance. Indeed, increasing plasma FFA concentrations by lipid infusion causes insulin resistance (1). However, increased plasma FFA concentrations are also related to other metabolic complications such as low-grade systemic inflammation, which on its turn may cause insulin resistance, hyperinsulinemia, and hyperglycemia (2-4). Indeed, several studies have demonstrated that insulin resistance is associated with elevated levels of for example high-sensitive C-reactive protein (hs-CrP) and IL-6, and decreased levels of the anti-inflammatory adipokine adiponectin $(5)$, independent of obesity $(5,6)$. Moreover, infusion of insulin in humans increases leptin concentrations, which has also been linked to inflammation (7), and decreases adiponectin concentrations (8). Finally, hyperglycemia can contribute to activation of NF-kB, as reviewed by Schwartz et al (9). Thus, a complex interplay exists between FFA concentrations, insulin resistance, and inflammation. Further, it is unknown if insulin resistance per se is more important than hyperinsulinemia or hyperglycemia.

Recently, we have shown that in lean healthy subjects prolonged fasting (60 hours) is accompanied by elevated plasma FFA levels and a reduction in insulin sensitivity (10). Importantly, fasting-induced insulin resistance is not accompanied by hyperinsulinemia or hyperglycemia, which makes it possible to study the effects of physiologically increased FFA concentrations apart from those of increased insulin and glucose concentrations on inflammatory markers.

Therefore, the aim of the present study was to study the contribution of FFA and insulin resistance, without the presence of increased glucose and insulin concentrations, on circulating levels of several adipokines who are known to play an important role in the development of low-grade systemic inflammation and that are increased in the obese state. Vascular endothelial growth factor (VEGF) will be studied as it is known that glycaemic control influences VEGF serum levels.

\section{Methods}

\section{Subjects}

Eleven healthy lean male volunteers without family history of diabetes mellitus or any other endocrine disorder participated in this study (table 1). None of the subjects engaged in sports activities for more than $2 \mathrm{~h}$ per week. Body composition and maximal aerobic capacity were measured as described previously (10). The study protocol was reviewed and approved by the Medical Ethical Committee of Maas- 
tricht University Medical Center ${ }^{+}$and all subjects gave their written informed consent before participating in the study.

\section{Experimental design}

Using a randomized crossover design with a 2-week wash-out period, subjects participated in two experimental periods: a $60 \mathrm{~h}$ fast and a $60 \mathrm{~h}$ normal fed condition. In the fast condition, subjects were fasted for $60 \mathrm{~h}$ (calorie-free drinks only), while in the other condition subjects were maintained in energy balance (50-35-15\% of energy as carbohydrates, fat and protein, respectively). Before the start of each experimental period, a standardized evening meal was provided. Subject stayed in a respiration chamber during the entire $60 \mathrm{~h}$ periods to ensure compliance to the strict dietary protocols and to allow for the measurement of $24 \mathrm{~h}$ substrate oxidation and energy expenditure (11). In the respiration chamber subjects followed an activity protocol as previously described (12). During each 60h period, blood samples were taken after 12, 36 and 60 hours - after an overnight fast in case of the fed condition.

\section{Hyperinsulinemic-euglycemic clamp}

After leaving the respiration chamber on the morning of the third day, a hyperinsulinemic-euglycemic clamp procedure was performed, as described previously (10).

\section{Blood analyses}

Blood was collected in EDTA containing tubes and immediately centrifuged at high speed. Plasma was transferred to Eppendorf tubes, snap frozen in liquid nitrogen, and stored at -80 ㅇ C until further analysis. Plasma FFA (Wako Nefa $\mathrm{C}$ test kit; Wako Chemicals, Neuss, Germany) and glucose (hexokinase method; LaRoche, Basel, Switzerland) were measured with enzymatic assays. Insulin concentration was determined using a radioimmunoassay (Linco Reseach, St. Charles, MO).

Plasma markers of inflammation (TNF- $\alpha$, IL-1b, IL-6, IL-8 and hs-CrP) were measured with a commercially available Multi Spot ELISA kit (Meso Scale Discovery, Gaithersburg, MD, USA). Leptin and adiponectin were determined using a radioimmunoassay (Biovender, Heidelberg, Germany). ELISA kits for chemerin analysis were purchased from Biovendor (Heidelberg, Germany) and those for VEGF from Millipore (Schwalbach, Germany).

\section{Statistics}

Data are reported as means \pm SEM. Statistical analyses were performed using SPSS 16.0 for Mac OS X. Statistical comparisons between the two conditions (fed vs. fast) 
were performed using the paired Student's t test. Plasma parameters over time were compared by two-way repeated measures ANOVA for investigation of treatment and time (treatment*time) interactions. When the interaction reached statistical significance, we performed post-hoc testing to determine the exact location of the difference. Differences were considered statistically significant when $p<0.05$.

\section{Results}

Results of one subject were removed from the statistical analysis, because of a hsCRP concentration at the start of the fed period $>50 \mathrm{mg} / \mathrm{L}$, as opposed to a value of $<1 \mathrm{mg} / \mathrm{L}$ at the start of the fasted period. Characteristics of the remaining $10 \mathrm{sub}$ jects are presented in table 1 . Results on insulin sensitivity have been described into detail previously (10). In summary, the glucose infusion rate for all subjects was decreased after the 60 hours fasted period as compared with the fed period, also the insulin sensitivity index $\left(S_{1}\right)$ was reduced by $\sim 45 \%(p<0.001)$. The reduction in whole body insulin sensitivity was mainly accounted for by a reduction in insulinstimulated glucose disposal. Insulin-induced suppression of endogenous glucose production was only marginally affected by fasting and was almost complete in both conditions.

Table 1. Subject characteristics

\begin{tabular}{ll}
\hline Parameter & Mean \pm SEM \\
\hline Age $(\mathrm{y})$ & $23.3 \pm 0.8$ \\
Body weight $(\mathrm{kg})$ & $79.6 \pm 2.5$ \\
Fat free mass $(\mathrm{kg})$ & $66.6 \pm 2.0$ \\
Height $(\mathrm{m})$ & $1.87 \pm 0.03$ \\
Body mass index $\left(\mathrm{kg} / \mathrm{m}^{2}\right)$ & $22.8 \pm 0.5$ \\
Maximal aerobic capacity $\left(\mathrm{ml} \mathrm{O} / \mathrm{kg}_{\mathrm{FFM}} / \mathrm{min}\right)$ & $57.8 \pm 1.6$ \\
\hline
\end{tabular}

Values refer to 10 male subjects. Values are Mean \pm SEM.

\section{Blood parameters}

Concentrations of all parameters were not significantly different at the start of the fed and fasted periods. A significant treatment $x$ time interaction $(p<0.001)$ was observed for plasma FFA, glucose and insulin concentrations (10). Plasma FFA increased steadily, up to $2016 \pm 118 \mu \mathrm{M}$ in de fasted condition vs. $421 \pm 39 \mu \mathrm{M}$ in the fed condition ( $p<0.001$ for the difference in changes). Plasma glucose values remained unchanged throughout the fed condition, but gradually decreased to $3.73 \pm$ $0.15 \mathrm{mM}$ after 60 hours of fasting $(p<0.001)$. Baseline plasma insulin levels did not change in the fed condition, but were markedly reduced in the fast condition to 7.3 
$\pm 0.7 \mu \mathrm{U} / \mathrm{ml}$ at $\mathrm{t}=36(\mathrm{p}<0.001)$ and were maintained at this lower level $(7.0 \pm 0.89$ $\mu \mathrm{U} / \mathrm{ml})$ at $\mathrm{t}=60(\mathrm{p}<0.001)$.

Plasma TNF- $\alpha$ concentrations did not significantly change during the fasted or fed condition. Similar conclusions could be drawn for IL-1b, IL-8, adiponectin and hsCRP. For IL-6, however, a statistically significant treatment $x$ time effect was found $(P=0.038)$, but pair wise comparisons did not reveal any statistical differences between the various time points.

A statistically significant treatment $x$ time effect was found for VEGF concentrations $(P=0.042)$. No differences were seen after 36 hours. After 60 hours, however, concentrations were increased with $63.2 \pm 10.1 \mathrm{pg} / \mathrm{ml}$ during the fed period, which was significantly less than the increase of $108.8 \pm 14.5 \mathrm{pg} / \mathrm{ml}$ during the fasted period $(P=0.02)$. The treatment $x$ time effect also reached statistical significance for changes in chemerin concentrations $(P<0.005)$. In the fed condition, concentrations remained virtually unaffected, but were significantly decreased after 60 hours of fasting $(P<0.001)$. Leptin concentrations were also affected and were significantly decreased after 36 and 60 hours of fasting $(P=0.04$ and $P<0.01$, respectively).

\section{Discussion}

In the present study we have found that fasting-induced increases in FFA concentrations did not relate to changes in the concentrations of the inflammatory cytokines TNF- $\alpha$, IL-1b, IL- 6 and IL- 8 , or of hs-CRP. This extends the findings of a smaller study with six healthy lean men, that also found no pro-inflammatory effects of 60 hours of fasting, as indicated by unchanged concentrations of IL-6, soluble TNF receptors I and II, and hs-CRP (13).

In our study, FFA concentrations were physiologically increased by fasting, which was accompanied by insulin resistance at reduced glucose and insulin concentrations (10). In contrast, insulin resistance induced by longer-term lipid infusion does lead to hyperglycemia and hyperinsulinemia, and to increased concentrations of FFA and pro-inflammatory cytokines. This suggests that in normal weight subjects, insulin-resistance or increased FFA concentrations per se are not a prerequisite to induce a pro-inflammatory cytokine profile, but hyperglycemia or hyperinsulinemia - possibly in combination with high FFA levels - are. As pre-diabetic subjects, who are characterized by normal glucose concentrations and slightly elevated insulin concentrations, also have increased concentrations of markers and mediators of inflammation (14), it can be speculated that insulin may be more important in this respect. This is further supported by the findings of Stegenga et al. (15), who found that a short-term (6 hr) lower-insulinemic hyperglycemic clamp decreased the expression of several pro-inflammatory cytokine in LPS-stimulated leucocytes. In con- 
trast, after a hyperinsulinemic euglycemic clamp, expressions of most of the inflammatory cytokines were increased.

VEGF concentrations increased significantly during both conditions at $t=60$ hours for which we do not have an obvious explanation. Concentrations, however, were significantly more increased in the fasted situation. The association between insulin and glucose concentrations on VEGF is not clear. Loebig et al. (16) could not demonstrate a relationship between VEGF concentrations and the insulin sensitivity index, as measured under euglycemic clamp conditions in lean, overweight or obese male subjects. In contrast, Dandona et al. (17) found suppressed VEGF concentrations during insulin infusion and steady glucose concentrations. Hypoglycemia, however, may also increase plasma VEGF concentrations, as suggested by in vitro and in vivo studies (18-20). In addition, a positive correlation between concentrations of circulating VEGF levels and BMI has been reported in healthy male subjects (16). As BMI is also positively related to FFA concentration (21), it can be speculated that fasting also increases plasma VEGF. In vitro, free fatty acids induce a significant release of VEGF from vascular smooth muscle cells that might contribute to increased circulating levels of this factor (22). Thus, although insulin sensitivity per se does not relate to VEGF, further studies are needed on the exact determinants of plasma VEGF levels.

Chemerin, an adipokine related to obesity and obesity related pathologies (23), decreased after fasting. In vitro, chemerin synthesis and secretion by 3T3-L1 adipocytes is upregulated by TNF- $\alpha$ (24) and furthermore we previously showed a regulation by TNF- $\alpha$ in human adipocytes (25). Similar results have been found for IL-1b (26). However, these two cytokines were in our study not affected by fasting and can therefore not have played a role in the decrease of plasma chemerin concentrations. Also, in vitro studies and studies in tissue explants have shown that insulin increases dose and time dependently chemerin secretion by adipocytes (27). Further, a study in subjects with normal glucose tolerance has found positive relationships between plasma chemerin concentrations and various measures of the metabolic syndrome, although chemerin was not different between subjects with type 2 diabetes mellitus and controls (23). At least for healthy subjects, this may suggest that insulin concentrations are an important determinant of plasma chemerin. To what extent plasma FFA concentrations play a role, is not known. It should be noted that chemerin secretion also occurs from liver (28). However, nothing is known about a possible regulation of hepatic chemerin release.

During fasting, plasma leptin levels decreased as expected (29), which was already evident after $24 \mathrm{hrs}$. Adiponectin concentrations were not affected by fasting, which agrees with other study in which subjects fasted for 48 or 72 hours $(29,30)$. These findings support the notion that circulating adiponectin concentrations observed after weight reduction do not result from a negative energy balance, but rather from a decreased body fat content (30). 
In conclusion, our study with healthy male subjects indicates that fastinginduced increases in FFA and insulin resistance do not lead to changes in the concentrations of the inflammatory cytokines. VEGF concentrations increased and those of chemerin decreased. These results suggest that hyperglycemia and/or hyperinsulinemia may be more important than elevated FFA levels or insulin sensitivity per se in obesity-associated chronic inflammation. The precise role of FFA and insulin concentrations within these parameters requires further study. 


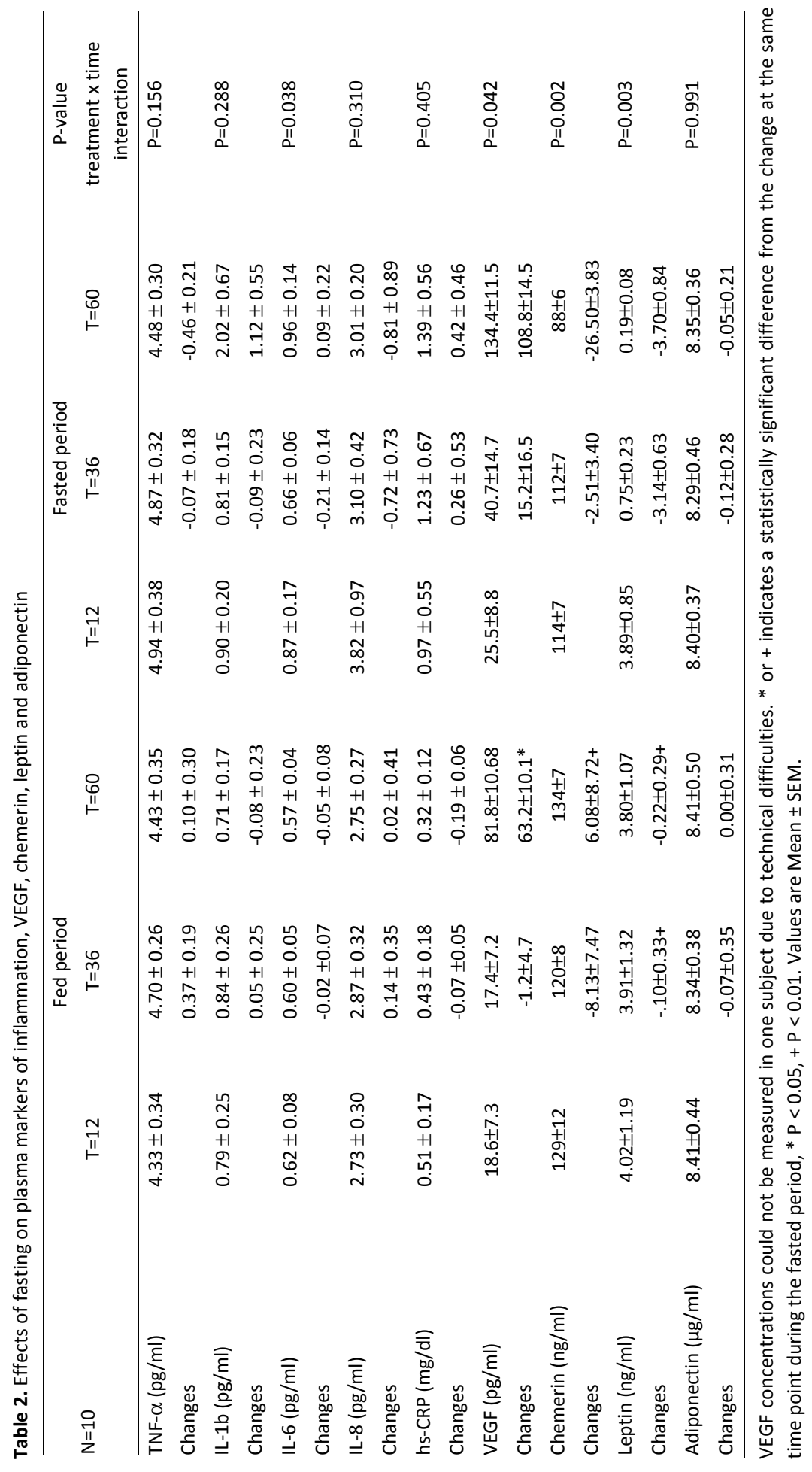




\section{References}

1. Tripathy D, Mohanty P, Dhindsa S, Syed T, Ghanim H, Aljada A, et al. Elevation of free fatty acids induces inflammation and impairs vascular reactivity in healthy subjects. Diabetes 2003; 52: 28822887.

2. Ford ES, Ajani UA, Mokdad AH. The metabolic syndrome and concentrations of C-reactive protein among U.S. youth. Diabetes Care 2005; 28: 878-881.

3. Ridker PM, Stampfer MJ, Rifai N. Novel risk factors for systemic atherosclerosis: a comparison of Creactive protein, fibrinogen, homocysteine, lipoprotein(a), and standard cholesterol screening as predictors of peripheral arterial disease. JAMA 2001; 285: 2481-2485.

4. Frohlich M, Imhof A, Berg G, Hutchinson WL, Pepys MB, Boeing $H$, et al. Association between Creactive protein and features of the metabolic syndrome: a population-based study. Diabetes Care 2000; 23: 1835-1839.

5. Abbasi F, Chu JW, Lamendola C, McLaughlin T, Hayden J, Reaven GM, et al. Discrimination between obesity and insulin resistance in the relationship with adiponectin. Diabetes 2004; 53: 585-590.

6. McLaughlin T, Abbasi F, Lamendola C, Liang L, Reaven G, Schaaf $P$, et al. Differentiation between obesity and insulin resistance in the association with C-reactive protein. Circulation 2002; 106: 2908-2912.

7. Saad MF, Khan A, Sharma A, Michael R, Riad-Gabriel MG, Boyadjian R, et al. Physiological insulinemia acutely modulates plasma leptin. Diabetes 1998; 47: 544-549.

8. Yu JG, Javorschi S, Hevener AL, Kruszynska YT, Norman RA, Sinha M, et al. The effect of thiazolidinediones on plasma adiponectin levels in normal, obese, and type 2 diabetic subjects. Diabetes 2002; 51: 2968-2974.

9. Schwartz EA, Reaven PD. Molecular and signaling mechanisms of atherosclerosis in insulin resistance. Endocrinol Metab Clin North Am 2006; 35: 525-549, viii.

10. Hoeks J, van Herpen NA, Mensink M, Moonen-Kornips E, van Beurden D, Hesselink MK, et al. Prolonged fasting identifies skeletal muscle mitochondrial dysfunction as consequence rather than cause of human insulin resistance. Diabetes 2010; 59: 2117-2125.

11. Schoffelen PF, Westerterp KR, Saris WH, Ten Hoor F. A dual-respiration chamber system with automated calibration. J Appl Physiol 1997; 83: 2064-2072.

12. Schrauwen $P$, van Marken Lichtenbelt WD, Saris WH, Westerterp KR. Changes in fat oxidation in response to a high-fat diet. Am J Clin Nutr 1997; 66: 276-282.

13. van der Crabben SN, Allick G, Ackermans MT, Endert E, Romijn JA, Sauerwein HP. Prolonged fasting induces peripheral insulin resistance, which is not ameliorated by high-dose salicylate. $J$ Clin Endocrinol Metab 2008; 93: 638-641.

14. Pickup JC, Crook MA. Is Type II diabetes mellitus a disease of the innate immune system? Diabetologia 1998; 41: 1241-1248.

15. Stegenga ME, Crabben SNvd, Dessing MC, Pater JM, Van Den Pangaart PS, De Vos AF, et al. Effect of acute hyperglycaemia and/or hyperinsulinaemia on proinflammatory gene expression, cytokine production and neutrophil function in humans. Diabetic Medicine 2008; 25: 157-164.

16. Loebig M, Klement J, Schmoller A, Betz S, Heuck N, Schweiger U, et al. Evidence for a relationship between VEGF and BMI independent of insulin sensitivity by glucose clamp procedure in a homogenous group healthy young men. PLoS One 2010; 5: e12610.

17. Dandona P, Aljada A, Mohanty P, Ghanim H, Bandyopadhyay A, Chaudhuri A. Insulin suppresses plasma concentration of vascular endothelial growth factor and matrix metalloproteinase-9. Diabetes Care 2003; 26: 3310-3314. 
18. Sone H, Kawakami $\mathrm{Y}$, Okuda $\mathrm{Y}$, Kondo S, Hanatani M, Suzuki H, et al. Vascular endothelial growth factor is induced by long-term high glucose concentration and up-regulated by acute glucose deprivation in cultured bovine retinal pigmented epithelial cells. Biochem Biophys Res Commun 1996; 221: 193-198.

19. Merl V, Peters A, Oltmanns KM, Kern W, Hubold C, Fehm HL, et al. Antecedent hypoglycaemia attenuates vascular endothelial growth factor response to subsequent hypoglycaemia in healthy men. Diabet Med 2005; 22: 1278-1281.

20. Dantz D, Bewersdorf J, Fruehwald-Schultes B, Kern W, Jelkmann W, Born J, et al. Vascular endothelial growth factor: a novel endocrine defensive response to hypoglycemia. J Clin Endocrinol Metab 2002; 87: 835-840.

21. Boden G. Pathogenesis of type 2 diabetes. Insulin resistance. Endocrinol Metab Clin North Am 2001; 30: 801-815, v.

22. Lamers D, Schlich R, Greulich S, Sasson S, Sell H, Eckel J. Oleic acid and adipokines synergize in inducing proliferation and inflammatory signalling in human vascular smooth muscle cells. J Cell Mol Med 2011; 15: 1177-1188.

23. Bozaoglu K, Bolton K, McMillan J, Zimmet P, Jowett J, Collier G, et al. Chemerin is a novel adipokine associated with obesity and metabolic syndrome. Endocrinology 2007; 148: 4687-4694.

24. Parlee SD, Ernst MC, Muruganandan S, Sinal CJ, Goralski KB. Serum chemerin levels vary with time of day and are modified by obesity and tumor necrosis factor-\{alpha\}. Endocrinology 2010; 151: 2590-2602.

25. Sell H, Laurencikiene J, Taube A, Eckardt K, Cramer A, Horrighs A, et al. Chemerin is a novel adipocyte-derived factor inducing insulin resistance in primary human skeletal muscle cells. Diabetes 2009; 58: 2731-2740.

26. Kralisch S, Weise S, Sommer G, Lipfert J, Lossner U, Bluher M, et al. Interleukin-1beta induces the novel adipokine chemerin in adipocytes in vitro. Regul Pept 2009; 154: 102-106.

27. Tan BK, Chen J, Farhatullah S, Adya R, Kaur J, Heutling D, et al. Insulin and metformin regulate circulating and adipose tissue chemerin. Diabetes 2009; 58: 1971-1977.

28. Weigert J, Neumeier M, Wanninger J, Bauer S, Farkas S, Scherer MN, et al. Serum galectin-3 is elevated in obesity and negatively correlates with glycosylated hemoglobin in type 2 diabetes. $J$ Clin Endocrinol Metab 2010; 95: 1404-1411.

29. Merl V, Peters A, Oltmanns KM, Kern W, Born J, Fehm HL, et al. Serum adiponectin concentrations during a 72-hour fast in over- and normal-weight humans. Int J Obes (Lond) 2005; 29: 998-1001.

30. Gavrila A, Chan JL, Yiannakouris N, Kontogianni M, Miller LC, Orlova C, et al. Serum adiponectin levels are inversely associated with overall and central fat distribution but are not directly regulated by acute fasting or leptin administration in humans: cross-sectional and interventional studies. J Clin Endocrinol Metab 2003; 88: 4823-4831. 


\section{Part 3. - A high-fat diet}

\section{Chapter 5.}

A high-fat diet increases intrahepatic lipid accumulation in healthy overweight men without affecting tissue specific or whole-body insulin sensitivity

\section{Chapter 6.}

A high-fat diet impairs metabolic flexibility and reduces genes involved in fatty acid oxidation without affecting insulin sensitivity and mitochondrial content in healthy overweight men 


\title{
Chapter 5.
}

\section{A high-fat diet increases intrahepatic lipid accumulation in healthy overweight men without affecting tissue specific or whole-body insulin sensitivity}

\author{
N.A. van Herpen \\ V.B. Schrauwen-Hinderling \\ G. Schaart, R.P. Mensink \\ and P. Schrauwen
}

The Journal of Clinical Endocrinology \& Metabolism. 2011; 96: E691-695. 


\section{Abstract}

\section{Context}

In rodents, high-fat diets increase intrahepatic lipid (IHL), but human studies are scarce.

\section{Objective}

To see whether the composition of a diet influences IHL and intramyocellular lipid (IMCL) accumulation and insulin resistance.

\section{Design}

Twenty overweight men were randomly allocated to the low- or high-fat group. Both groups started with a three-week low-fat diet (15 En\% protein, 65 En\% carbohydrates, $20 \mathrm{En} \%$ fat), after which half of the subjects switched to a three-week isocaloric high-fat diet (15 En\% protein, $30 \mathrm{En} \%$ carbohydrates, $55 \mathrm{En} \%$ fat). After 3 and 6 weeks, IHL and IMCL content were assessed by $1 \mathrm{H}-\mathrm{MRS}$ and a muscle biopsy. Insulin-sensitivity was studied using a hyperinsulinemic-euglycemic clamp. Blood samples were taken and substrate oxidation was measured. An additional liver scan was performed after 1 week in the high-fat group.

\section{Results}

In the low-fat group, IHL decreased with $13 \%$ and increased with $17 \%$ in the high-fat group ( $p=0.047)$. IMCL content was unaffected $(p=0.304)$. Insulin sensitivity of both liver and muscle was unaffected. At week 3 , IHL correlated negatively with insulin sensitivity ( $r$ : $-0.584, p=0.009$, all subjects combined). Metabolic flexibility was decreased after 3 weeks of high-fat diet $(\Delta R Q:+0.02 \pm 0.02$ vs. $-0.05 \pm 0.1$ in low-fat versus high-fat group, $p=0.009)$. Basal plasma glucose increased $(p=0.038)$ and HOMA-ir tended to increase after the high-fat diet $(p=0.075)$. Plasma parameters: insulin, FFA, hs-CRP and liver enzymes were unaffected. Also bodyweight was unaffected by the diet intervention.

\section{Conclusion}

A three-week high-fat diet leads to IHL accumulation and a decreased metabolic flexibility, but insulin sensitivity is unaffected. 


\section{Introduction}

High-fat diets have been suggested to lead to insulin resistance, although the evidence in humans is rather limited (1). A suggested link between high-fat diets and insulin resistance is the accumulation of fat in non-adipose tissues such as skeletal muscle and liver (2). With proton magnetic resonance spectroscopy (1H-MRS), it is now possible to measure IHL non-invasively in humans very accurately $(3,4)$.

IHL accumulation correlates with a reduced suppressive effect of insulin, not only leading to hyperglycaemia, but also to hypertriglyceridaemia (5). IHL accumulation or non-alcoholic hepatic steatosis is therefore considered to be an important feature of the metabolic syndrome (6). It's prevalence is high and was $34 \%$ in Dallas County (4). Obtaining more insight into the dynamics and functional consequences of IHL accumulation, especially in relation to dietary intake, is therefore important. In that respect, rodent data have clearly indicated that dietary manipulation mainly increasing total dietary fat content - can rapidly change lipid storage in liver. In humans, however, dietary interventions are scarce. It has been shown that a single high-fat meal did not increase IHL accumulation (4). In contrast, on the longer term, dietary fat intake affected IHL and was accompanied by effects on markers of insulin resistance (7). However, in this study only a surrogate marker of insulin resistance was used, i.e. fasting insulin levels. Furthermore, this study investigated the effect of a high-fat diet specifically in obese women who had liver steatosis prior to the start of the intervention. Although these data provide support for the suggestion that in humans diet can affect IHL and insulin sensitivity, evidence is still rather limited.

With regard to skeletal muscle, more information is available as muscle fat content can be measured in skeletal muscle biopsies. For example, using biochemical methods it was shown that intramyocellular lipid (IMCL) increases by $36 \%$ to $90 \%$ after high fat feeding periods ranging from 24 hours to 7 weeks (8-13). Using $1 \mathrm{H}$ MRS, the effect of high-fat diets (55- 60\% of energy as fat) has been investigated after two to three days $(14,15)$ and after one week $(16)$. In all three studies, an increase (between $48 \%$ and $56 \%$ ) in IMCL content was reported. However, these studies investigated young lean subjects, while this is not the population at risk for the developing the metabolic syndrome. Furthermore, high-fat diets were not given in energy balance in all cases. The aim of the present study was to perform a wellcontrolled isocaloric dietary intervention study in healthy overweight men to examine the effects of high- versus low-fat diet on hepatic and muscle lipid accumulation and tissue-specific, liver and muscle, insulin sensitivity. We hypothesized that consumption of a high-fat diet would increase IHL and IMCL content, thereby contributing to the development of insulin resistance. 


\section{Methods}

\section{Subjects}

Twenty sedentary, healthy overweight men participated (table1). . All subjects had no family history of diabetes mellitus, liver disease or any other endocrine disorders. Before the start of the study, a medical examination was performed and a fasting blood sample was taken to determine fasting blood glucose $(<6.1 \mathrm{mmol} / \mathrm{L})$, plasma triacylglycerol ( $<4.5 \mathrm{mmol} / \mathrm{L}$ ) and liver enzymes ( $\gamma$-GT, ALAT, $<70 \mathrm{IU} / \mathrm{L}$ ) to assess eligibility. Body composition (17) and maximal aerobic capacity (18) was measured as described previously. Subjects with an unstable body weight (weight gain or loss $>3 \mathrm{~kg}$ in the past three months) or $>20$ gram alcohol intake/day were excluded from participation. The study protocol was reviewed and approved by the Medical Ethical Committee of Maastricht University Medical Center+ and all subjects gave their written informed consent before participating in the study.

Table 1. Baseline characteristics of the subjects.Experimental design

\begin{tabular}{|c|c|c|c|}
\hline \multicolumn{2}{|l|}{ Parameter } & $\begin{array}{l}\text { Low-fat group } \\
\mathrm{N}=10\end{array}$ & $\begin{array}{l}\text { High-fat group } \\
\mathrm{N}=10\end{array}$ \\
\hline \multicolumn{2}{|l|}{ Age (y) } & $54.0 \pm 2.3$ & $56.4 \pm 2.5$ \\
\hline \multicolumn{2}{|c|}{ Body weight (kg) } & $92.0 \pm 2.9$ & $91.3 \pm 1.8$ \\
\hline \multicolumn{2}{|c|}{ Fat free mass $(\mathrm{kg})$} & $64.0 \pm 1.7$ & $65.9 \pm 1.9$ \\
\hline \multicolumn{2}{|l|}{ Body fat (\%) } & $30.1 \pm 1.3$ & $27.5 \pm 1.7$ \\
\hline \multicolumn{2}{|l|}{ Height (m) } & $1.77 \pm 0.02$ & $1.80 \pm 0.02$ \\
\hline \multicolumn{2}{|c|}{ Body mass index $\left(\mathrm{kg} / \mathrm{m}^{2}\right)$} & $29.3 \pm 0.6$ & $28.3 \pm 0.5$ \\
\hline \multicolumn{2}{|c|}{$\begin{array}{l}\text { Maximal aerobic capacity } \\
(\mathrm{mL} \mathrm{O} /(\mathrm{kg} \text { body weight*min }))\end{array}$} & $33.6 \pm 1.9$ & $33.5 \pm 1.7$ \\
\hline \multicolumn{2}{|c|}{ Plasma glucose (mmol/L) } & $5.7 \pm 0.1$ & $5.7 \pm 0.1$ \\
\hline \multicolumn{2}{|c|}{ Plasma insulin (mU/L) } & $15.7 \pm 2.2$ & $16.7 \pm 2.8$ \\
\hline \multicolumn{2}{|c|}{ Plasma FFA ( $\mu \mathrm{mol} / \mathrm{L})$} & $301 \pm 30$ & $416 \pm 59$ \\
\hline \multicolumn{2}{|c|}{ Plasma hs-CRP (mg/L) } & $2.64 \pm 0.71$ & $1.19 \pm 0.28$ \\
\hline \multirow{2}{*}{ Liver enzymes } & ALAT (iU/L) & $27.9 \pm 2.6$ & $23.1 \pm 1.9$ \\
\hline & $\gamma$-GT (iU/L) & $30.8 \pm 3.8$ & $27.1 \pm 3.2$ \\
\hline \multirow{4}{*}{ Lipid profile } & TG (mmol/L) & $1.72 \pm 0.43$ & $1.48 \pm 0.16$ \\
\hline & Cholesterol (mmol/L) & $5.73 \pm 0.38$ & $5.51 \pm 0.39$ \\
\hline & LDL-Cholesterol (mmol/L) & $4.01 \pm 0.35$ & $3.96 \pm 0.35$ \\
\hline & HDL-Cholesterol (mmol/L) & $1.23 \pm 0.08$ & $1.25 \pm 0.06$ \\
\hline
\end{tabular}

Values refer to 10 subjects in the low-fat group and 10 subjects in the high-fat group. Values are mean \pm SEM and there were no statistical differences between the groups. FFA = Free Fatty Acids, hs-Crp $=$ high sensitive C-reactive proetein, ALAT = alanine aminotransferase, $\gamma$-GT = gamma - glutamine tranferase, TG = Triglyceride, $\mathrm{LDL}=$ Low-Density Lipoprotein and $\mathrm{HDL}=$ High-Density Lipoprotein. 
All subjects consumed a low-fat run-in diet for 3-weeks, after which baseline measurements were made (Day 21). Subsequently, subjects were randomly assigned to a high-fat diet or low-fat diet for 3 weeks after which measurements were repeated (Day 42). Measurements included the determination of liver and muscle fat content, insulin sensitivity substrate oxidation and blood sampling. As we anticipated an increase in IHL content upon a high-fat diet, we included an additional liver measurement at day 28. Subjects were asked not to alter physical activity pattern over the entire course of the study.

\section{Diet intervention}

Before the study started, subjects recorded their habitual food intake for two working days and one weekend day. From these food records, each subjects' actual energy intake was estimated by using the Dutch food-composition table (19). In addition, energy intake was estimated using the formula of Harris and Benedict (20). Based on these two estimates of energy intake, an example of a daily diet was created by a dietician for each individual. The targeted intake of protein for the low-fat diet was 15\% of energy (En\%), fat $20 \mathrm{En \%}$, and carbohydrates $65 \mathrm{En \%}$, and $15 \mathrm{En \%}$, $55 \mathrm{En} \%$, and $30 \mathrm{En} \%$ for HF. In addition, subjects were provided with a list of products, which could be exchanged for those of the sample menu. Food products were given points according to their fat and energy contents. Each subject was required to eat a certain number of points daily, corresponding with his energy and fat intake, and to record all consumed products. The dietary records were checked and the subject was weighed at each visit to check energy balance. At least once every week subjects had contact with the dietician to discuss any questions and the progress of the study. At the end of the experimental period energy and nutrient intakes was estimated based on the daily reported intake using the Dutch foodcomposition table (19).

\section{Lipid accumulation in liver}

1H-MRS was used to quantify the lipid content in liver according to Szczepaniak et al (4), on a 1.5 T whole body scanner (Intera, Philips Healthcare, Best, The Netherlands). Respiratory-triggered magnetic resonance imaging was used to guide the spectroscopic measurements and fine tuned shimming was performed to optimize the magnetic field homogeneity within the region of interest. A dedicated flexible multi-element surface coil was used for signal acquisition. For spectroscopy, the element of the coil closest to the area of interest was selected. A voxel of $3 \times 3 \times 2 \mathrm{~cm}$ was selected and $1 \mathrm{H}-\mathrm{MRS}$ spectra were acquired from this region of interest (TR= $4000 \mathrm{~ms}, \mathrm{TE}=23 \mathrm{~ms}, \mathrm{~N}=64,1024$ points, spectral bandwidth $=1000 \mathrm{~Hz}$ ). Care was taken to avoid vascular structures and the proximity of subcutaneous fat. 
Figure 1. Representative spectrum, with the three peaks clearly visible

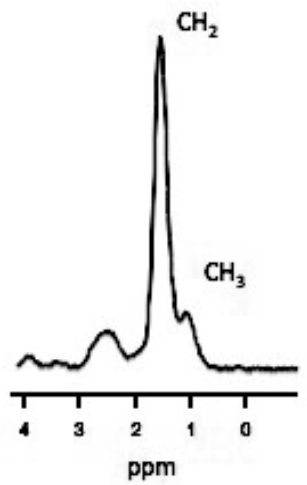

Subjects were asked to breath in the rhythm of the measurement and ensure to be at end-expiration when they hear the sound of gradient switching. Water signal was suppressed using frequency-selective pre-pulses and the spectra were fitted with AMARES (21) in the jMRUI software (22) to quantify the lipid peak. Three peaks were fitted (see figure 1) with Gaussian line form, prior knowledge was used to constrain the frequency shift and the area ratios of the three peaks (23). A reference spectrum without water suppression was acquired to determine water signal intensity $(\mathrm{N}=16)$. The long repetition time minimized $\mathrm{T} 1$ relaxation effects. $\mathrm{CH} 2$ and water intensities were corrected for $\mathrm{T} 2$ relaxation (according to (4)) and the ratio of $\mathrm{CH} 2$ to water signal intensity is given as percentage. Values were converted to weight/weight ratios by assuming a proton density of $\mathrm{CH} 2$ protons within triglycerides of $60.2 \mathrm{~mol} / \mathrm{mg}$ (converted to $\mathrm{mol} / \mathrm{mol}$ assuming an average molecular weight of TG of $860 \mathrm{~g} / \mathrm{mol}$ and a density of 0.9 (3)) and a water content of liver tissue of $71 \%(4)$.

When the measurement was repeated on day 28 , after one week on the highfat diet or on day 42, after the end of the experimental period, the voxel was placed on the same position as during the earlier measurement(s), This was possible because we used a image-guided technique.

\section{Hyperinsulinemic-euglycemic clamp}

A 6-hour hyperinsulinemic-euglycemic clamp $(40 \mathrm{mU} /(\mathrm{m} 2 * \mathrm{~min}))$, with glucose tracer ([6,6-2H2]-glucose was performed as described previously (24). At $\mathrm{t}=180$, a primed constant infusion of insulin started and glucose infusion rates were adjusted to maintain euglycemia. Plasma glucose levels were clamped at $5.0 \mathrm{mM}$ by variable coinfusion of $20 \%$ glucose. In the final 30 minutes of the non-insulin stimulated period 
( $t=150-180)$ and under steady clamp conditions $(t=330-360)$, blood was sampled and indirect calorimetry (ventilated hood) was performed.

\section{Tracer calculations}

Isotopic enrichment of plasma glucose was determined by electron ionization gas chromatography-mass spectrometry. Steele's single-pool non-steady-state equations (25) were used to calculate glucose Ra and Rd. Volume of distribution was assumed to be $0.160 \mathrm{~L} / \mathrm{kg}$ for glucose. Insulin stimulated glucose disposal was computed as the difference between Rd under insulin stimulated conditions and Rd under basal non-insulin-stimulated conditions (delta Rd). Endogenous glucose production (EGP) was calculated as Ra minus exogenous glucose infusion rate. Nonoxidative glucose disposal (NOGD) was calculated as Rd minus carbohydrate oxidation. Insulin sensitivity was also calculated using a homeostasis model assessment for insulin resistance (HOMA-ir) (26). Fat and carbohydrate oxidation were calculated using stoichiometric equations according to Frayn (27).

\section{Muscle biopsy}

A muscle biopsy was taken from the vastus lateralis muscle (28), directly frozen in melting isopentane and stored at $-80^{\circ} \mathrm{C}$ until assayed. Muscle biopsies were available in 8 subjects in the low-fat diet group and 9 subjects in the high-fat group.

Fresh cryosections $(5 \mu \mathrm{m})$ were stained for $\mathrm{IMCL}$ by Oil Red $\mathrm{O}$ staining to allow quantification of IMCL, as described previously (29).

\section{Blood analyses}

In EDTA plasma samples NEFA (Wako Nefa C test kit; Wako Chemicals, Neuss, Germany) and glucose (hexokinase method; LaRoche, Basel, Switzerland) were measured with enzymatic assays automated on a Cobas Fara/Mira. Insulin levels were determined using a radioimmunoassay (Linco Reseach, St. Charles, MO).

Levels of total cholesterol (CHOD-PAP method; Roche, Basel, Switzerland), HDLcholesterol (precipitation method; Roche, Basel, Switzerland), and triglyceride (TG) with correction for free glycerol (GPO Trinder; Sigma Diagnostics, St. Louis, USA) were determined. LDL-cholesterol was calculated using the Friedewald equation (30). Hs-CRP was measured in serum with a commercially available kit (Kamiya Biomedical, Company, Seattle, USA).

\section{Statistics}

Data are reported as means \pm SEM. Statistical analyses were performed using the statistical computer program SPSS 16.0 for Mac OS X (SPSS, Chicago, USA). Statisti- 
cal comparisons between the two conditions were performed using a Student unpaired t-test comparing the changes of each group between the end of the run-in period and the end of the experimental period. Differences were considered statistically significant when $\mathrm{p}<0.05$.

\section{Results}

\section{Dietary intake and compliance}

During the run-in period, the intakes of energy, macronutrients and cholesterol did not differ between the low-fat and high-fat groups (table 2). Intakes of protein, carbohydrates, and fat were close to the targeted intakes of respectively 15 En\%, 55 En\% and 20 En\%. During the experimental period, only slight changes in the dietary composition of the low-fat group were evident. For the high-fat group, however, protein intake remained unchanged, while the intake of in particular simple carbohydrates decreased, mainly at the expense of fat intake. The change in self-reported energy intake between low- and high-fat diets was slightly, but significantly higher in the high-fat group. However, body weight was stable over the study (from $93.1 \pm 3.2 \mathrm{~kg}$ to $93.2 \pm 3.1 \mathrm{~kg}$ and $92.8 \pm 1.7 \mathrm{~kg}$ to $92.2 \pm 1.8 \mathrm{~kg}$ for the low-fat and highfat groups). On average, alcohol intake in the low-fat group was similar during the run-in period and during the experimental period, but decreased in the group that switched to a high-fat diet.

\section{Lipid accumulation in liver}

IHL averaged $4.0 \pm 1.4 \%$ of the water peak after the run-in period in the low-fat group and $2.2 \pm 0.5 \%$ of the water peak in the high-fat group (IHL is given as $\mathrm{CH} 2$ signal intensity relative to water signal intensity). This apparent difference in baseline liver fat content - which was not significantly different $(p=0.23)$ - was entirely due to one subject in the low-fat group who had an IHL content of $14.8 \%$. Exclusion of this subject would reduce the average $\mathrm{IHL}$ content in the low-fat group to $2.6 \pm 0.5 \%$. Traditionally, a liver fat content of $50 \mathrm{mg} / \mathrm{g}$ ( $5 \%$ by wet weight) is diagnosed as hepatic steatosis $(31,32)$. To apply this standard to the current data set, the signal intensities were converted to percentages weight/wet weight of liver tissue. Two subjects in the high-fat group would be diagnosed with hepatic steatosis after the high-fat diet (respectively $5.5 \%$ and $5.9 \%$ by wet weight), while one subject in the low-fat group had hepatic steatosis ( $16.7 \%$ by wet weight averaged between two periods).

In the low-fat group, IHL decreased by $13 \%$ (from $4.0 \pm 1.4 \%$ to $3.6 \pm 1.4 \%$ of water peak), whereas it increased by $17 \%$ during the high-fat diet (from $2.4 \pm 0.5 \%$ to 
$2.6 \pm 0.6 \%$ of water peak), the changes being statistically different ( $p=0.047$ for change in liver fat, figure 2). Exclusion of the subject with the high IHL content from the low-fat group did not change the results.

We also examined IHL content after one week on the high-fat diet. Interestingly, the increase in IHL upon the high-fat diet already occurred in the first week (from $2.4 \pm 0.5 \%$ (day 21 ) to $2.7 \pm 0.6 \%$ (day 28 ) with no further increase in the following two weeks (to $2.6 \pm 0.6 \%$ of the water peak (day 42 )).

Figure 2. Lipid accumulation liver

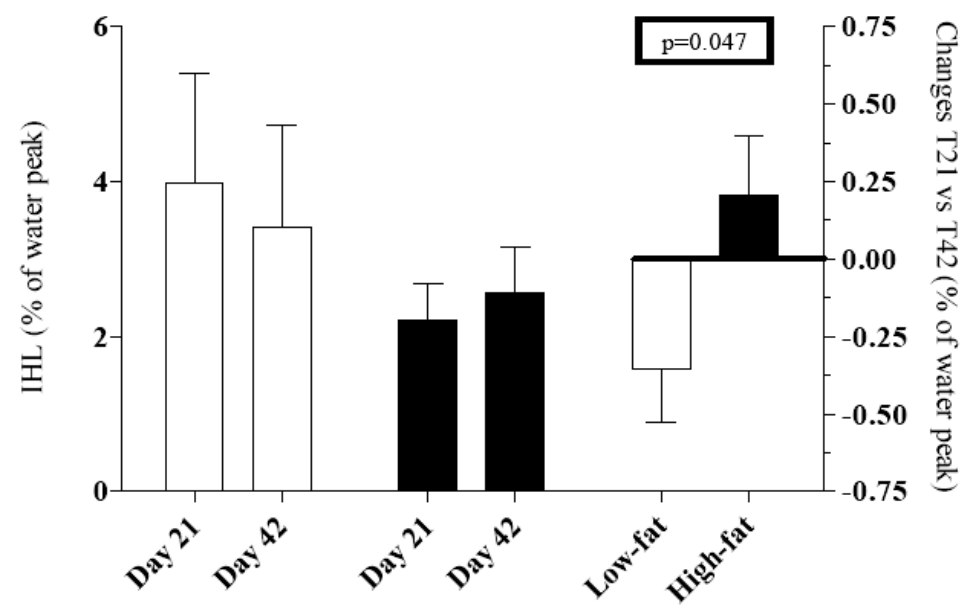

Values refer to 9 subjects in the low-fat group and 9 subjects in the high-fat group. In two subjects we were not able to perform IHL measurements due to technical problems with the scanner.

Values are mean \pm SEM. White bars represent the low-fat group and black bars represent the high-fat group. IHL (\% of water peak) is representing the $\mathrm{CH}_{2}$ signal intensity relative to water resonance. P-value is based on the difference in changes between the low-fat group vs. the high-fat group. IHL = IntraHepatic Lipid

\section{Lipid accumulation in muscle}

IMCL content was not differently affected by the high-fat diet in comparison with the low-fat diet (change of $0.49 \pm 0.45$ vs. $1.38 \pm 0.67 \%$ in low-fat vs. high-fat group, $\mathrm{p}=0.304)$. In the low-fat group the IMCL area fraction after the 3 weeks was $1.42 \pm 0.26 \%$ and this was $1.91 \pm 0.63 \%$ after another 3 weeks on the low-fat diet. In the high diet group the IMCL area fraction after the 3 weeks was $1.96 \pm 0.50 \%$ and this was $3.33 \pm 1.15 \%$ after the high-fat diet. 


\section{Insulin sensitivity}

Baseline insulin sensitivity after the run-in period was similar between groups (delta $\mathrm{Rd}: 18.7 \pm 3.0$ vs. $20.8 \pm 3.1 \mu \mathrm{mol} /\left(\mathrm{kg}^{*} \mathrm{~min}\right)$ in low-fat vs. high-fat group, $\mathrm{p}=0.634$, table $3)$. The dietary intervention did not differentially affect this insulin-stimulated glucose disposal (change of $1.4 \pm 2.6$ vs. $1.1 \pm 2.0 \mu \mathrm{mol} /\left(\mathrm{kg}^{*} \mathrm{~min}\right)$ in low-fat vs. high-fat group, $p=0.927$, table 3 ). Similarly, NOGD was not different between groups after the run-in diet, but insulin-stimulated glucose oxidation was higher in the high-fat group after the run-in period $(6.7 \pm 0.8$ vs. $9.5 \pm 0.9 \mu \mathrm{mol} /(\mathrm{kg} * \mathrm{~min})$ in low-fat vs. highfat group, $p=0.031$, table 3$)$. The intervention did not differentially affect NOGD, but insulin-stimulated glucose oxidation was significantly decreased in the high-fat group (delta CHOox: $+0.9 \pm 0.8$ vs. $-2.9 \pm 1.0 \mu \mathrm{mol} /\left(\mathrm{kg}^{*} \mathrm{~min}\right)$ in low-fat vs. high-fat group respectively, $\mathrm{p}=0.011$, table 3 ).

Basal EGP was higher in high-fat group after the run-in diet $(10.0 \pm 0.2$ vs. $11.1 \pm 0.9 \mu \mathrm{mol} /\left(\mathrm{kg}^{*} \mathrm{~min}\right)$ in low-fat vs. high-fat group, $\mathrm{p}=0.03$, table 3$)$, but was not significantly changed by the dietary intervention (change of $-0.4 \pm 0.3$ vs. $-0.4 \pm 0.7$ $\mu \mathrm{mol} /(\mathrm{kg} * \mathrm{~min})$ in low-fat vs. high-fat group, $\mathrm{p}=0.954$, table 3 ).

Insulin-induced suppression of EGP was complete and not different after run-in diet $(-105.8 \pm 9.1 \%$ vs. $-91.9 \pm 6.7 \%$, in low-fat vs. high-fat group, $p=0.269)$. Insulininduced suppression of EGP was not changed by the dietary intervention (from $105.8 \pm 9.1 \%$ to $-108.9 \pm 11.0 \%$ vs. $-91.9 \pm 6.7 \%$ to $-92.6 \pm 5.6 \%$ in low-fat vs. high-fat group, $\mathrm{p}=0.903$, table 3 ).

Liver fat content correlated negatively with the glucose infusion rate (GIR) after the run-in period $(r:-0.584, p=0.009, N=20)$.

\section{Metabolic flexibility}

Whole-body lipid oxidation was similar after the run-in diet and was not differentially affected by the intervention (table 3 ). Insulin-induced suppression of lipid oxidation was not different between groups after the run-in period. Diet intervention did not significantly affect whole body lipid oxidation, but insulin-induced suppression of lipid oxidation was significantly affected by the diet intervention (changes of $0.06 \pm 0.09$ vs. $-0.31 \pm 0.1 \mu \mathrm{mol} /\left(\mathrm{kg}^{*} \mathrm{~min}\right.$ ) in low-fat vs. high-fat group, respectively, $p=0.007)$. Metabolic flexibility, defined as the change in $R Q$ upon insulin stimulation, was not different between groups after the run-in period. However, diet intervention affected metabolic flexibility differentially in the two groups ( $\triangle \mathrm{RQ}$ $+0.02 \pm 0.02$ vs. $-0.05 \pm 0.01$ in low-fat vs. high-fat group respectively, $p=0.009$, table 3). 


\section{Plasma parameters}

None of the plasma parameters were significantly different between groups after the run-in period (see table 4). Basal plasma glucose levels were increased after high-fat diet $(-0.3 \pm 0.1$ vs. $+0.2 \pm 0.2 \mathrm{mmol} / \mathrm{L}$ in low-fat vs. high-fat group respectively, $p=0.038$ ). Plasma insulin levels were not affected by the diet intervention. As a consequence HOMA-ir tended to be affected by the diet intervention (see table 4 , $\mathrm{p}=0.075)$.

Diet intervention did not affect plasma FFA levels, hs-CRP or liver enzymes, although ALAT tended to increase in the high-fat group $(-5.2 \pm 3.8$ vs. $+2.5 \pm 0.6 \mathrm{iU} / \mathrm{L}$ in low-fat vs. high-fat group respectively, $p=0.06$ ).

Plasma levels of total cholesterol, LDL-cholesterol and TG were not affected by the diet intervention. HDL-cholesterol increased by $0.16 \pm 0.06 \mathrm{mmol} / \mathrm{L}$ in the highfat group and did not change in the low-fat group $(0.00 \pm 0.04 \mathrm{mmol} / \mathrm{L} ; p=0.041$ for the difference in change).

\section{Discussion}

In the present study we evaluated the effect of an isocaloric low-fat versus a highfat diet on lipid accumulation in liver and muscle in relation to insulin sensitivity. We found that three weeks of a high-fat diet increased IHL content compared to three weeks on a low fat diet, but did not affect lipid accumulation in muscle or wholebody insulin sensitivity. However, IHL content was negatively correlated to wholebody insulin sensitivity. Furthermore, we found that three weeks of a high-fat diet reduced metabolic flexibility.

High-fat diets are often associated with the development of diabetes and hepatic steatosis, although this suggestion is mainly derived from animal studies. In fact, the number of human studies investigating the effect of dietary fat intake on liver fat content is rather limited. Thus, using slightly more extreme diets (16 En\% vs. 56 En\% of fat), Westerbacka et al. previously found that liver fat decreased by $20 \%$ during a low-fat diet and increased by $35 \%$ during a high-fat diet in obese women who had liver steatosis prior to the start of the intervention (7). We extended these findings and showed that also in a relatively healthy population a switch from a low- to high-fat diet increased IHL. We included overweight, but nonobese, middle-aged men without liver steatosis. When the relative magnetic resonance intensities were converted to weight/wet weight values, our subjects had on average $3.4 \%$ of fat in the liver (after run-in and all 20 subjects combined), whereas most investigators define hepatic steatosis as triglyceride content exceeding $5 \%$ of the liver weight $(31,32))$ Interestingly, we further found that in the high-fat group, IHL was already increased after one week and did not increase further. This is in line with our previous finding that - when fed in energy balance - subjects are capable 
of increasing fat oxidation to match fat intake after one week of a high-fat diet (33, 34). Thus, prolonged consumption of a high-fat diet may lead to an increase in $24 \mathrm{~h}$ fat oxidation, sufficient to match fat intake, and thereby prevent further accumulation of ectopic fat. In that regard, although we did not observe an increase in resting fat oxidation after the high-fat diet, we did observe that metabolic flexibility was reduced, with a reduced inhibition of lipid oxidation during insulin infusion. Although speculative, the reduced ability to suppress lipid oxidation during insulin infusion may reflect the postprandial situation and could indicate that also postprandial fat oxidation is increased after high-fat diet, reducing the necessity to deposit excess lipids in ectopic fat stores.

Our study shows that changes in fat content of the diet are able to affect hepatic lipid content, even when diets are provided iso-energetically. This finding is consistent with a large body of evidence, showing that in animals high-fat diets lead to hepatic steatosis. In contrast, we could not demonstrate a significant effect of high-fat diet on skeletal muscle lipid content. Although this seems to contrast previous results, it is important to stress that in the present study, diets were given isoenergetically. Furthermore, an overweight study population was investigated here, while earlier studies are limited to younger, lean subjects, which may explain the differential outcomes.

While induction of insulin resistance is well documented in animal studies however, three weeks of a high-fat diet did not result in insulin resistance in humans: GIR, Rd of glucose and insulin-induced suppression of EGP were not affected by diet. In accordance, Riccardi et al., reviewed that when total fat intake is exchanged isoenergetically with carbohydrates and fat intake is between 20 and 40 En\% no major effect is observed on whole body insulin sensitivity (1). In contrast, diets with a very high fat content ( $80 \%$ ) (35) or high-fat diets with excessive energy intake (14) do result in insulin resistance, suggesting that extremes in excessive fat or energy intake are needed to cause insulin resistance in humans.

The finding in our study that a high-fat diet increased IHL without affecting insulin sensitivity, would suggest that the relation between IHL and insulin sensitivity is not affected in a one to one relationship. This is remarkable as a recent study showed that IHL was the best predictor of insulin action in liver, skeletal muscle, and adipose tissue, independent of BMI and body fat\% (36). However, in that study obese subjects with a very broad range of $\mathrm{IHL}$ ( $1 \%-46 \%$ of water peak) were studied. Compared to this large range, the increase in $\mathrm{IHL}$ in the present study was modest, with $0.6 \%$ of water peak after the high-fat diet compared to the low fat diet. Nevertheless, despite a lack of an overall effect of a high-fat diet on insulin sensitivity, we did observe a negative association between IHL and whole body insulin sensitivity, and the dosage of insulin used in our study was not optimal to detect liver specific changes in insulin sensitivity. 
It has been suggested that a reduced metabolic flexibility is an early component of the development of insulin resistance (37) suggesting that ultimately, and with prolonged duration of the high-fat diet, insulin resistance may develop. Alternatively, however, it could also be suggested that the reduction in metabolic flexibility is a physiological adaptation to the high-fat diet. Thus, the reduced insulinstimulation of glucose oxidation after the high-fat diet in our study was compensated by a non-significant increase in NOGD, thereby leaving insulin-stimulated glucose disposal unaffected. It could be suggested that reduced stimulation of glucose oxidation by insulin, and the (non-significant) increase in NOGD served to replenish glycogen stores that may have dropped on the high-fat, low-carbohydrate diet, as it is well know that the carbohydrate content of the diet influences glycogen content (38). Consistently, it was shown that 6 days of an iso-energetic high fat diet (75 en\% fat) did not induce whole-body insulin resistance, but shifted glucose metabolism from oxidation to glycogen storage (39). In accordance, Bisschop et al (35) compared three different diets, which were identical in energy and protein contents but differed in percentages of energy as fat (0 En\%, $44 \mathrm{En \%}$ and $85 \mathrm{En \%}$ ). Insulinstimulated NOGD tended to increase and insulin-stimulated glucose oxidation was significantly lower after the high-fat diet compared to the intermediate- and low-fat diets. Together, these findings indicate that the reduction in metabolic flexibility upon high-fat diet may as well be a physiological adaptation to the diet, and not necessarily be a reflection of altered (muscle) insulin sensitivity.

Although not always statistically significant, possibly because the study was not designed to pick up changes in serum lipids, effects of the diets on the serum lipoprotein profile were as expected, further confirming dietary compliance (40).

In conclusion, we have shown that a high-fat diet increased IHL accumulation, when compared to an isocaloric low-fat diet. This increase was already evident after one week. Fat oxidation was increased in the insulin-stimulated condition indicating a decreased metabolic flexibility, although this can also be interpreted as an adaptation to the high-fat diet allowing to oxidize the high amount of fatty acids from the diet and to restore glycogen storages. 


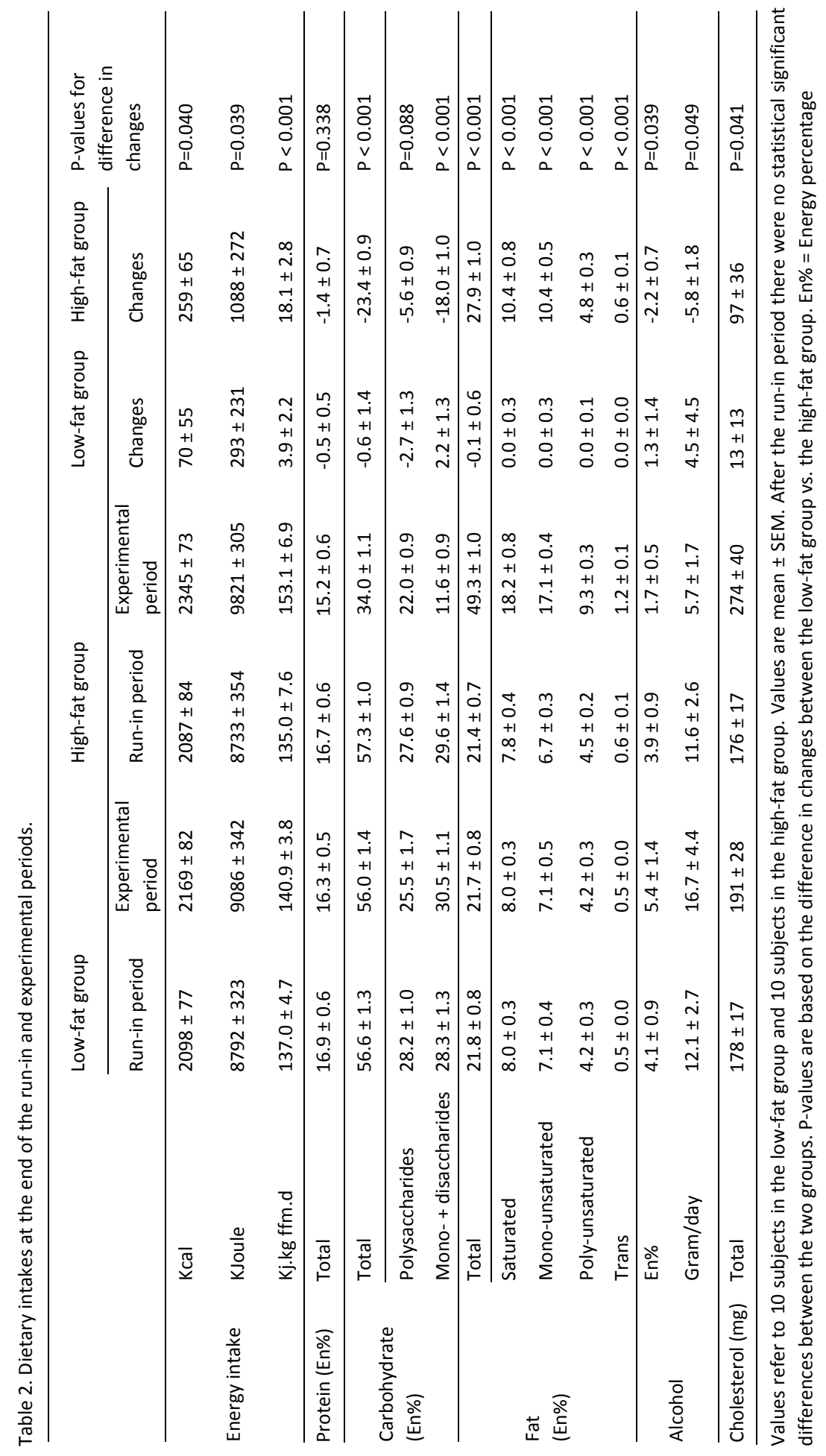




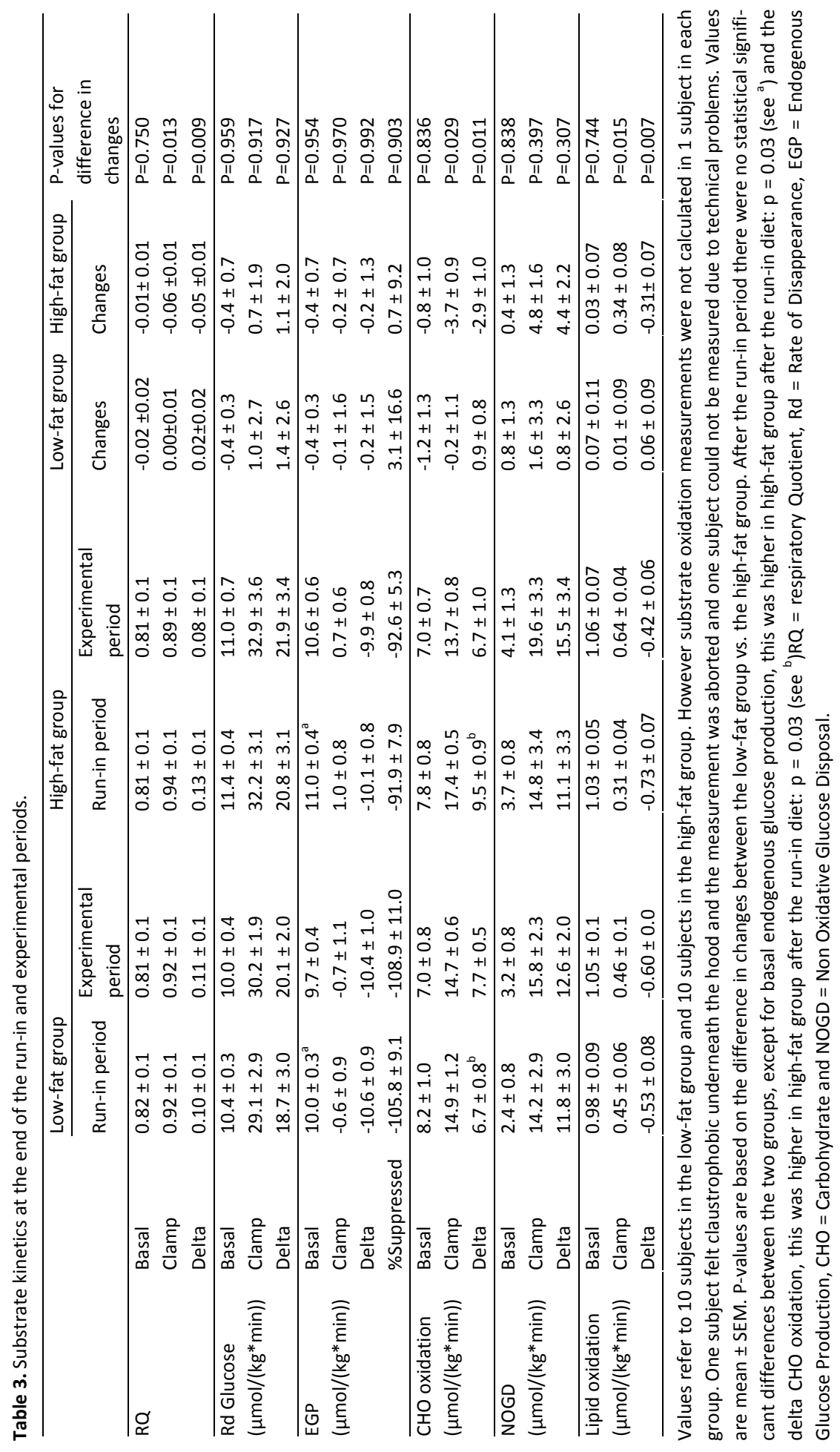




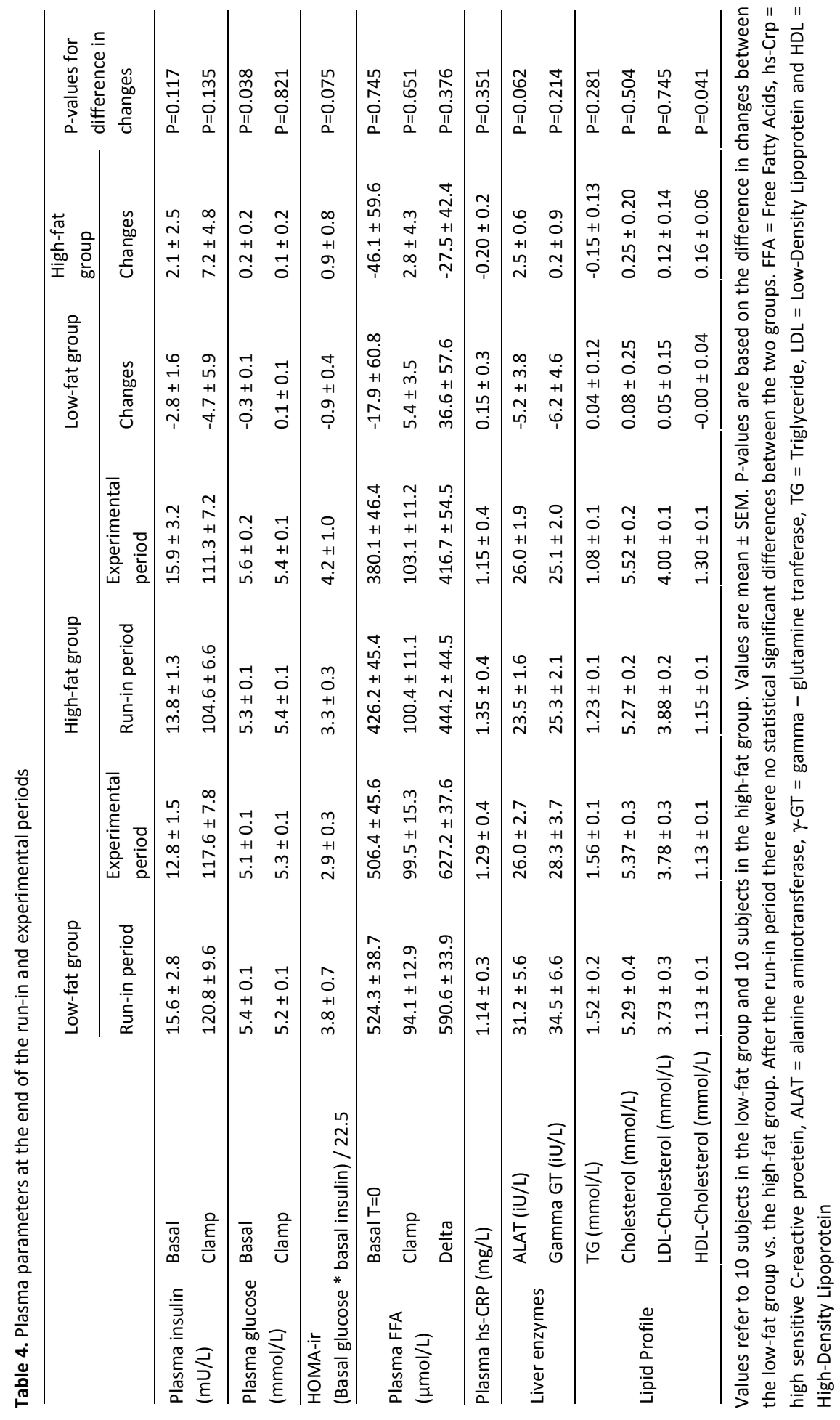




\section{References}

1. Riccardi G, Giacco R, Rivellese AA. Dietary fat, insulin sensitivity and the metabolic syndrome. Clin Nutr 2004;23:447-56.

2. Shulman GI. Cellular mechanisms of insulin resistance. J Clin Invest 2000;106:171-6.

3. Szczepaniak LS, Babcock EE, Schick F, et al. Measurement of intracellular triglyceride stores by $\mathrm{H}$ spectroscopy: validation in vivo. Am J Physiol 1999;276:E977-89.

4. Szczepaniak LS, Nurenberg P, Leonard D, et al. Magnetic resonance spectroscopy to measure hepatic triglyceride content: prevalence of hepatic steatosis in the general population. Am J Physiol Endocrinol Metab 2005;288:E462-8.

5. Seppala-Lindroos A, Vehkavaara S, Hakkinen AM, et al. Fat accumulation in the liver is associated with defects in insulin suppression of glucose production and serum free fatty acids independent of obesity in normal men. J Clin Endocrinol Metab 2002;87:3023-8.

6. Marchesini G, Marzocchi R, Agostini F, Bugianesi E. Nonalcoholic fatty liver disease and the metabolic syndrome. Curr Opin Lipidol 2005;16:421-7.

7. Westerbacka J, Lammi K, Hakkinen AM, et al. Dietary fat content modifies liver fat in overweight nondiabetic subjects. J Clin Endocrinol Metab 2005;90:2804-9.

8. Helge JW, Wulff B, Kiens B. Impact of a fat-rich diet on endurance in man: role of the dietary period. Med Sci Sports Exerc 1998;30:456-61.

9. Helge JW, Watt PW, Richter EA, Rennie MJ, Kiens B. Fat utilization during exercise: adaptation to a fat-rich diet increases utilization of plasma fatty acids and very low density lipoproteintriacylglycerol in humans. J Physiol 2001;537:1009-20.

10. Zderic TW, Davidson CJ, Schenk S, Byerley LO, Coyle EF. High-fat diet elevates resting intramuscular triglyceride concentration and whole body lipolysis during exercise. Am J Physiol Endocrinol Metab 2004;286:E217-25.

11. Starling RD, Trappe TA, Parcell AC, Kerr CG, Fink WJ, Costill DL. Effects of diet on muscle triglyceride and endurance performance. J Appl Physiol 1997;82:1185-9.

12. Kiens B, Essen-Gustavsson B, Gad P, Lithell H. Lipoprotein lipase activity and intramuscular triglyceride stores after long-term high-fat and high-carbohydrate diets in physically trained men. Clin Physiol 1987;7:1-9.

13. Jansson E, Kaijser L. Effect of diet on muscle glycogen and blood glucose utilization during a shortterm exercise in man. Acta Physiol Scand 1982;115:341-7.

14. Bachmann OP, Dahl DB, Brechtel K, et al. Effects of intravenous and dietary lipid challenge on intramyocellular lipid content and the relation with insulin sensitivity in humans. Diabetes 2001;50:2579-84.

15. Johnson NA, Stannard SR, Mehalski K, et al. Intramyocellular triacylglycerol in prolonged cycling with high- and low-carbohydrate availability. J Appl Physiol 2003;94:1365-72.

16. Schrauwen-Hinderling VB, Kooi ME, Hesselink MK, et al. Intramyocellular lipid content and molecular adaptations in response to a 1-week high-fat diet. Obes Res 2005;13:2088-94.

17. Hoeks J, van Baak MA, Hesselink MK, et al. Effect of beta1- and beta2-adrenergic stimulation on energy expenditure, substrate oxidation, and UCP3 expression in humans. Am J Physiol Endocrinol Metab 2003;285:E775-82.

18. Kuipers H, Verstappen FT, Keizer HA, Geurten P, van Kranenburg G. Variability of aerobic performance in the laboratory and its physiologic correlates. Int J Sports Med 1985;6:197-201.

19. Voedingscentrum. NEVO-tabel 2009: Nederlands Voedingsstoffenbestand 2009. Den Haag: Stichting Nederlands Voedingsstoffenbestand, 2009.

20. Roza AM, Shizgal HM. The Harris Benedict equation reevaluated: resting energy requirements and the body cell mass. Am J Clin Nutr 1984;40:168-82. 
21. Vanhamme L, van den Boogaart A, Van Huffel S. Improved method for accurate and efficient quantification of MRS data with use of prior knowledge. J Magn Reson 1997;129:35-43.

22. Naressi A, Couturier C, Devos JM, et al. Java-based graphical user interface for the MRUI quantitation package. MAGMA 2001;12:141-52.

23. Schrauwen-Hinderling VB, van Loon LJ, Koopman R, Nicolay K, Saris WH, Kooi ME. Intramyocellular lipid content is increased after exercise in nonexercising human skeletal muscle. J Appl Physiol 2003;95:2328-32.

24. Mensink M, Hesselink MK, Russell AP, Schaart G, Sels JP, Schrauwen P. Improved skeletal muscle oxidative enzyme activity and restoration of PGC-1 alpha and PPAR beta/delta gene expression upon rosiglitazone treatment in obese patients with type 2 diabetes mellitus. Int J Obes (Lond) 2007;31:1302-10.

25. Steele R. Influences of glucose loading and of injected insulin on hepatic glucose output. Ann N Y Acad Sci 1959;82:420-30.

26. Matthews DR, Hosker JP, Rudenski AS, Naylor BA, Treacher DF, Turner RC. Homeostasis model assessment: insulin resistance and beta-cell function from fasting plasma glucose and insulin concentrations in man. Diabetologia 1985;28:412-9.

27. Frayn KN. Calculation of substrate oxidation rates in vivo from gaseous exchange. J Appl Physiol 1983;55:628-34.

28. Bergstrom J, Hermansen L, Hultman E, Saltin B. Diet, muscle glycogen and physical performance. Acta Physiol Scand 1967;71:140-50.

29. Roorda BD, Hesselink MK, Schaart G, et al. DGAT1 overexpression in muscle by in vivo DNA electroporation increases intramyocellular lipid content. J Lipid Res 2005;46:230-6.

30. Friedewald WT, Levy RI, Fredrickson DS. Estimation of the concentration of low-density lipoprotein cholesterol in plasma, without use of the preparative ultracentrifuge. Clin Chem 1972;18:499-502.

31. Hoyumpa AM, Jr., Greene HL, Dunn GD, Schenker S. Fatty liver: biochemical and clinical considerations. Am J Dig Dis 1975;20:1142-70.

32. Thomsen C, Becker U, Winkler K, Christoffersen P, Jensen M, Henriksen O. Quantification of liver fat using magnetic resonance spectroscopy. Magn Reson Imaging 1994;12:487-95.

33. Schrauwen $P$, van Marken Lichtenbelt WD, Saris WH, Westerterp KR. Changes in fat oxidation in response to a high-fat diet. Am J Clin Nutr 1997;66:276-82.

34. Schrauwen $P$, van Marken Lichtenbelt WD, Westerterp KR. Fat and carbohydrate balances during adaptation to a high-fat diet. Am J Clin Nutr 2000;72:1239-41.

35. Bisschop PH, de Metz J, Ackermans MT, et al. Dietary fat content alters insulin-mediated glucose metabolism in healthy men. Am J Clin Nutr 2001;73:554-9.

36. Korenblat KM, Fabbrini E, Mohammed BS, Klein S. Liver, muscle, and adipose tissue insulin action is directly related to intrahepatic triglyceride content in obese subjects. Gastroenterology 2008;134:1369-75.

37. Sparks LM, Ukropcova B, Smith J, et al. Relation of adipose tissue to metabolic flexibility. Diabetes Res Clin Pract 2009;83:32-43.

38. Maughan RJ, Greenhaff PL, Leiper JB, Ball D, Lambert CP, Gleeson M. Diet composition and the performance of high-intensity exercise. J Sports Sci 1997;15:265-75.

39. Chokkalingam K, Jewell K, Norton L, et al. High-fat/low-carbohydrate diet reduces insulinstimulated carbohydrate oxidation but stimulates nonoxidative glucose disposal in humans: An important role for skeletal muscle pyruvate dehydrogenase kinase 4. J Clin Endocrinol Metab 2007;92:284-92.

40. Mensink RP, Zock PL, Kester AD, Katan MB. Effects of dietary fatty acids and carbohydrates on the ratio of serum total to $\mathrm{HDL}$ cholesterol and on serum lipids and apolipoproteins: a meta-analysis of 60 controlled trials. Am J Clin Nutr 2003;77:1146-55. 
Chapter 6.

A high-fat diet impairs metabolic flexibility and reduces genes involved in fatty acid oxidation without affecting insulin sensitivity and mitochondrial content in healthy overweight men

N.A. van Herpen, L.M. Sparks

and P. Schrauwen

(Submitted), 2012. 


\section{ABSTRACT}

\section{Context}

High fat diets have been suggested to lead to insulin resistance and mitochondrial dysfunction, but data in humans is scarce.

\section{Objective}

To determine whether metabolic flexibility and genes regulating metabolism and mitochondrial function are compromised in overweight, insulin-sensitive humans upon a high-fat diet (HFD).

\section{Participants}

Twenty overweight men (age $55.2 \pm 2.4 \mathrm{yr}$; body mass index $28.8 \pm 0.6 \mathrm{~kg} / \mathrm{m} 2$ ) were randomly allocated to a low-fat diet (LFD) or a HFD.

\section{Intervention}

Participants underwent a 3-week run-in LFD (20\% fat) and were then studied before and after a 3 -week LFD ( $20 \%$ fat) or HFD ( $55 \%$ fat).

\section{Outcomes}

Insulin sensitivity and metabolic flexibility were determined using a hyperinsulinemic euglycemic clamp. Skeletal muscle biopsies (vastus lateralis) were obtained and mRNA expression for genes involved in lipid and glucose metabolism, mitochondrial content and function were determined. Finally intramyocellular lipid (IMCL), by Oil-red-O, was determined.

\section{Results}

Insulin sensitivity and IMCL were unaffected by either diet. Metabolic flexibility was reduced by HFD $(p<0.05)$. mRNA expression of the lipid metabolism genes carnitine palmitoyl-transferase 1 (CPT1) and peroxisome proliferator activated receptor $\gamma$ coactivator-1beta (PGC1b) were reduced by HFD $(p<0.05)$. mRNA of genes of glucose metabolism, mitochondrial biogenesis genes, and protein content of OXPHOS were unaltered.

\section{Conclusions}

Excess dietary lipid reduces metabolic flexibility and expression of CPT1 and PGC1b without altering insulin sensitivity, IMCL or mitochondrial content in healthy overweight men. 


\section{Introduction}

Kelley et al. first described metabolic flexibility as the ability to switch between lipid and glucose oxidation in response to insulin (1). An inability to efficiently switch between these substrates in the post-prandial state has been observed in obese insulin-resistant and type 2 diabetic individuals $(2,3)$. Mitochondrial dysfunction and accumulation of high levels of intramyocellular lipid (IMCL) have been implicated as the culprits of this metabolic inflexibility in insulin resistance and type 2 diabetes $(4,5)$. In fact, Phielix et al. demonstrated that permeabilized skeletal muscle fibers of type 2 diabetic patients have reduced oxygen consumption after normalization for mtDNA content (6). Thus, these data suggest that in addition to decreased mitochondrial density, there is an intrinsic defect(s) in TCA cycle and OXPHOS capacity in mitochondria of individuals with insulin resistance and type 2 diabetes.

One of the environmental factors that have been suggested to lead to metabolic inflexibility and insulin resistance in humans is the consumption of high fat diets. However, it has also been demonstrated that healthy lean individuals adapt to excess dietary fat by maintaining their metabolic flexibility (7) and mitochondrial content (8) and even enhancing their skeletal muscle capacity for fatty acid oxidation (FAO) (9). These data suggest that it is not IMCL and excess dietary lipid per se that cause metabolic inflexibility and insulin resistance. A recent study by Boyle et al. compared the differential responses of lean insulin-sensitive and obese insulinresistant individuals to a high fat diet (HFD) (10). From Pre- to Post-HFD, a body size $\times$ HFD interaction was observed, where the lean insulin-sensitive individuals increased while the obese insulin-resistant individuals decreased mRNA content of genes involved in lipid metabolism such as pyruvate dehydrogenase kinase 4 (PDK4), uncoupling protein 3 (UCP3), PPARa, and PPARy coactivator-1 alpha (PGC1a). These findings raise the question of whether insulin resistance and body size are separate influences on metabolic inflexibility and mitochondrial function. Indeed, obesity, insulin resistance and type 2 diabetes are all associated with impaired mitochondrial function, metabolic inflexibility and high IMCL levels, coupled with an inability to adapt to excess dietary FFAs (11-13). Interestingly, however, we previously reported that 3 weeks of a HFD impaired metabolic flexibility in healthy overweight subjects without affecting IMCL accumulation or insulin sensitivity (14). In the present study, we aimed to investigate the effects of 3 weeks of a high fat diet on transcriptional markers of lipid and glucose metabolism reflective of metabolic flexibility, as well as markers of mitochondrial content and function in healthy overweight men. 


\section{Methods}

\section{Experimental Design and Subjects}

Twenty sedentary, healthy overweight men were randomly allocated to low- or high-fat groups $(54.0 \pm 2.3$ and $56.4 \pm 2.5$ y, BMl: $29.3 \pm 0.6$ and $28.3 \pm 0.5 \mathrm{~kg} / \mathrm{m} 2$, respectively). Subjects with a body weight gain or loss $>3 \mathrm{~kg}$ in past three months or $>20$ gram alcohol intake/day were excluded. No subjects had a family history of type 2 diabetes (T2D). Both groups underwent a three-week low-fat diet, after which half of the subjects switched to a three-week isocaloric high-fat diet. At three and six weeks, insulin sensitivity was measured using a hyperinsulinemic-euglycemic clamp as previously described (14). The study was approved by the Institutional Medical Ethical Committee, and all subjects gave written informed consent.

\section{Dietary Intervention}

Habitual food intake was recorded for two working days and one weekend day. Based on this data and the Harris \& Benedict formula, sample menus were composed. Low- and high-fat diets consisted of $15 \% / 20 \% / 65 \%$ and $15 \% / 55 \% / 30 \%$ of energy as protein, fat and carbohydrates, respectively. Subjects were provided a list of food products that were given points according to their fat and energy contents, which could be exchanged for those of the sample menu. Each subject recorded all consumed products. Subjects were weighed weekly by the study dietician. At the end of the experimental period, energy and nutrient intake was estimated using the Dutch food-composition table.

\section{Blood analyses}

Arterialised blood samples (hotbox heated) were collected from a hand vein and glucose was measured spectrophotometrically (Wako Chemicals, Neuss, Germany). Insulin concentration was determined using a radioimmunoassay (Linco Research, St. Charles, MO, USA).

\section{Substrate Utilization Calculations}

Oxygen $\left(\mathrm{O}_{2}\right)$ consumption and carbon dioxide $\left(\mathrm{CO}_{2}\right)$ production were measured under resting conditions in supine position by a custom-built ventilated hood system. Energy expenditure was calculated according to Weir $\left(\mathrm{kcal} / \mathrm{min}=3.9 * \mathrm{VO}_{2}\right.$ $(\mathrm{I} / \mathrm{min})+1.1 * \mathrm{VCO}_{2}(\mathrm{l} / \mathrm{min})(15)$. Both in the basal state and during insulin stimulation, substrate oxidation was measured by indirect calorimetry. Fat and carbohydrate oxidation were calculated using stoichiometric equations according to Frayn (16) with the assumption that protein oxidation was negligible. Metabolic flexibility 
$(\Delta R Q)$ was expressed as the change in respiratory exchange ratio from the fasted state to the insulin-stimulated condition.

\section{Muscle Analyses}

Muscle biopsies were obtained from the vastus lateralis muscle (ref) and total RNA was isolated from $20 \mathrm{mg}$ of skeletal muscle tissue using the acid phenol method of Chomczynski and Sacchi (17). Primers and probes were designed using Primer Express version 2.1 (Applied Biosystems, Roche, Branchburg, NJ, USA). Real Time qRTPCR were performed as one-step reactions in ABI PRISM 7900 (Applied Biosystems, Nieuwerkerk aan den IJssel, Netherlands) as previously described (8). Ribosomal phosphoprotein large PO gene (RPLPO) was used as an internal control and was tested for intra-individual variability, as well as diet effect to ensure precision in the measurements. All expression data were normalized by dividing the target gene by the internal control gene. Fresh cryosections $(5 \mu \mathrm{m})$ were stained for IMCL by OilRed-O staining to allow quantification (18).

\section{Statistical Analyses}

Data are reported as means \pm SEM. Statistical analyses were performed using SPSS 16.0 for MacOS-X (SPSS, Chicago, USA) and JMP v8.0 (SAS, Cary, NC, USA). Though fold change data are presented for ease of visualization, statistical analyses were performed on raw data. Statistical comparisons between conditions were performed using a Student unpaired t-test comparing the changes of each group from the run-in and experimental periods. For genes and protein values are expressed as the fold-change (post-diet divided by pre-diet) (mean \pm sem). No change is a value of 1 , with values $>1.0$ indicative of an increase in respective mRNA and protein content with the diet. For genes and proteins pre- and post-diet intervention values were tested. For all data a $\mathrm{p}<0.05$ was considered statistically significant.

\section{Results}

\section{Dietary Intake and Metabolic Analyses}

For baseline subject characteristics see supplemental table 1. During run-in, energy, macronutrients and cholesterol intake did not differ between groups and were compliant with the recommendations. During the experimental period, the low- and high-fat groups consumed $16.3 \pm 0.5 \%, 21.8 \pm 0.8 \%$ and $56.6 \pm 1.7 \%$ versus $15.2 \pm 0.6 \%$, $49.3 \pm 1.0 \%$ and $34.0 \pm 1.1 \%$ as protein, fat and carbohydrate, respectively (19). Body weight and insulin sensitivity ( $R d)$ were unaltered by the dietary intervention (19). Whole-body lipid oxidation was similar after the run-in diet, and remained similar 
after the dietary intervention (Table 1). Insulin-induced suppression of lipid oxidation was not different between groups after run-in. However, insulin-induced suppression of lipid oxidation was significantly decreased after the high-fat diet (HFD) ( $p=0.007$, Table 1); whereas, the low-fat diet (LFD) had no effect. In aggregate, metabolic flexibility, defined as the change in $R Q$ upon insulin stimulation $(\Delta R Q)$, was not different between groups after the run-in period nor was it different after the LFD. However, the HFD decreased metabolic flexibility by $38 \%(p=0.009$, Table 1 and Figure $1 \mathrm{~A})$.

\section{Muscle Analyses}

In lieu of the HFD-induced decrease in metabolic flexibility, we next investigated the effects of the HFD on IMCL, mRNA expression of lipid and glucose metabolism and mitochondrial biogenesis genes, as well as protein content of OXPHOS. IMCL was not significantly different between groups after the run-in diet $(p=0.244$, Figure 1B), and in response to the dietary interventions, subjects also did not change their IMCL content (change of $0.49 \pm 0.45$ vs. $1.38 \pm 0.67 \%$ in LFD vs. HFD, $p=0.304$; Figure $1 B$ ).

Figure 1. Metabolic flexibility and IMCL content

A

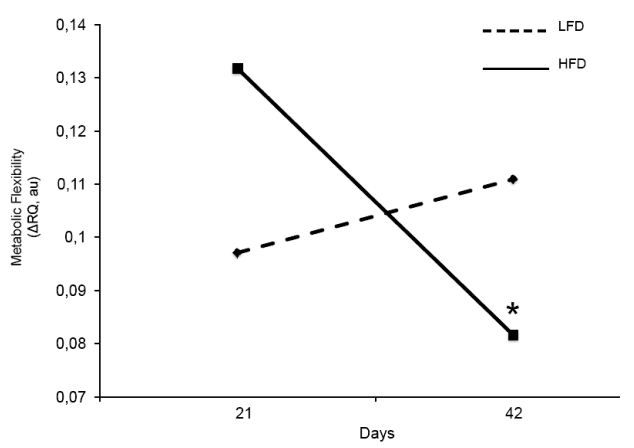

B

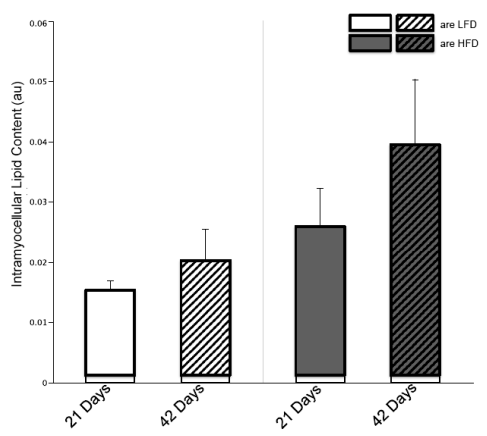

Effect of LFD ( $n=10)$ and HFD ( $n=10)$ on metabolic flexibility ( $\triangle R Q)(A)$ and intramyocellular lipid (IMCL) content (B). Changes in whole-body respiratory quotient (RQ) in response to insulin during a hyperinsulinemic-euglycemic clamp (metabolic flexibility) after 3 weeks of either a LFD (dashed line) or a HFD (solid line) in healthy overweight men. Changes in IMCL after 3 weeks of either a LFD (white bars) or a HFD (gray bars) in the skeletal muscle of healthy overweight men. Values are expressed as mean \pm sem. *Significant difference $(p<0.05)$ between pre- and post-diet intervention.

After the run-in diet, there were no significant differences in mRNA expression of any gene between groups (Figure 2). LFD had no significant effect on genes involved in lipid and glucose metabolism (Figure 2A). The HFD, however, decreased mRNA content of two key genes involved in lipid oxidation by $66 \%$ and $75 \%$ (carnitine palmitoyl transferase $1, \mathrm{CPT} 1, \mathrm{p}<0.05$ and peroxisome proliferator-activated recep- 
tor gamma coactivator-1 beta, $\mathrm{PGC1b}, \mathrm{p}<0.05$, respectively; Figure $2 \mathrm{~A}$ ). Neither the LFD nor the HFD had a significant effect on mRNA expression of genes involved in glucose metabolism (HKII, GYS1 and PDK4) and mitochondrial biogenesis (NRF1 and PGC1a) (Figure 2). Furthermore, there was no significant dietary effect on mitochondrial density as measured by the protein content of the respiratory complexes of the electron transport chain.

Figure 2. mRNA content

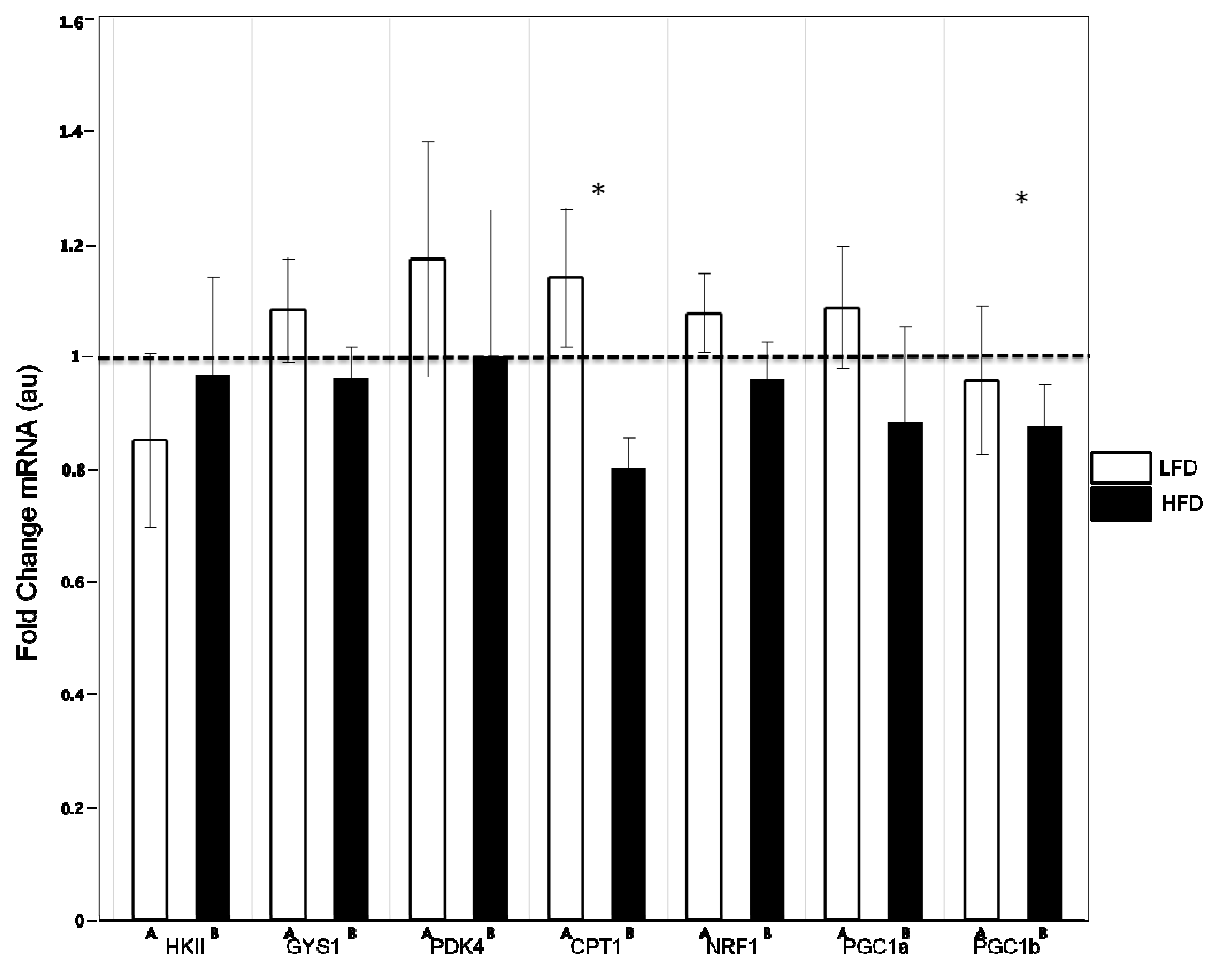

Effect of LFD $(n=10)$ and HFD $(n=10)$ on mRNA content. Changes in fasting mRNA and protein content with the 3 weeks of LFD (white bars) and HFD (black bars) in the skeletal muscle of healthy overweight men. Values are expressed as the fold-change (post-diet divided by pre-diet) (mean \pm sem). No change is a value of 1 , which is represented by the dashed line, with values $>1.0$ indicative of an increase in respective mRNA and protein content with the diet. *Significant difference $(p<0.05)$ between pre- and post-diet intervention for the indicated genes and protein. 


\section{Discussion}

A controversy exists as to whether a high fat diet induces insulin resistance with reduced mitochondrial content or if it actually sensitizes mitochondria to enhance lipid oxidation and increase mitochondrial content. The accumulation of lipid in skeletal muscle has long been associated with the development of insulin resistance (20), and multiple human studies suggest that this insulin resistance is indeed accompanied by impaired mitochondrial oxidative function - in turn linked to reduced mitochondrial density $(6,21)$. Ritov et al. demonstrated that the enzymatic activity of OXPHOS Complex I was reduced by about $40 \%$ in the skeletal muscle of individuals with type 2 diabetes and by $20 \%$ in obese individuals (21). Differences in oxidative capacity did not remain after normalization for mitochondrial mass by citrate synthase activity or mtDNA content, suggesting that reduced mitochondrial mass might be a major contributor. This is consistent with electron micrographs from Kelley et al. demonstrating diminished mitochondrial size in obesity and type 2 diabetes (5). In aggregate, skeletal muscle of obese individuals is characterized by profound reductions in mitochondrial function, as evidenced by decreased expression of metabolic genes $(22,23)$, reduced respiratory capacity $(21,24,25)$, and mitochondria that are smaller and less abundant (5), leading to speculation that a decrease in the capacity to oxidize fat due to acquired or inherited mitochondrial insufficiency may be an underlying cause of the lipid-induced insulin resistance (2628).

In contrast, Turner et al. recently demonstrated that a high fat diet actually enhances skeletal muscle fatty acid oxidative capacity in mice(9) accompanied by increased mitochondrial content. Another study in rats revealed that while a high fat diet induced insulin resistance, it actually increased mitochondrial content (29). Regarding such discrepancies in the literature, it is important to note that substantial inter-individual variability exists in the change of fat oxidation during adaptation to a HFD (30). Impaired fat oxidation during adaptation to a HFD is observed in restrained eaters $(31)$, post-obese $(32,33)$ and obese $(34)$ individuals, and in individuals with a family history of obesity and insulin resistance (35-37), pointing toward a possible genetic basis for reduced fat oxidation (33). Impaired substrate switching in response to insulin (metabolic inflexibility) and dietary stimuli (attenuated adaptation to a HFD) are thought to contribute to obesity and insulin resistance $(32,38)$. In fact, a recent study by Boyle et al. demonstrated a differential response to a dietary lipid stimulus in the skeletal muscle of lean insulin-sensitive and obese insulinresistant humans (10). These data led us to investigate the effects of a high fat diet on insulin sensitivity and mitochondrial content in the skeletal muscle of overweight but type 2 diabetes family history negative, insulin sensitive individuals.

Our study demonstrates that 3 weeks of an iso-caloric high fat diet has no adverse effect on body weight, IMCL and insulin sensitivity. The increased dietary lipid 
content did impair insulin-suppression of lipid oxidation and subsequently metabolic flexibility. Regarding this metabolic inflexibility it is important to stress that the difference in metabolic flexibility is mainly seen in the insulin-stimulated response, i.e. fat oxidation is less suppressed and glucose oxidation is blunted during insulin stimulation. Taking into consideration that these effects occur without a change in insulin sensitivity, our data clearly demonstrates that the capacity to switch substrate oxidation is decreased after the HFD.

While the HFD impaired metabolic flexibility, it had no effect on transcriptional markers of mitochondrial biogenesis (PGC1a and NRF1). Furthermore, the protein content of OXPHOS was unaltered by the HFD. In agreement an elegant study by Toledo et al. also demonstrated that reducing adiposity and insulin resistance through weight loss has no effect on skeletal muscle mitochondrial content (39). These data suggest that a reduction in mitochondrial content is not a prerequisite for changes in metabolic flexibility.

We did find that a 3-week HFD reduced the mRNA content of two key lipid oxidation genes, carnitine palmitoyl-transferase 1 (CPT1) and peroxisome proliferator activated receptor $\gamma$ coactivator-1beta (PGC1b), in the skeletal muscle of these healthy overweight men without any effect on several important glucose metabolism genes, such as hexokinase (HKII), glycogen synthase (GYS1) and pyruvate dehydrogenase kinase 4 (PDK4). It has long been shown that CPT1 is a key lipid oxidation enzyme and that overexpression of CPT1 in skeletal muscle is sufficient to enhance fatty acid oxidation and improve high-fat-diet-induced insulin resistance (40). Recently, PGC1b has been revealed as another key player in lipid metabolism. In fact, Wright et al. showed that overexpression of PGC1b also ameliorates lipid-induced skeletal muscle insulin resistance (41). Furthermore PGC-1b induces oxidative mitochondrial function, particularly in skeletal muscle $(42,43)$. As such, these two genes, CPT1 and PGC1b are proven to be highly responsive to dietary lipid stimuli. However, even though mRNA content of CPT1 and PGC1b are reduced in response to the 3-week HFD in our study, it was not sufficient to adversely affect IMCL and whole-body insulin sensitivity.

These findings are in agreement with a recent study by Han et al. that argues against the hypothesis that a deficiency of the electron transport chain (ETC) and imbalance between the ETC and b-oxidation pathways causes muscle insulin resistance (29). Taken together, these data provide evidence that increased dietary fat content for three weeks, leading to lipid-induced metabolic inflexibility and reduced CPT1 and PGC1 expression are not sufficient to induce IMCL accumulation and insulin resistance when mitochondrial content is unchanged.

While our findings do not completely resolve the ongoing debate of lipidinduced insulin resistance and mitochondrial function, it is important to note that all data should be examined with these factors in mind: 1) duration of the dietary in- 
tervention, 2) composition of the dietary intervention, 3) insulin sensitivity status of the subjects and 4) body composition of the subjects.

Our findings suggest that high lipid availability does not lead to intramuscular lipid accumulation and insulin resistance in healthy, insulin-sensitive overweight men. However, it does suggest that increased dietary fat content impairs the muscle's ability to adapt its metabolic flexibility/substrate switching in response to insulin. We cannot exclude that the metabolic inflexibility and reduced CPT1 and PGC1 expression are early markers of insulin resistance and that a prolonged consumption of high-fat diets may indeed lead to insulin resistance. However, we can conclude that increased dietary fat content, markers of decreased fat oxidation capacity and lipid-induced metabolic inflexibility are not sufficient to induce insulin resistance on the short term. 


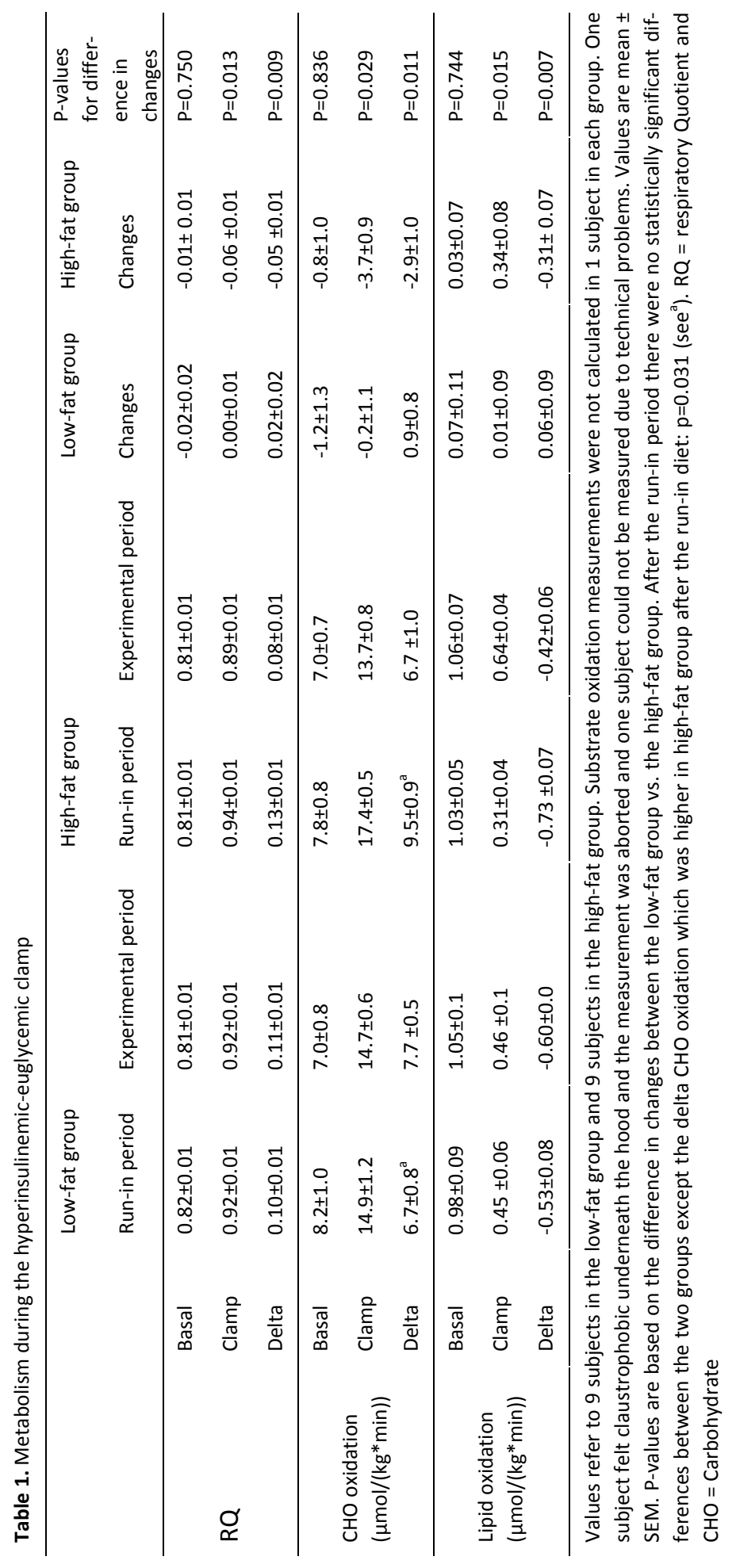




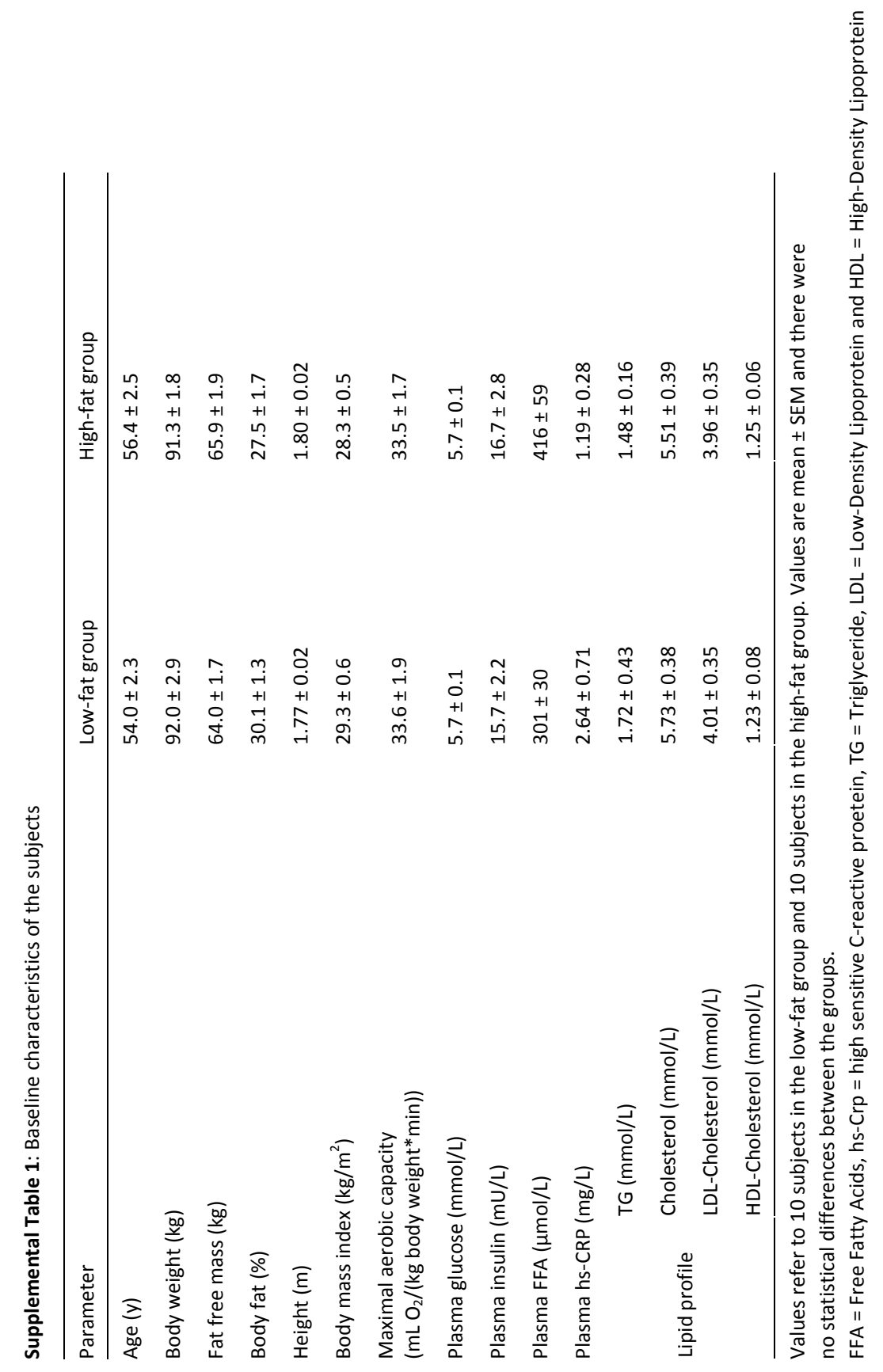




\section{References}

1. Kelley DE, Mandarino LJ. Fuel selection in human skeletal muscle in insulin resistance: a reexamination. Diabetes 2000; 49: 677-683.

2. Kelley DE, Goodpaster B, Wing RR, Simoneau JA. Skeletal muscle fatty acid metabolism in association with insulin resistance, obesity, and weight loss. Am J Physiol 1999; 277: E1130-1141.

3. Kelley DE, Reilly JP, Veneman T, Mandarino LJ. Effects of insulin on skeletal muscle glucose storage, oxidation, and glycolysis in humans. Am J Physiol 1990; 258: E923-929.

4. Kelley DE, Goodpaster BH, Storlien L. Muscle triglyceride and insulin resistance. Annu Rev Nutr 2002; 22: 325-346.

5. Kelley DE, He J, Menshikova EV, Ritov VB. Dysfunction of mitochondria in human skeletal muscle in type 2 diabetes. Diabetes 2002; 51: 2944-2950.

6. Phielix E, Schrauwen-Hinderling VB, Mensink M, Lenaers E, Meex R, Hoeks J, et al. Lower intrinsic ADP-stimulated mitochondrial respiration underlies in vivo mitochondrial dysfunction in muscle of male type 2 diabetic patients. Diabetes 2008; 57: 2943-2949.

7. Ukropcova B, McNeil M, Sereda O, de Jonge L, Xie H, Bray GA, et al. Dynamic changes in fat oxidation in human primary myocytes mirror metabolic characteristics of the donor. J Clin Invest 2005; 115: 1934-1941.

8. Sparks LM, Xie H, Koza RA, Mynatt RL, Hulver MW, Bray G, et al. A High-Fat Diet Coordinately Downregulates Genes Required for Mitochondrial Oxidative Phosphorylation in Skeletal Muscle. Diabetes 2005; 54: 1926-1933.

9. Turner N, Bruce CR, Beale SM, Hoehn KL, So T, Rolph MS, et al. Excess lipid availability increases mitochondrial fatty acid oxidative capacity in muscle: evidence against a role for reduced fatty acid oxidation in lipid-induced insulin resistance in rodents. Diabetes 2007; 56: 2085-2092.

10. Boyle KE, Canham JP, Consitt LA, Zheng D, Koves TR, Gavin TP, et al. A high-fat diet elicits differential responses in genes coordinating oxidative metabolism in skeletal muscle of lean and obese individuals. The Journal of clinical endocrinology and metabolism 2011; 96: 775-781.

11. Bajaj M, Berria R, Pratipanawatr T, Kashyap S, Pratipanawatr W, Belfort R, et al. Free fatty acidinduced peripheral insulin resistance augments splanchnic glucose uptake in healthy humans. American journal of physiology Endocrinology and metabolism 2002; 283: E346-352.

12. Groop LC, Saloranta C, Shank M, Bonadonna RC, Ferrannini E, DeFronzo RA. The role of free fatty acid metabolism in the pathogenesis of insulin resistance in obesity and noninsulin-dependent diabetes mellitus. The Journal of clinical endocrinology and metabolism 1991; 72: 96-107.

13. Groop LC, Bonadonna RC, DelPrato S, Ratheiser K, Zyck K, Ferrannini E, et al. Glucose and free fatty acid metabolism in non-insulin-dependent diabetes mellitus. Evidence for multiple sites of insulin resistance. The Journal of clinical investigation 1989; 84: 205-213.

14. van Herpen NA, Schrauwen-Hinderling VB, Schaart G, Mensink RP, Schrauwen P. Three weeks on a high-fat diet increases intrahepatic lipid accumulation and decreases metabolic flexibility in healthy overweight men. J Clin Endocrinol Metab 2011; 96: E691-695.

15. Weir JB. New methods for calculating metabolic rate with special reference to protein metabolism. J Physiol 1949; 109: 1-9.

16. Frayn KN. Calculation of substrate oxidation rates in vivo from gaseous exchange. J Appl Physiol 1983; 55: 628-634.

17. Chomczynski $P$, Sacchi N. Single-step method of RNA isolation by acid guanidinium thiocyanatephenol-chloroform extraction. Anal Biochem 1987; 162: 156-159.

18. Koopman R, Schaart G, Hesselink MK. Optimisation of oil red O staining permits combination with immunofluorescence and automated quantification of lipids. Histochem Cell Biol 2001; 116: 63-68. 
19. van Herpen NA, Schrauwen-Hinderling VB, Schaart G, Mensink RP, Schrauwen P. Three weeks on a high-fat diet increases intrahepatic lipid accumulation and decreases metabolic flexibility in healthy overweight men. The Journal of clinical endocrinology and metabolism 2011; 96: E691-695.

20. McGarry JD. Banting lecture 2001: dysregulation of fatty acid metabolism in the etiology of type 2 diabetes. Diabetes 2002; 51: 7-18.

21. Ritov VB, Menshikova EV, He J, Ferrell RE, Goodpaster BH, Kelley DE. Deficiency of subsarcolemmal mitochondria in obesity and type 2 diabetes. Diabetes 2005; 54: 8-14.

22. Mootha VK, Lindgren CM, Eriksson KF, Subramanian A, Sihag S, Lehar J, et al. PGC-1alpharesponsive genes involved in oxidative phosphorylation are coordinately downregulated in human diabetes. Nat Genet 2003; 34: 267-273.

23. Patti ME, Butte AJ, Crunkhorn S, Cusi K, Berria R, Kashyap S, et al. Coordinated reduction of genes of oxidative metabolism in humans with insulin resistance and diabetes: Potential role of PGC1 and NRF1. Proc Natl Acad Sci U S A 2003; 100: 8466-8471.

24. Boushel R, Gnaiger E, Schjerling P, Skovbro M, Kraunsoe R, Dela F. Patients with type 2 diabetes have normal mitochondrial function in skeletal muscle. Diabetologia 2007; 50: 790-796.

25. Mogensen M, Sahlin K, Fernstrom M, Glintborg D, Vind BF, Beck-Nielsen $H$, et al. Mitochondrial respiration is decreased in skeletal muscle of patients with type 2 diabetes. Diabetes 2007; 56: 1592-1599.

26. Lowell BB, Shulman GI. Mitochondrial dysfunction and type 2 diabetes. Science 2005; 307: 384387.

27. Morino K, Petersen KF, Shulman GI. Molecular mechanisms of insulin resistance in humans and their potential links with mitochondrial dysfunction. Diabetes 2006; 55 Suppl 2: S9-S15.

28. Morino K, Petersen KF, Dufour S, Befroy D, Frattini J, Shatzkes N, et al. Reduced mitochondrial density and increased IRS-1 serine phosphorylation in muscle of insulin-resistant offspring of type 2 diabetic parents. The Journal of clinical investigation 2005; 115: 3587-3593.

29. Han DH, Hancock CR, Jung SR, Higashida K, Kim SH, Holloszy JO. Deficiency of the mitochondrial electron transport chain in muscle does not cause insulin resistance. PLoS One 2011; 6: e19739.

30. Smith SR, de Jonge L, Zachwieja JJ, Roy H, Nguyen T, Rood JC, et al. Fat and carbohydrate balances during adaptation to a high-fat. Am J Clin Nutr 2000; 71: 450-457.

31. Verboeket-van de Venne WP, Westerterp KR, ten Hoor F. Substrate utilization in man: effects of dietary fat and carbohydrate. Metabolism: clinical and experimental 1994; 43: 152-156.

32. Astrup A, Buemann B, Christensen NJ, Toubro S. Failure to increase lipid oxidation in response to increasing dietary fat content in formerly obese women. The American journal of physiology 1994; 266: E592-599.

33. Astrup A, Buemann B, Western P, Toubro S, Raben A, Christensen NJ. Obesity as an adaptation to a high-fat diet: evidence from a cross-sectional study. The American journal of clinical nutrition 1994; 59: 350-355.

34. Thomas CD, Peters JC, Reed GW, Abumrad NN, Sun M, Hill JO. Nutrient balance and energy expenditure during ad libitum feeding of high-fat and high-carbohydrate diets in humans. The American journal of clinical nutrition 1992; 55: 934-942.

35. Holm JC, Gamborg M, Ward L, Ibsen KK, Gammeltoft S, Sorensen TI, et al. Longitudinal analysis of leptin variation during weight regain after weight loss in obese children. Obesity facts 2009; 2 : 243248.

36. Adegboye AR, Andersen LB, Froberg K, Sardinha LB, Heitmann BL. Linking definition of childhood and adolescent obesity to current health outcomes. International journal of pediatric obesity : IJPO : an official journal of the International Association for the Study of Obesity 2010; 5: 130-142.

37. Ukropcova B, Sereda O, de Jonge L, Bogacka I, Nguyen T, Xie H, et al. Family history of diabetes links impaired substrate switching and reduced mitochondrial content in skeletal muscle. Diabetes 2007; 56: 720-727.

38. Storlien L, Oakes ND, Kelley DE. Metabolic flexibility. Proc Nutr Soc 2004; 63: 363-368. 
39. Toledo FG, Menshikova EV, Azuma K, Radikova Z, Kelley CA, Ritov VB, et al. Mitochondrial capacity in skeletal muscle is not stimulated by weight loss despite increases in insulin action and decreases in intramyocellular lipid content. Diabetes 2008; 57: 987-994.

40. Bruce CR, Hoy AJ, Turner N, Watt MJ, Allen TL, Carpenter K, et al. Overexpression of carnitine palmitoyltransferase-1 in skeletal muscle is sufficient to enhance fatty acid oxidation and improve high-fat diet-induced insulin resistance. Diabetes 2009; 58: 550-558.

41. Wright LE, Brandon AE, Hoy AJ, Forsberg GB, Lelliott CJ, Reznick J, et al. Amelioration of lipidinduced insulin resistance in rat skeletal muscle by overexpression of Pgc-1beta involves reductions in long-chain acyl-CoA levels and oxidative stress. Diabetologia 2011; 54: 1417-1426.

42. Lin J, Yang R, Tarr PT, Wu PH, Handschin C, Li S, et al. Hyperlipidemic effects of dietary saturated fats mediated through PGC-1beta coactivation of SREBP. Cell 2005; 120: 261-273.

43. Lelliott CJ, Medina-Gomez G, Petrovic N, Kis A, Feldmann HM, Bjursell M, et al. Ablation of PGC1 beta results in defective mitochondrial activity, thermogenesis, hepatic function, and cardiac performance. PLoS Biol 2006; 4: e369. 


\section{Part 4- General discussion}

Chapter 7.

General discussion 
Chapter 7.

General Discussion

N.A. van Herpen 
Obesity is well-known to be related to several diseases such as cardiovascular diseases (CVD), type II diabetes (T2DM), and even cancer (1-3). Lipid accumulation in non-adipose tissue has been suggested to be a link between obesity and T2DM and CVD. These diseases have a major impact on people's health and are therefore staggering public health costs. Lipid accumulation in non-adipose tissue is also known as ectopic lipid accumulation. Lipids can for example accumulate inside the muscle, liver, pancreas, and heart (see also chapter $\mathbf{2}$ for an review on ectopic lipid accumulation).

Lipid accumulation in ectopic sites can occur either by increased uptake of fatty acids (FAs), increased synthesis within the tissue involved, or reduced FA oxidation/disposal (4). Indeed 2 days to 5 weeks of high-fat feeding increases intramyocellular lipid (IMCL) stores and this accumulation of intramuscular fat may simply be due to a positive fat balance when changing to a high-fat diet (5-9). Physically inactive humans consuming a high-energy, high-fat diet, may have a chronically positive energy and fat balance, resulting in fat accumulation in adipose tissue and probably also in skeletal muscle. Indeed, obesity is correlated with increased $\operatorname{IMCL}(10,11)$. In accordance with the above suggestion, other conditions with high FA availability also increases IMCL content. For example, the elevation of plasma free fatty acids (FFA) by infusions and 72 hours of fasting increased IMCL (12-14). Under these conditions, fat in muscle is simply stored, because FA availability and oxidation are not in balance.

In this thesis we studied two potential determinants of ectopic fat manipulation: prolonged fasting and high-fat feeding. Prolonged fasting is a model in which FFA and IMCL levels are elevated in a physiological way, but still decreases insulin sensitivity $(8,14)$. Another model for the development of insulin resistance may be high-fat feeding. The high availability of fast food nowadays may be one of the important factors related to the obesity epidemic. High-fat diets therefore have been suggested to lead to insulin resistance (15).

\subsection{Intramyocellular lipid and insulin sensitivity}

In chapter 3 we investigated whether prolonged fasting indeed leads to increases in FFA, which in turn could lead to lipid accumulation in muscle with decreased insulin sensitivity as a consequence. Indeed, FFA levels were increased $\sim 9$-fold after sixty hours of fasting in healthy male subjects leading to elevated intramuscular lipid levels and a decreased muscular insulin sensitivity. IMCL levels were 2 2.7-fold higher after 60 hours of fasting in comparison with the fed condition. The increase in lipid accumulation was more pronounced ( 3.5 fold) in fibers identified as slow, oxidative (type 1 ) fibers. Within type 2 muscle fibers IMTG levels increased by 2 fold after 60 hours of fasting. The insulin sensitivity index $\left(\mathrm{S}_{\mathrm{I}}\right)$, an index that takes 
into account the variation in insulin and glucose levels during the clamp (16), was reduced by $\sim 45 \%$ upon 60 hours of fasting, as compared to the fed condition. This means that, in agreement with previous literature, an increase in FFA leads to IMCL accumulation and a decreased insulin sensitivity. Indeed, there is now accumulating evidence that fatty-acid metabolite accumulation in non-adipose tissue, in particular in skeletal muscle, is a central feature of type II diabetes (17-22).

In chapter $\mathbf{5}$ we investigated whether a high-fat diet, often indicated as the main reason for obesity in modern society, leads to an accumulation of IMCLs and decreases insulin sensitivity. We investigated twenty overweight men, who were randomly allocated to the low- or high-fat group. Both groups started with a threeweek low-fat diet (15 En\% protein, 65 En\% carbohydrates, 20 En\% fat), after which half of the subjects switched to a three-week isocaloric high-fat diet (targeted composition 15 En\% protein, 30 En\% carbohydrates, 55 En\% fat). Using these diets we did not find a statistically significant increase in IMCL levels after the high-fat diet or an effect on insulin sensitivity. Based on the suggested relationship between the accumulation of fat in non-adipose tissues such as skeletal muscle (4) and insulin resistance, a lack of effect of high-fat on both $\mathrm{IMCL}$ accumulation and insulin sensitivity fits with this model. It may indicate that when subjects are in energy balance, in other words when fat oxidation matches fat intake, there is no accumulation of IMCLs and therefore also no effect on insulin sensitivity.

With regard to fat oxidation, we did not observe an increase in resting fat oxidation after the high-fat diet, but we did observe that metabolic flexibility was reduced, with a reduced inhibition of lipid oxidation during insulin infusion. Although speculative, the reduced ability to suppress lipid oxidation during insulin infusion may reflect the postprandial situation and could indicate that also postprandial fat oxidation is increased after high-fat diet, reducing the necessity to deposit excess lipids in ectopic fat stores.

From a more classic point of view, a decreased metabolic flexibility has been linked to type II diabetes, i.e. an impaired switching from fatty acid to glucose oxidation in response to insulin. Besides an impaired metabolic flexibility, type II diabetic patients are characterized by a decreased fat oxidative capacity and high levels of circulating FFAs. The latter is known to cause insulin resistance, in particularly in skeletal muscle, most likely via accumulation of lipid inside the muscle cell (for a review see (23)).

To further investigate the mechanism underlying the decreased metabolic flexibility, which we observed after the 3-week high-fat diet, we determined mRNA expression for genes involved in lipid and glucose metabolism and mitochondrial content in skeletal muscle biopsies (vastus lateralis). As described in Chapter 6, we found that mRNA expression of the lipid metabolism genes carnitine palmitoyltransferase 1 (CPT1) and peroxisome proliferator activated receptor $\gamma$ coactivator1beta (PGC1b) were reduced by the high-fat diet. It has long been known that CPT1 
is a key enzyme involved in lipid oxidation and that overexpression of CPT1 in skeletal muscle is sufficient to enhance fatty acid oxidation and improve high-fat dietinduced insulin resistance (Bruce, 2009). Recently, however, PGC1b has been revealed as another key player in lipid metabolism. In fact, Wright et al. showed that overexpression of PGC1b also ameliorates lipid-induced skeletal muscle insulin resistance (Wright, 2011). As such, these two genes are proven to be highly responsive to dietary lipid stimuli. However, even though mRNA content of CPT1 and PGC1b were reduced in response to the 3-week HFD in our study, it was not sufficient to adversely affect IMCL or whole-body insulin sensitivity.

Moreover, lower CPT1b mRNA did not result in reduced basal fat oxidation, but was associated with decreased metabolic flexibility, mainly reflected in a reduced capacity of insulin to suppress fat oxidation. So far, it is unknown if insulin-induced suppression of fat oxidation is dependent on CPT1 activity. Therefore, we cannot conclude if the decrease in CPT1 and PGC1b are causally related to the reduction in metabolic flexibility. However, future longer-term studies should examine if the changes in metabolic flexibility that we observed will ultimately lead to skeletal muscle insulin resistance. However, for now, our findings suggest that high lipid availability does not lead to intramuscular lipid accumulation and insulin resistance in healthy, insulin-sensitive overweight men. However, it does suggest that increased dietary fat content impairs the muscle's ability to adapt its metabolic flexibility in response to insulin.

\subsection{Oxidative capacity, intramyocellular lipid and insulin sensitivity}

The finding that high-fat feeding reduced metabolic flexibility without affecting insulin sensitivity is interesting in the light of other findings in literature. Thus, a reduced fat oxidative capacity and metabolic inflexibility are often considered as important components of lipid accumulation and insulin resistance of the skeletal muscle. The cause of these derangements in skeletal muscle of type 2 diabetic patients remains however to be elucidated. In this regard a combination of human and rodent studies have convincingly documented mitochondrial abnormalities in insulin-resistant and diabetic states, which suggests that mitochondrial dysfunction may be the primary defect in obesity-related ectopic lipid accumulation which can lead to insulin resistance (reviewed in (24)). These studies include ex vivo, morphological and biochemical analyses of tissue samples and/or isolated mitochondria (25-28) as well as noninvasive in vivo magnetic resonance spectroscopy (MRS) measures (2934). However, although these associations appear robust, the direction of causality remains uncertain $(24,35)$. We used the model of prolonged fasting to answer this question (chapter 3). As mentioned previously, prolonged fasting increases FFA levels and causes insulin resistance. In addition, it is also known that this is accom- 
panied by an increased whole-body fat oxidation (36). It could therefore be anticipated that despite the development of insulin resistance, mitochondrial function is maintained to accommodate increased fat oxidation during prolonged fasting. Alternatively, if lipid-induced insulin resistance or factors associated with the insulin resistant state indeed cause mitochondrial dysfunction, this seems to be a secondary effect. We found that prolonged fasting, despite an increase in whole-body fat oxidation, leads to an overall reduction in both coupled state 3 respiration and maximally uncoupled respiration in permeabilized skeletal muscle fibers, which could not be explained by changes in mitochondrial density.

Therefore, the decrease in mitochondrial capacity in skeletal muscle is counterintuitive, especially since this decrease was substrate-independent and also apparent upon a lipid substrate. Therefore one might speculate that, when even a decrease of $20 \%$ in mitochondrial function does not stop the body from increasing whole-body fat oxidation in the fasted situation, a comparable decrease in mitochondrial function which is found in type II diabetic subject is not the cause of ectopic lipid accumulation and insulin resistance, which would be in line with the results from the high-fat feeding model. We therefore think that mitochondrial dysfunction is rather a consequence of lipid accumulation and insulin resistance. This finding is supported by a study showing that subjects who had genetic defects in insulin receptor function also had an impaired oxidative phosphorylation in vivo. In this situation it is very clear that insulin resistance is primary and can produce mitochondrial dysfunction secondary (37). Dumas et al recently reviewed whether muscle mitochondrial dysfunction is a cause or an indirect consequence of insulin resistance in humans and concluded that it is still unclear whether altered mitochondria are the cause or the result of a state of insulin resistance (38). Our results, and those of others (37), are in favour of the statement that mitochondrial dysfunction is a consequence of insulin resistance rather than a cause.

\subsection{Inflammation and insulin sensitivity}

So far, we can conclude that increased concentrations of FFA, when not matched by increased oxidation, may be the factor underlying lipid accumulation in muscle. In addition, it has also been speculated that the same FFA are underlying factors contributing to the associations between increased body fat and low-grade systemic inflammation. Indeed, it has been shown that increasing plasma FFA concentrations by lipid infusion has a proinflammatory effect (39). In addition, systemic inflammation may be related to hyperinsulinemia (40-42). In agreement, insulin resistance is associated with elevated levels of high-sensitive C-reactive protein (hs-CrP) (43) and decreased levels of the anti-inflammatory factor adiponectin (44), independent of obesity $(43,44)$. Moreover, infusion of insulin in humans is associated with in- 
creases in leptin, which has been linked to inflammation (45), and decreases in the adiponectin (46). Also hyperglycemia can contribute to activation of NF-kB, as reviewed by Schwartz et al (47). Thus, the contribution of physiologically increased FFA concentrations to inflammation, as frequently seen in type 2 diabetes, apart from those of hyperinsulinemia and hyperglycemia, is not known. In chapter 4 we used the model of prolonged fasting to study the effects of increased FFA on inflammatory markers. Interestingly, the model of prolonged fasting does not lead to hyperinsulinemia or hyperglycemia, which makes it possible to study the effects of increased FFA concentrations apart from those of increased insulin and glucose concentrations. We found that fasting for 60 hours did not affect concentrations in plasma of the inflammatory markers TNF- $\alpha$, IL-1b, IL-8, and hs-CRP. For IL-6, however, a statistically significant treatment $x$ time effect was found. During the fed period, II- 6 concentrations remained virtually unchanged, but decreased after 36 hours of fasting and returned to baseline after 60 hours. Therefore, we can conclude that prolonged fasting does not cause an inflammatory response. In contrast, insulin resistance induced by longer-term lipid infusion does lead to hyperglycaemia and hyperinsulinemia, and to increased concentrations of FFA and pro-inflammatory cytokines. This suggests that in normal-weight subjects, insulin-resistance or increased FFA concentrations per se are not a prerequisite to induce a proinflammatory cytokine profile, but hyperglycemia or hyperinsulinemia - possibly in combination with high FFA levels - are. As pre-diabetic subjects, who are characterized by normal glucose concentrations and slightly elevated insulin concentrations, also have increased concentrations of markers and mediators of inflammation (48), it can be speculated that insulin may be more important in this respect. This is further supported by the findings of Stegenga et al. (49), who found that a short-term (6 hr) lower-insulinemic hyperglycaemic clamp decreased the expression of several pro-inflammatory cytokine in LPS-stimulated leucocytes. In contrast, after a hyperinsulinaemic euglycaemic clamp, expressions of most of the inflammatory cytokines were increased.

\subsection{Ectopic fat in liver}

As mentioned in the beginning of this chapter, not only accumulation in muscle is important, but also accumulation of fat in other tissues such as the liver. Usually, the hepatic lipid content is below $5 \%$ of fat by wet weight and when the liver lipid stores exceed this value, this is known as a fatty liver or liver steatosis. A well-known cause for a fatty liver is alcohol abuse, but a fatty liver is also found in overweight and obese subjects. Fat accumulation in the liver is generally associated with the cluster of metabolic abnormalities related to the metabolic syndrome (50). It has been suggested that non-alcoholic fatty liver disease (NAFLD), in its whole spectrum 
ranging from pure fatty liver to non-alcoholic steatohepatitis (NASH) and cryptogenic cirrhosis, which in the end may lead to hepatocellular carcinoma, is simply the hepatic manifestation of the metabolic syndrome (51). Therefore, it is not surprising that a fatty liver is associated with an increased risk of all-cause death (52). The mechanisms underlying the development of NAFLD are not completely understood, but it has been shown that FA in the liver come from several different sources: dietary fat, FA released from adipose tissue, and from de novo hepatic lipogenesis. An imbalance of any of the pathways involved in FA and TG delivery, synthesis, export or oxidation could contribute to lipid accumulation in the liver. Regarding dietary fat, rodent data have clearly indicated that dietary manipulation - mainly increasing total dietary fat content - can rapidly change lipid storage in liver. In humans, however, dietary interventions are scarce. It has been shown that a single high-fat meal did not increase IHL accumulation (53). In contrast, on the longer term, dietary fat intake affected IHL and was accompanied by effects on markers of insulin resistance (54). However, in this study only a surrogate marker of insulin resistance was used, i.e. fasting insulin levels. Furthermore, this study investigated the effect of a high-fat diet specifically in obese women, who had liver steatosis prior to the start of the intervention. Although these data provide support for the suggestion that in humans diet can affect IHL and insulin sensitivity, evidence is still rather limited. Furthermore, high-fat diets were not given in energy balance in all cases. Therefore we used the dietary intervention, which we also used to study lipid accumulation in the muscle, to examine the effects of a high- versus low-fat diet on hepatic lipid accumulation. We found in chapter 5 that in the low-fat group, IHL decreased by $13 \%$, whereas it increased by $17 \%$ during the high-fat diet. When we compared the changes in the low-fat group versus the changes in high-fat group we found an, as expected, statistically different effect of diet on IHL accumulation between the two groups. Although there was an increase in hepatic lipid after high-fat diet the absolute IHL level remained below $5 \%$ of fat by wet weight, or in other words IHL levels were still within the normal range. As we anticipated an increase in IHL content in the high-fat group, we also examined IHL content after one week on the high-fat diet. Interestingly, the increase in IHL upon the high-fat diet already occurred in the first week with no further increase in the following two weeks upon the high-fat diet. This is in line with our previous finding that - when fed in energy balance subjects are capable of increasing fat oxidation to match fat intake after one week of a high-fat diet $(55,56)$. It could thus be suggested that prolonged consumption of a high-fat diet leads to an increase in $24 \mathrm{~h}$ fat oxidation, sufficient to match fat intake, and thereby does not lead to further accumulation of ectopic fat. 


\subsection{Concluding remarks}

In this thesis we used two models to study in humans lipid accumulation, oxidative capacity, metabolic flexibility and insulin sensitivity. The model of prolonged fasting is an effective model to increase FFA and IMCL and to decrease insulin sensitivity. Based on this model, we conclude that mitochondrial dysfunction is a consequence of insulin resistance rather than a cause. With regard to inflammation, the model of prolonged fasting suggests that hyperglycemia and especially hyperinsulinemia may be more important than elevated FFA levels or insulin sensitivity per se. The second model we used was a comparison between the effects of an isocaloric high-fat diet vs. low-fat diet. This interesting model showed that a high-fat diet causes IHL accumulation within one week, but that two more weeks on this high-fat diet does not cause a further increase of fat accumulation inside the liver. We did not find a statistically significant increase in IMCL levels after the high-fat diet or an effect on insulin sensitivity. This indicates that when subjects are in energy balance, in other words when fat oxidation matches fat availability, there is no accumulation of IMCLs or an effect on insulin sensitivity. An increased dietary fat content did cause metabolic inflexibility, but from our studies we cannot conclude if this is an early marker of insulin resistance or rather an adaptation to the high-fat diet. After three weeks on the high-fat diet, two key genes involved in lipid oxidation were reduced. These results indicate that increased dietary fat content for three weeks, leading to lipidinduced metabolic inflexibility, are not sufficient to induce insulin resistance. However, the reduction in gene expression of CPT1 and PGC1b and the reduced metabolic flexibility may suggest that longer term high-fat diet could lead to insulin resistance.

\subsection{Overall conclusion}

A mismatch between lipid oxidation and lipid availability is needed for ectopic lid accumulation to occur, and high-fat diets given in energy balance may therefore not lead to insulin resistance. Furthermore our studies showed that a reduced oxidative capacity/mitochondrial function may be a consequence of increased lipid availability. This statement seems valid for both short term (60hours) and a long-term time period ( 3 weeks). Finally, we showed that consumption of high-fat diets, often used to initiate insulin resistance in animal models, did not affect insulin sensitivity in humans. These findings suggest that the development of human insulin resistance cannot simply be explained by one factor, but rather depends on an interplay between mitochondrial function, lipid availability and lipid accumulation. 


\section{References}

1. McGarry JD. Banting lecture 2001: dysregulation of fatty acid metabolism in the etiology of type 2 diabetes. Diabetes 2002; 51: 7-18.

2. Wilson PW, D'Agostino RB, Sullivan L, Parise H, Kannel WB. Overweight and obesity as determinants of cardiovascular risk: the Framingham experience. Arch Intern Med 2002; 162: 1867-1872.

3. Craigie AM, Caswell S, Paterson C, Treweek S, Belch JJ, Daly F, et al. Study protocol for BeWEL: The impact of a BodyWEight and physicaL activity intervention on adults at risk of developing colorectal adenomas. BMC Public Health 2011; 11: 184.

4. Shulman GI. Cellular mechanisms of insulin resistance. J Clin Invest 2000; 106: 171-176.

5. Hill JO, Peters JC, Reed GW, Schlundt DG, Sharp T, Greene HL. Nutrient balance in humans: effects of diet composition. Am J Clin Nutr 1991; 54: 10-17.

6. Vogt M, Puntschart A, Howald H, Mueller B, Mannhart C, Gfeller-Tuescher L, et al. Effects of dietary fat on muscle substrates, metabolism, and performance in athletes. Med Sci Sports Exerc 2003; 35: 952-960.

7. Helge JW, Watt PW, Richter EA, Rennie MJ, Kiens B. Fat utilization during exercise: adaptation to a fat-rich diet increases utilization of plasma fatty acids and very low density lipoproteintriacylglycerol in humans. J Physiol 2001; 537: 1009-1020.

8. Johnson NA, Stannard SR, Mehalski K, Trenell MI, Sachinwalla T, Thompson CH, et al. Intramyocellular triacylglycerol in prolonged cycling with high- and low-carbohydrate availability. J Appl Physiol 2003; 94: 1365-1372.

9. Zderic TW, Davidson CJ, Schenk S, Byerley LO, Coyle EF. High-fat diet elevates resting intramuscular triglyceride concentration and whole body lipolysis during exercise. Am J Physiol Endocrinol Metab 2004; 286: E217-225.

10. Forouhi NG, Jenkinson G, Thomas EL, Mullick S, Mierisova S, Bhonsle U, et al. Relation of triglyceride stores in skeletal muscle cells to central obesity and insulin sensitivity in European and South Asian men. Diabetologia 1999; 42: 932-935.

11. Hulver MW, Berggren JR, Cortright RN, Dudek RW, Thompson RP, Pories WJ, et al. Skeletal muscle lipid metabolism with obesity. Am J Physiol Endocrinol Metab 2003; 284: E741-747.

12. Bachmann OP, Dahl DB, Brechtel K, Machann J, Haap M, Maier T, et al. Effects of intravenous and dietary lipid challenge on intramyocellular lipid content and the relation with insulin sensitivity in humans. Diabetes 2001; 50: 2579-2584.

13. Boden G, Lebed B, Schatz M, Homko C, Lemieux S. Effects of acute changes of plasma free fatty acids on intramyocellular fat content and insulin resistance in healthy subjects. Diabetes 2001; 50: 1612-1617.

14. Stannard SR, Thompson MW, Fairbairn K, Huard B, Sachinwalla T, Thompson CH. Fasting for $72 \mathrm{~h}$ increases intramyocellular lipid content in nondiabetic, physically fit men. Am J Physiol Endocrinol Metab 2002; 283: E1185-1191.

15. Riccardi G, Giacco R, Rivellese AA. Dietary fat, insulin sensitivity and the metabolic syndrome. Clin Nutr 2004; 23: 447-456.

16. Bergman RN, Finegood DT, Ader M. Assessment of insulin sensitivity in vivo. Endocr Rev 1985; 6: 45-86.

17. Krssak M, Falk Petersen K, Dresner A, DiPietro L, Vogel SM, Rothman DL, et al. Intramyocellular lipid concentrations are correlated with insulin sensitivity in humans: a $1 \mathrm{H}$ NMR spectroscopy study. Diabetologia 1999; 42: 113-116.

18. Perseghin G, Scifo P, De Cobelli F, Pagliato E, Battezzati A, Arcelloni C, et al. Intramyocellular triglyceride content is a determinant of in vivo insulin resistance in humans: a $1 \mathrm{H}-13 \mathrm{C}$ nuclear magnetic resonance spectroscopy assessment in offspring of type 2 diabetic parents. Diabetes 1999; 48: 1600-1606.

19. Schmitz-Peiffer C. Signalling aspects of insulin resistance in skeletal muscle: mechanisms induced by lipid oversupply. Cell Signal 2000; 12: 583-594. 
20. Cooney GJ, Thompson AL, Furler SM, Ye J, Kraegen EW. Muscle long-chain acyl CoA esters and insulin resistance. Ann N Y Acad Sci 2002; 967: 196-207.

21. Itani SI, Ruderman NB, Schmieder F, Boden G. Lipid-induced insulin resistance in human muscle is associated with changes in diacylglycerol, protein kinase C, and IkappaB-alpha. Diabetes 2002; 51: 2005-2011.

22. Summers SA. Ceramides in insulin resistance and lipotoxicity. Prog Lipid Res 2006; 45: 42-72.

23. Phielix E, Mensink M. Type 2 diabetes mellitus and skeletal muscle metabolic function. Physiol Behav 2008; 94: 252-258.

24. Patti ME, Corvera S. The role of mitochondria in the pathogenesis of type 2 diabetes. Endocr Rev 2010; 31: 364-395.

25. Kelley DE, He J, Menshikova EV, Ritov VB. Dysfunction of mitochondria in human skeletal muscle in type 2 diabetes. Diabetes 2002; 51: 2944-2950.

26. Morino K, Petersen KF, Dufour S, Befroy D, Frattini J, Shatzkes N, et al. Reduced mitochondrial density and increased IRS-1 serine phosphorylation in muscle of insulin-resistant offspring of type 2 diabetic parents. J Clin Invest 2005; 115: 3587-3593.

27. Ritov VB, Menshikova EV, Azuma K, Wood R, Toledo FG, Goodpaster BH, et al. Deficiency of electron transport chain in human skeletal muscle mitochondria in type 2 diabetes mellitus and obesity. Am J Physiol Endocrinol Metab 2010; 298: E49-58.

28. Ritov VB, Menshikova EV, He J, Ferrell RE, Goodpaster BH, Kelley DE. Deficiency of subsarcolemmal mitochondria in obesity and type 2 diabetes. Diabetes 2005; 54: 8-14.

29. Petersen KF, Dufour S, Befroy D, Garcia R, Shulman GI. Impaired mitochondrial activity in the insulin-resistant offspring of patients with type 2 diabetes. N Engl J Med 2004; 350: 664-671.

30. Schrauwen P, Schrauwen-Hinderling V, Hoeks J, Hesselink MK. Mitochondrial dysfunction and lipotoxicity. Biochim Biophys Acta 2009.

31. Szendroedi J, Schmid Al, Chmelik M, Toth C, Brehm A, Krssak M, et al. Muscle mitochondrial ATP synthesis and glucose transport/phosphorylation in type 2 diabetes. PLoS Med 2007; 4: e154.

32. Phielix E, Schrauwen-Hinderling VB, Mensink M, Lenaers E, Meex R, Hoeks J, et al. Lower intrinsic ADP-stimulated mitochondrial respiration underlies in vivo mitochondrial dysfunction in muscle of male type 2 diabetic patients. Diabetes 2008; 57: 2943-2949.

33. Schrauwen-Hinderling VB, Kooi ME, Hesselink MK, Jeneson JA, Backes WH, van Echteld CJ, et al. Impaired in vivo mitochondrial function but similar intramyocellular lipid content in patients with type 2 diabetes mellitus and BMI-matched control subjects. Diabetologia 2007; 50: 113-120.

34. Schrauwen-Hinderling VB, Roden M, Kooi ME, Hesselink MK, Schrauwen P. Muscular mitochondrial dysfunction and type 2 diabetes mellitus. Curr Opin Clin Nutr Metab Care 2007; 10: 698-703.

35. Stump CS, Short KR, Bigelow ML, Schimke JM, Nair KS. Effect of insulin on human skeletal muscle mitochondrial ATP production, protein synthesis, and mRNA transcripts. Proc Natl Acad Sci U S A 2003; 100: 7996-8001.

36. Carlson MG, Snead WL, Campbell PJ. Fuel and energy metabolism in fasting humans. Am J Clin Nutr 1994; 60: 29-36.

37. Sleigh A, Raymond-Barker P, Thackray K, Porter D, Hatunic M, Vottero A, et al. Mitochondrial dysfunction in patients with primary congenital insulin resistance. J Clin Invest 2011.

38. Dumas JF, Simard G, Flamment M, Ducluzeau PH, Ritz P. Is skeletal muscle mitochondrial dysfunction a cause or an indirect consequence of insulin resistance in humans? Diabetes Metab 2009; 35: 159-167.

39. Tripathy D, Mohanty P, Dhindsa S, Syed T, Ghanim H, Aljada A, et al. Elevation of free fatty acids induces inflammation and impairs vascular reactivity in healthy subjects. Diabetes 2003; 52: 28822887.

40. Ford ES, Ajani UA, Mokdad AH. The metabolic syndrome and concentrations of C-reactive protein among U.S. youth. Diabetes Care 2005; 28: 878-881. 
41. Ridker PM, Stampfer MJ, Rifai N. Novel risk factors for systemic atherosclerosis: a comparison of Creactive protein, fibrinogen, homocysteine, lipoprotein(a), and standard cholesterol screening as predictors of peripheral arterial disease. JAMA 2001; 285: 2481-2485.

42. Frohlich $M$, Imhof A, Berg G, Hutchinson WL, Pepys MB, Boeing $H$, et al. Association between Creactive protein and features of the metabolic syndrome: a population-based study. Diabetes Care 2000; 23: 1835-1839.

43. McLaughlin T, Abbasi F, Lamendola C, Liang L, Reaven G, Schaaf $P$, et al. Differentiation between obesity and insulin resistance in the association with C-reactive protein. Circulation 2002; 106: 2908-2912.

44. Abbasi F, Chu JW, Lamendola C, McLaughlin T, Hayden J, Reaven GM, et al. Discrimination between obesity and insulin resistance in the relationship with adiponectin. Diabetes 2004; 53: 585-590.

45. Saad MF, Khan A, Sharma A, Michael R, Riad-Gabriel MG, Boyadjian R, et al. Physiological insulinemia acutely modulates plasma leptin. Diabetes 1998; 47: 544-549.

46. Yu JG, Javorschi S, Hevener AL, Kruszynska YT, Norman RA, Sinha M, et al. The effect of thiazolidinediones on plasma adiponectin levels in normal, obese, and type 2 diabetic subjects. Diabetes 2002; 51: 2968-2974.

47. Schwartz EA, Reaven PD. Molecular and signaling mechanisms of atherosclerosis in insulin resistance. Endocrinol Metab Clin North Am 2006; 35: 525-549, viii.

48. Pickup JC, Crook MA. Is Type II diabetes mellitus a disease of the innate immune system? Diabetologia 1998; 41: 1241-1248.

49. Stegenga ME, Crabben SNvd, Dessing MC, Pater JM, Van Den Pangaart PS, De Vos AF, et al. Effect of acute hyperglycaemia and/or hyperinsulinaemia on proinflammatory gene expression, cytokine production and neutrophil function in humans. Diabetic Medicine 2008; 25: 157-164.

50. Unger RH. Lipotoxic diseases. Annu Rev Med 2002; 53: 319-336.

51. Marchesini G, Bugianesi E, Forlani G, Cerrelli F, Lenzi M, Manini R, et al. Nonalcoholic fatty liver, steatohepatitis, and the metabolic syndrome. Hepatology 2003; 37: 917-923.

52. Adams LA, Angulo P. Recent concepts in non-alcoholic fatty liver disease. Diabet Med 2005; 22: 1129-1133.

53. Szczepaniak LS, Nurenberg P, Leonard D, Browning JD, Reingold JS, Grundy S, et al. Magnetic resonance spectroscopy to measure hepatic triglyceride content: prevalence of hepatic steatosis in the general population. Am J Physiol Endocrinol Metab 2005; 288: E462-468.

54. Westerbacka J, Lammi K, Hakkinen AM, Rissanen A, Salminen I, Aro A, et al. Dietary fat content modifies liver fat in overweight nondiabetic subjects. J Clin Endocrinol Metab 2005; 90: 2804-2809.

55. Schrauwen $P$, van Marken Lichtenbelt WD, Saris WH, Westerterp KR. Changes in fat oxidation in response to a high-fat diet. Am J Clin Nutr 1997; 66: 276-282.

56. Schrauwen $P$, van Marken Lichtenbelt WD, Westerterp KR. Fat and carbohydrate balances during adaptation to a high-fat diet. Am J Clin Nutr 2000; 72: 1239-1241. 



\section{Summary}

The prevalence of type II diabetes mellitus ("diabetes") is increasing rapidly all around the world. Diabetes has serious health consequences, as it can induce damage to the eyes, and is related to cardiovascular disease and kidney failure. Furthermore, there is an increased risk of developing inflammation and impaired wound healing. Increased levels of glucose in the blood, which are caused by a decreased insulin sensitivity, are central in the development of type II diabetes mellitus and its harmful consequences.

An increased level of circulating free fatty acids (FFA), in combination with a decreased mitochondrial function, leads to lipid accumulation in non-adipose tissue such as skeletal muscle and liver. Mitochondria are known as the energy factories of cells. They are responsible for oxidation of FFA. Therefore, when mitochondria are less capable of burning free fatty acids, for example because the mitochondria are damaged, accumulation of lipid intermediates can occur inside a cell. These lipid intermediates can interfere with insulin signaling of muscle cells, which in turn leads to a decreased insulin sensitivity or in other words insulin resistance. Furthermore insulin resistance is often related to low-grade systemic inflammation. For example, several studies have suggested that inflammation and insulin resistance reinforce each other via a positive feedback loop. Indeed, the two often come together: for instance, rheumatoid arthritis, an inflammatory disease, increases the risk to develop insulin resistance. This thesis focuses on the relationship between FFA, lipid accumulation, insulin sensitivity, and inflammation.

In chapter 3, we showed that prolonged fasting leads to increases in FFA, which in turn lead to lipid accumulation in muscle and decreased insulin sensitivity. Furthermore, whole-body fat oxidation increased. Furthermore, we found that prolonged fasting, despite an increase in whole-body fat oxidation, leads to an overall reduction in both state 3 respiration and maximally uncoupled respiration in permeabilized skeletal muscle fibers. This decrease in mitochondrial capacity in skeletal muscle is counterintuitive, especially since this decrease was substrate-independent and also apparent upon a lipid substrate. Furthermore, these reductions could not be explained by changes in mitochondrial density. It is important to note that the reduction in muscle mitochondrial capacity does not (yet) affect the capability of the body to enhance fat oxidation. This is an important finding, since it has generally been assumed that a reduction in muscle mitochondrial function will result in reductions in whole-body fat oxidative capacity. Here, we show that this extrapolation may not be justified. Since prolonged fasting is a physiological condition in which increased fat oxidation becomes very important, a reduced mitochondrial function 
seems unbeneficial from a physiological point of view. Our findings suggest that the elevated plasma FFA and/or intramuscular lipid levels associated with the insulin resistant state are responsible for the secondary negative effects on mitochondrial function. We therefore think that mitochondrial dysfunction is rather a consequence of lipid accumulation and insulin resistance.

As already mentioned, inflammation and insulin resistance reinforce each other via a positive feedback loop. It has been suggested that this inflammation is related to increased FFA levels. However, increased levels of glucose and insulin may also contribute to inflammation. In chapter 4 , we used the model of prolonged fasting to study the effects of increased FFA on inflammatory markers. Interestingly, the model of prolonged fasting does not lead to hyperinsulinemia or hyperglycemia, which made it possible to study the effects of increased FFA concentrations apart from those of increased insulin and glucose concentrations. We found that fasting for 60 hours did not affect concentrations in plasma inflammatory markers such as TNF- $\alpha$, IL-1b, IL-8, and hs-CRP. Therefore, we can conclude that in normal-weight subjects, insulin-resistance or increased FFA concentrations per se are not a prerequisite to induce a pro-inflammatory cytokine profile.

To investigate the relation between dietary lipids, lipid accumulation and insulin resistance we examined the effects of a high-fat diet versus a low-fat diet on hepatic lipid accumulation (chapter 5 ). It was hypothesized that a high-fat diet would lead to an accumulation of lipids in muscle and liver (intrahepatic lipid, IHL), and consequently to a decreased insulin sensitivity. For this, twenty apparently overweight men were randomly allocated to a low-fat or high-fat diet group. Both groups started with a three-week low-fat diet (15 En\% protein, 65 En\% carbohydrates, 20 En\% fat), after which half of all subjects switched to a three-week isocaloric high-fat diet (15 En\% protein, 30 En\% carbohydrates, 55 En\% fat). We found that in the low-fat diet group, IHL decreased by $13 \%$, whereas it increased by $17 \%$ in the high-fat diet group. This difference in change was statistically significant. As we anticipated an increase in IHL content in the high-fat diet group, we also examined IHL content after one week on the high-fat diet. Interestingly, the increase in IHL upon the highfat diet already occurred in the first week, with no further increase in the following two weeks. This agrees with literature, which states that - when fed in energy balance - subjects are capable of increasing fat oxidation to match fat intake after one week on a high-fat diet. It can thus be suggested that prolonged consumption of a high-fat diet increases $24 \mathrm{~h}$ fat oxidation to match fat intake, and thereby does not lead to further accumulation of ectopic fat. In this study, we did not find a statistically significant increase in IMCL levels after the high-fat diet or an effect on insulin sensitivity. This indicates that, in humans, high-fat feeding does not lead to insulin resistance when subjects are in energy balance. 
In chapter 6, we studied substrate oxidation in response to a three week high-fat diet into more detail. With regard to fat oxidation, resting fat oxidation did not increase after the high-fat diet, but we did observe that metabolic flexibility was reduced, as indicated by a reduced inhibition of lipid oxidation during insulin infusion. Although speculative, a reduced ability to suppress lipid oxidation during insulin infusion may reflect the postprandial situation and could indicate that postprandial fat oxidation is increased after high-fat diet, reducing the necessity to deposit excess lipids in ectopic fat stores.

A decreased metabolic flexibility, i.e. an impaired switching from fatty acid to glucose oxidation in response to insulin, has been linked to type II diabetes. To further investigate the mechanism underlying a decreased metabolic flexibility, we determined mRNA expression of genes involved in lipid and glucose metabolism, and mitochondrial content in skeletal muscle biopsies (vastus lateralis). We found that mRNA expression of genes involved in lipid metabolism such as carnitine palmitoyl-transferase 1 (CPT1) and peroxisome proliferator activated receptor $\gamma$ coactivator-1beta (PGC1b) were reduced by the high-fat diet. So far, it is unknown if insulininduced suppression of fat oxidation is dependent on CPT1 activity. Therefore, we cannot conclude if a decrease in CPT1 and PGC1b are causally related to a reduced metabolic flexibility.

From the results described in this thesis, we conclude that a mismatch between lipid oxidation and lipid availability is needed to induce ectopic lid accumulation. Furthermore, we showed that high-fat diets, when subjects are in energy balance, do not lead to insulin resistance. These findings suggest that overfeeding and therefore an increase in bodyweight are needed for the development of insulin resistance. Furthermore our studies showed that a reduced oxidative capacity/mitochondrial function might be a consequence of increased FFA availability.

These findings suggest that the development of human insulin resistance cannot simply be explained by one factor, but rather depends on an interplay between lipid availability and oxidation and related mitochondrial function. 



\section{Samenvatting}

Net zoals in de rest van de wereld neemt in Nederland de prevalentie van type 2 diabetes mellitus ("diabetes") toe. De gevolgen van diabetes zijn onder andere beschadigingen aan het netvlies van het oog, hart- en vaatziekten, en nieraandoeningen. Ook is er een verhoogde kans op ontstekingen en slecht genezende wonden. De verhoogde glucosewaarden in het bloed, veroorzaakt door een verminderde insulinegevoeligheid van diverse weefsels, staan centraal in het ontstaan van deze gevolgen.

Een overmaat aan vrije vetzuren in de bloedsomloop, in combinatie met een verminderde mitochondriële functie, leidt tot vetstapeling in de zogenaamde perifere weefsels zoals de skeletspier en de lever. Mitochondriën bevinden zich in de cel en spelen een belangrijke rol bij de verbranding van deze vrije vetzuren. Als de werking van de mitochondriën verstoord is, dan stapelen bepaalde schadelijke stoffen (lipid-intermediairen) in een cel op, waardoor de werking van insuline afneemt. Met andere woorden, de insulinegevoeligheid van een cel neemt af. Insulineresistentie gaat ook vaak gepaard met verhoogde hoeveelheden ontstekingsstoffen in het bloed. In dit proefschrift staat de relatie tussen verhoogde vrije vetzuren, vetstapeling, insulinegevoeligheid en ontsteking centraal.

In hoofdstuk 3 hebben we laten zien dat een verhoging van vrije vetzuren tot vetstapeling in de spier leidt en tot een verminderde insulinegevoeligheid. In het geval van diabetes gaat de aanwezigheid van insulineresistentie gepaard met een verminderde oxidatieve capaciteit van de spier, veroorzaakt door minder goed functionerende mitochondria, de energiecentrales van de cel. Er is echter nog een discussie gaande of deze verminderde oxidatieve capaciteit een oorzaak of een gevolg is van insulineresistentie. Bij diabetes wordt gesuggereerd dat een verminderde oxidatieve capaciteit - vanwege slechter functionerende mitochondria - zorgt voor een verminderde vetverbranding, hetgeen op lange termijn zou leiden tot vetstapeling en insulineresistentie. Het is echter ook mogelijk dat een vermindere mitochondriele functie het gevolg is van bijvoorbeeld hoge vetzuurconcentraties of insuline resistentie, zoals bij diabetes het geval is. Deze hypothese hebben we onderzocht door jonge gezonde vrijwilligers 60 uur te laten vasten, een model om acuut insuline resistentie op te wekken. Het vasten zorgde voor een enorme toename van de hoeveelheid vrije vetzuren in de bloedsomloop en - zoals verwacht - een grote daling van de insuline gevoeligheid. Wij vonden dat, ondanks een verhoging van de vetverbranding in het lichaam, de oxidatieve capaciteit van spiervezels na vasten was afgenomen door minder goed functionerende mitochondriën. Dit toont aan dat het acuut verhogen van de vetzuren, waarvan bekend is dat het tot insulineresistentie leidt, 
gepaard gaat met een vermindering van de mitochondriële functie. Dit kan suggereren dat mitochondriële dysfunctie een gevolg van hoge vetzuren en/of insulineresistentie kan zijn in plaats van een oorzaak.

Zoals hierboven besproken, hebben mensen met diabetes vaak meer moeite om te herstellen van een ontsteking. Het wordt gesuggereerd dat dit gerelateerd is aan een overmaat aan vrije vetzuren, maar ook de verhoogde waardes van insuline en glucose zijn genoemd als veroorzakers van de ontsteking. Echter, welke afwijkingen in het bloedprofiel nu van doorslaggevend belang zijn, is onbekend. Het model waarin jonge gezonde vrijwilligers 60 uur vasten zou hier een uitkomst kunnen bieden. Dit model wordt namelijk gekenmerkt door een verhoging van vrije vetzuren en insulineresistentie zoals het geval is bij type II diabeten. Maar in tegenstelling tot wat we zien bij diabetes, zijn de glucose- en insulinewaardes in het bloed verlaagd. We hebben gevonden dat 60 uur vasten geen verhoging gaf van de ontstekingsstoffen (TNF- $\alpha$, IL-1b, IL-8, en hs-CRP) in het bloed. Om deze reden concluderen wij dat een verhoogde hoeveelheid vrije vetzuren in het bloed niet persé leidt tot een verhoging van de hoeveelheid ontstekingsstoffen in het bloed. Mogelijk is het noodzakelijk dat ook de glucose- en insulinewaardes verhoogd zijn om effecten van vrije vetzuren op deze ontstekingsstoffen te vinden. Deze bevindingen hebben we beschreven in hoofdstuk 4.

Om de relatie tussen vet, vetstapeling en insulineresistentie verder uit te diepen hebben we, buiten 60 uur vasten, gebruik gemaakt van een hoog-vet voeding. In hoofdstuk 5 hebben mannen met overgewicht (BMI tussen 25 en $30 \mathrm{~kg} / \mathrm{m} 2$ ) tussen de 40 en 60 jaar gedurende 3 weken een laag-vet voeding (20 energieprocent (En\%) vet) geconsumeerd waarna de helft van de groep overging op een iso-energetische hoog-vet voeding (55 En\% vet). Na 1 week op de hoog-vet voeding hebben we de hoeveelheid vet in de lever gemeten en deze was toegenomen. Na 3 weken hebben we de vetstapeling opnieuw gemeten en deze was niet verder toegenomen in vergelijking met de meting na 1 week. Dit komt mogelijk omdat het lichaam de vetverbranding aan kan passen aan de hoeveelheid vet in de voeding.

Naast vetstapeling in de lever hebben we ook naar de vetstapeling in de spier gekeken en vonden hier geen effecten van de voeding. Ook vonden we geen effecten van de hoog-vet voeding op de insulinegevoeligheid. Dit suggereert dat bij de mens een vetrijke voeding niet per se tot insulineresistentie leidt, althans zolang de voeding in energiebalans wordt gegeven.

We hebben daarna in meer detail gekeken naar de verbranding van verschillende substraten als gevolg van de hoog-vet voeding. Dit is beschreven in hoofdstuk 6 . We vonden geen verhoging van de vetoxidatie in rust, maar wel een verminderde capaciteit van insuline om de koolhydraatoxidatie te stimuleren. Deze verminderde me- 
tabole flexibiliteit suggereert dat het lichaam, na 3 weken hoog-vet voeding, in de postprandiale situatie de voorkeur geeft aan het verbranden van vetten in plaats van koolhydraten. Om deze verminderde metabole flexibiliteit verder te verklaren hebben we in spierbiopten van het bovenbeen gekeken naar de mRNA-expressie van verschillende genen betrokken bij het vet- en glucosemetabolisme. Het bleek dat de mRNA-expressie van carnitine palmitoyl-transferase 1 (CPT1) en peroxisome proliferator activated receptor $\gamma$ coactivator-1beta (PGC1b) waren afgenomen na de hoog-vet voeding. De verminderde genexpressie was geassocieerd met een verminderde metabole flexibiliteit, zoals gevonden door een verminderde remming van de vetoxidatie door insuline. We kunnen echter niet concluderen, dat dit werd veroorzaakt door een verlaging van de CPT1 en PGC1b activiteit. Verder onderzoek zal aan moeten tonen of de veranderingen in metabole flexibiliteit nu een gunstige aanpassing zijn aan een hoog-vet voeding of op de lange termijn wel leidt tot insulineresistentie van de skeletspier.

Uit de resultaten verkregen in dit proefschrift concluderen we dat een disbalans tussen het aanbod van vet en vetoxidatie nodig is voor vetstapeling in de lever en de spier. Verder tonen we aan dat het consumeren van een vetrijke voeding, in energiebalans, niet leidt tot insulineresistentie. Dit kan suggereren dat overvoeding, en dus een toename van lichaamsgewicht, nodig is voor het ontstaan van insulineresistentie. Daarnaast geven onze studies aan dat een verminderde oxidatieve capaciteit / mitochondriële functie een gevolg kan zijn van verhoogde vetzuurconcentraties in het bloed en/of insuline resistentie.

Onze bevindingen tonen daarom aan dat insulineresistentie in mensen niet verklaard kan worden door één factor, het consumeren van een vetrijke voeding, in energiebalans, maar eerder afhankelijk is van een samenspel tussen het aanbod en verbranding van vet en de daarbij betrokken mitochondriële functie. 



\section{Dankwoord}

Last but not least...het dankwoord.

Om er voor te zorgen dat ik sowieso niemand vergeet wil ik bij deze iedereen die op wat voor manier dan ook heeft bijgedragen aan dit proefschrift bedanken, BEDANKT! Dan ga ik nu een poging ondernemen om de personen die meer verdienen dan dit summiere bedankje kort te noemen.

Een eerste woord van dank gaat dit keer eens niet naar de beoordelingscommissie maar naar de persoon die me het meeste gesteund heeft de afgelopen jaren....Dushi van Santi! Laat we hopen dat de afgelopen jaren slechts het begin is geweest van een nog mooiere tijd, vanaf nu als dokter van Sante \& doctor van Herpen!

Als tweede wil ik alle leden van de leescommissie bedanken voor het beoordelen van mijn thesis. Prof. dr. E.E. Blaak (voorzitter), Prof. dr. M van Baak, Dr. G.H. Koek, Prof. dr. M.R. Müller \& Dr. J. Plat. Bedankt voor het lezen en kritisch beoordelen, tot aan spelfouten toe, van mijn proefschrift.

Mijn promotoren, Ronald Mensink en Patrick Schrauwen. Ik heb veel van jullie geleerd. Zowel op wetenschappelijk als niet-wetenschappelijk gebied. Ronald, ik ben blij dat ik onder jouw begeleiding heb mogen promoveren. Bedankt voor je nuchtere kijk op zaken en je oog voor de niet wetenschappelijke persoon in mij. Ik waardeerde je opmerkingen over voetbal en tennis (sorry Sabine).

Patrick, ik heb diep respect voor je manier van werken. Zo gedreven, efficiënt en daadkrachtig ken ik er maar weinig (bijna nader inzien denk ik geen een). Ook jij bedankt voor alles wat je me bijgebracht hebt en je steun. Heren, bedankt, en bij deze nogmaals mijn excuses voor mijn lettertype en tekengrootte blindheid ;-)

Natuurlijk kunnen mijn mede SHOCKers en Middenlobbers ook niet ontbreken in dit woord van dank. In willekeurige volgorde, de (ex)SHOCKERS: Marco (nou misschien niet helemaal willekeurig dan, want Marco jij hebt me qua technieken/methoden wel heel veel geleerd), Matthijs, Vera, Joris, Johan, Ronnie, Katarina, Sparky, Sabina, Chris, Gert, Esther K. Alie, Johanna, Wendy, Denis, Esther P, Miranda, Ellen, Ruth, Silvie, Tineke, Lena, Madeleen en Bianca, jullie hebben me een leuke tijd gegeven. Ik las een tijd terug een artikel op NU.nl met de titel 'Langer leven door leuke collega's'. De boodschap van het artikel was dat mensen die het goed kunnen vinden met hun collega's langer leven dan mensen die niet met hun collega's op kunnen 
schieten. Ik durf toch wel te beweren dat jullie me in ieder geval geen levensjaren gekost hebben ;-) Bedankt voor alle nuttige maar ook zeker de minder nuttige bijeenkomsten!

Buiten de SHOCK-groep heb ik veel op getrokken met de middenlobbers. Natuurlijk met mijn kamergenoten Julia, Kirsten en voor kortere periodes Yvonne, Els en Julian. Julia, ik ben blij dat we uitgegroeid zijn tot meer dan alleen roomy's. Ik ben er nog steeds trots op dat ik, zelfs met een winkelhaak in mijn pantalon, je paranimf mocht zijn. Bijkomend voordeel van dat paranimf zijn was dat ik dit mocht doen samen met Leonie. Leonie ik sluit me aan bij de woorden die jij gebruikte in jouw dankwoord. Al vrij snel na mijn eerste dag konden we het erg goed met elkaar vinden en gelukkig is dat altijd zo gebeleven. Van de collega's waarmee ik buiten werktijd afspreek sta jij qua tijd toch wel met stip op 1. Daar zal wel een reden voor zijn... ;-) Kirsten, mijn andere langdurige roomy, bedankt voor je hulp bij de dieet studie maar vooral voor alle gezelligheid.

De overige (ex)middenlobbers ook weer in willekeurige volgorde: Jogchum, Sabine Elke, Marjolijn, Chris, Ruth V, Carla, Sanne, Herman, Ariënne, Chantal, Florence, Martine, Pascal, Stan en Stefan. Bedankt voor alle praktische zaken die ik met jullie heb mogen doen maar ook voor de lunches, koffiebreaks en overige gezelligheid.

Maar er zijn veel meer mensen bij Humane Biologie en Bewegingswetenschappen die me geholpen helpen op werklvlak (ik noem als voorbeeld diegene die me meer dan eens hebben geholpen als ik weer eens met infusen zat te hannessen zoals Ralph, Gijs, Johan en Antoine) danwel diegene die op het sociale vlak voor inspiratie zorgden (sorry Jos dat ik nu net jou weer hier als voorbeeld moet noemen...)! Maar ook de analisten, diëtisten, secretaresses, computerdeskundigen en overige collega's bij deze zijn ook jullie ALLEMAAL bedankt.

Zonder proefpersonen, in mijn geval, geen onderzoek en geen proefschrift. Ditzelfde kan gezegd worden over mijn stagaires. Dus ook mijn dank voor jullie bijdrage.

De stap van proefpersonen naar vrienden is in mijn geval een kleine stap. Menig dispuutsgenoot, jaarclubgenoot, teamgenoot en familielid heeft zich opgeofferd om mij te hulp te schieten als er weer eens iemand nodig was. Voor 'kleine dingen' als het testen van een nieuw scan protocol tot 60 uur niet eten en allerlei 'enge' testen doen. Altijd stonden jullie klaar... Op een gegeven moment meldde zelfs Thijs V. zich om me te helpen. Deze stoere bink valt al flauw bij het zien van een infuusnaald, moet je nagaan wat zijn reactie zou zijn geweest bij het nemen van spierbiopten. Maar schijnbaar gaat vriendschap zo ver.

Naast hulp met het onderzoek zelf zijn jullie natuurlijk nog veel belangrijker geweest buiten het onderzoek om. Zonder de nodige ontspanning ook zeker geen proefschrift! Dus leden van Ob Nievoow (Buijs, Rens, Sander en paranamifen Remco 
en Rob), het Racc, Ormètikos, overige vrienden binnen KoKo, DBSV-ers, mijn PSVclan uit de glimlach van Brabant, mijn 'nieuwe' vrienden van dushi Korsou en ieder ander die zich aangesproken voelt onder de noemer vriend(in) maar niet bij een van deze clubjes zit; THANKS!!

Van vrienden naar familie is het ook maar een kleine stap. Zo zit mijn neef Sander ook in Ob Nievoow en mijn broer Nils is ook zo een fanatieke PSV-er. Ik hoop dat jullie stiekem een beetje trots zijn op deze Dr. in de familie. Familie Ruijs bedankt voor de onstpanning tijdens voor alle gezellige dinertjes. Familie van Herpen, ik kijk al weer uit naar het volgende familieweekend! Laat de potjes 'kop-tafeltennis' maar komen! Van een beetje competitie is nog nooit iemand slechter geworden.

Maar naast mijn eigen familie wil ik de ouders, ooms \& tantes, neven \& nichten en broer van Merel hier ook even noemen. Ik waardeer jullie interesse en overheerlijke kookkunsten (en Thomas zijn inzet voor de mooie kaft)! Dat er nog maar veel pom gegeten mag worden!

Ons Pap, ons Mam en mijn broer(tje) Nils verdienen toch nog wel een extra benoeming in dit dankwoord buiten het stukje 'familie'. Jullie hebben me o.a. (LET OP! Dit is heus niet het enige hoor...) geleerd hoog aan te vliegen. Zonder jullie was ik nooit begonnen aan deze onderneming....laat staan dat ik het af had kunnen maken. 



\section{Curriculum Vitae}

Noud van Herpen was born on the 26th of April 1984. He started his bachelor Health Sciences at Maastricht University in 2002 and got his bachelor degree in 2005 with a major in Movement Sciences and Bioregulation as a minor subject. During his bachelor he did an internship in Jyvaskyla, Finland, at the University of Sports and wrote his bachelor thesis about the influence of strength training on endurance capacity. In September 2005 he started his master Physical Activity \& Health also at the university of Maastricht. His master thesis was about the training response of combined strength- and endurance training in insulin dependent type II diabetic subjects with co-morbidities, this with a focus on the aerobic capacity. He finished his master Physical Activity \& Health in August 2006.

The first of September 2006 he started his PhD project on diet, insulin resistance and chronic inflammation at the department of Human Biology of Maastricht University, under the supervision of Prof. P. Schrauwen \& Prof. R.P. Mensink. This project is a cooperation of the Maastricht University and TI Food and Nutrition (TIFN), formerly known as the Wageningen Centre for Food Sciences (WCFS).

In September 2010 he went to Curaçao for one year to finish his PhD thesis and decide what to do afterwards. In September 2011 he started his current job as a teacher at the Hague University of Applied Sciences - Academy of Sports Studies. 


\section{Scientific Output}

\section{Published}

van Herpen NA, Schrauwen-Hinderling VB. Lipid accumulation in non-adipose tissue and lipotoxicity. Physiology \& Behaviour 2008; 94: 231-241.

van Herpen NA \& Hoeks J, Mensink M, Moonen-Kornips E, van Beurden D, Hesselink MK, Schrauwen P. Prolonged fasting identifies skeletal muscle mitochondrial dysfunction as consequence rather than cause of human insulin resistance. Diabetes 2010; 59: 2117-2125.

van Herpen NA, Schrauwen-Hinderling VB, Schaart G, Mensink RP, Schrauwen P. Three weeks on a high-fat diet increases intrahepatic lipid accumulation and decreases metabolic flexibility in healthy overweight men. Journal of Clinical Endocrinology and Metabolism 2011; 96: E691-695.

\section{Submitted}

van Herpen NA \& Sparks LM, Schrauwen P. A decreased metabolic flexibility after a three weeks high fat diet can be explained by genes expression

van Herpen NA, Sell H, Eckel J, Schrauwen P, Mensink RP. Prolonged fasting and the effects on biomarkers of inflammation and several adipokines including chemerin in healthy subjects.

van de Weijer T, Sparks LM, Phielix E, Meex R, van Herpen NA, Kessels AG, Hesselink MKC, Schrauwen-Hinderling VB, Schrauwen P. Relationships between mitochondrial function and metabolic flexibility in type 2 diabetes mellitus 